\title{
UNDERSTANDING THE ENERGY PERFORMANCE GAP: CASE STUDIES OF ENERGY EFFICIENT HOMES
}

\author{
By \\ Moe Otsubo \\ Hon. B.A., University of Toronto, 2010 \\ A thesis \\ presented to Ryerson University \\ in partial fulfillment of the \\ requirements for the degree of \\ Master of Applied Science \\ in the Program of \\ Building Science
}

Toronto, Ontario, Canada, 2015

(C) Moe Otsubo 2015 


\section{AUTHOR'S DECLARATION FOR ELECTRONIC SUBMISSION OF A THESIS}

I hereby declare that I am the sole author of this thesis. This is a true copy of the thesis, including any required final revisions, as accepted by my examiners.

I authorize Ryerson University to lend this thesis to other institutions or individuals for the purpose of scholarly research.

I further authorize Ryerson University to reproduce this thesis by photocopying or by other means, in total or in part, at the request of other institutions or individuals for the purpose of scholarly research.

I understand that my thesis may be made electronically available to the public. 
Investigation of the Energy Performance Gap of Residential Homes in Southern Ontario: A Comparison of HOT2000 and EnergyPlus

Masters of Applied Science 2015 - Moe Otsubo - Building Science Program Ryerson University

\begin{abstract}
The energy performance gap between the predicted and actual energy consumption of 3 LEED for Homes certified buildings were investigated. The actual energy consumptions of the homes were found to be 23 to $77 \%$ higher than the initial energy consumption predictions made during the design stage. Revisions to the HOT2000 models to account for changes made between the design and occupancy phase of the buildings helped reduce the gap ( 9 to $40 \%$ ). The sources of the discrepancies were found to be related to the energy modeling program's limitations, inconsistency between the energy model and the actual building, and additional loads in the homes.
\end{abstract}

The HOT2000 program, which is used for obtaining the EnerGuide rating for LEED certified homes, was compared against a dynamic energy simulation program to assess the applicability of the use of the former for energy efficient homes. The use of EnergyPlus not only allowed for a more accurate representation of the actual homes in the energy models, but an increase in the EnerGuide rating for the home was seen, which in turn equates to additional points for the home under the "Energy \& Atmosphere" category for the LEED for Homes certification process. 


\section{A note from the author:}

This research was not meant to criticize the design or construction of the homes included.

Through using the specification of the homes and with the cooperation of the occupants, two energy modeling programs were assessed on their applicability of modeling energy efficient homes accurately. These homes are beautifully designed and have influenced positive changes to the occupants' lifestyles and the author has no intention of undermining the design teams' work on these homes. 


\section{Acknowledgements}

I would like to thank my supervisor, Dr. Mark Gorgolewski for his continued support and to have allowed me to take this research opportunity. There were several road blocks along the way but with his guidance they were overcome to get the results presented here. I would also like to thank the home owners and designers who have generously provided me with information and data required to complete this research, without them this research could not have happened. I am very grateful to have had the opportunity to work with people who are conscious about their energy consumption and trying to do their part to improve our built environment. 


\section{Table of Contents}

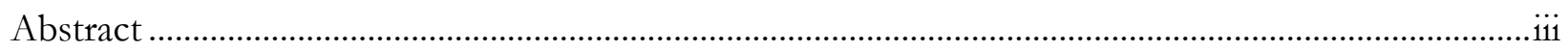

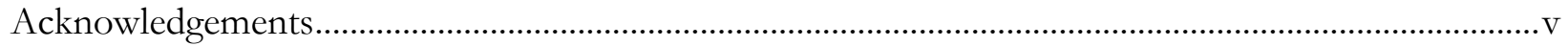

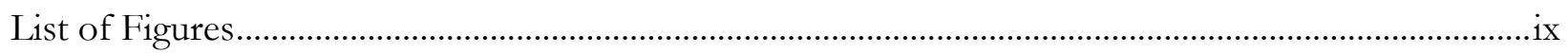

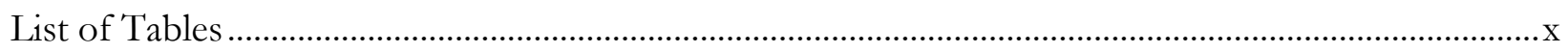

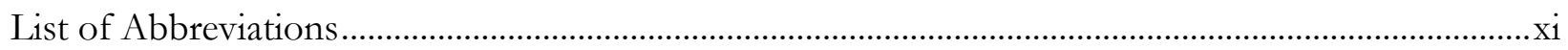

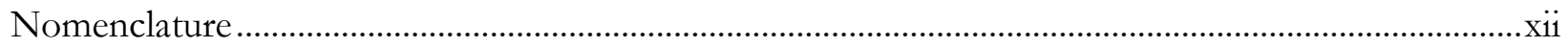

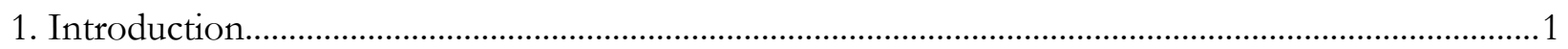

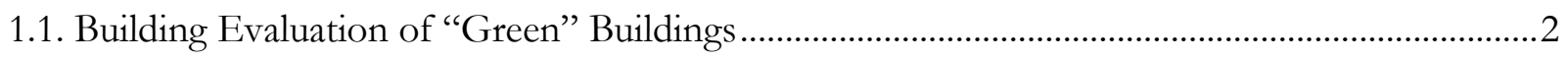

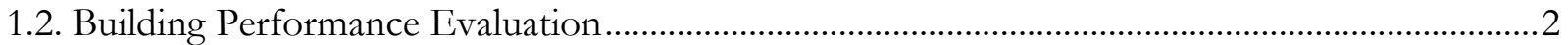

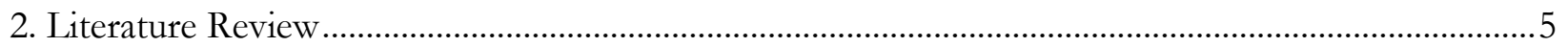

2.1. Evaluation of Commercial and Institutional Buildings ............................................................

2.2. Evaluation of Residential Buildings.............................................................................................

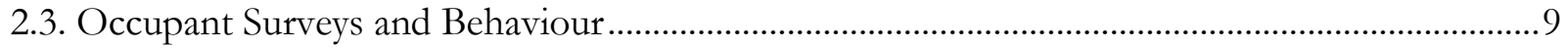

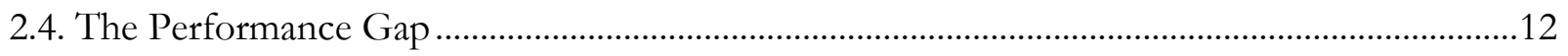

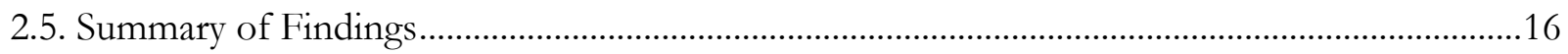

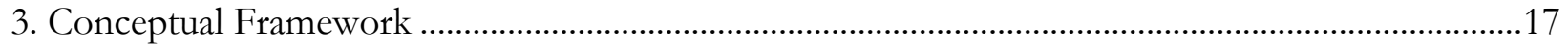

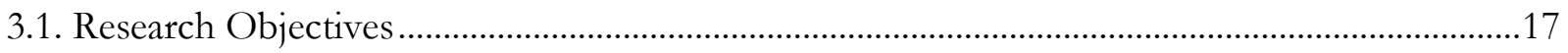

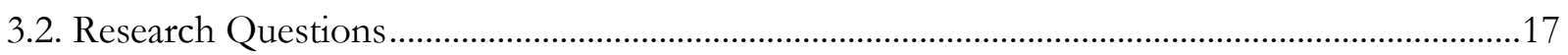

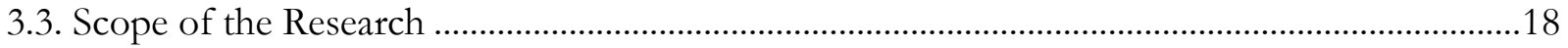

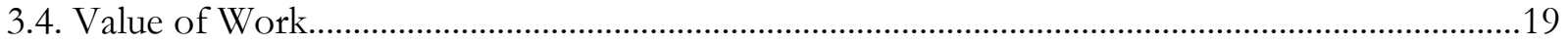

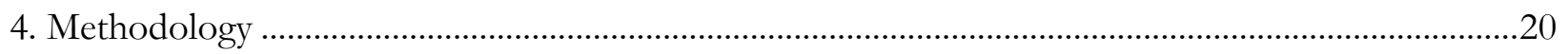

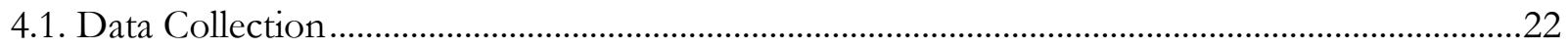

4.1.1. Physical Data Collection ........................................................................................................22

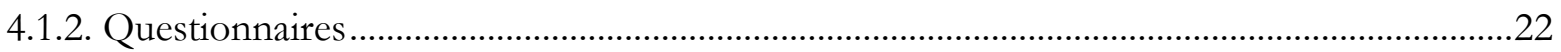

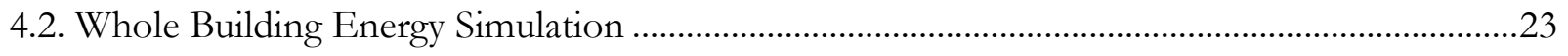

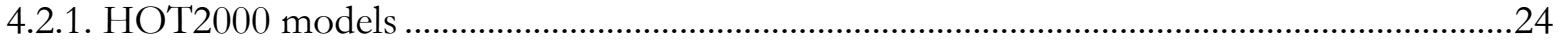

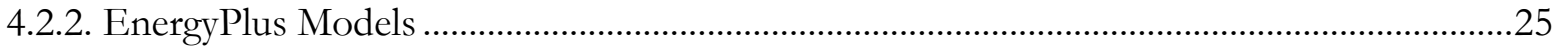

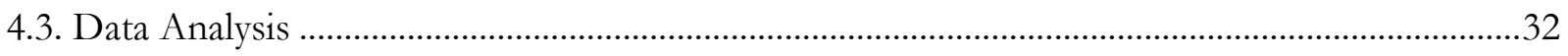

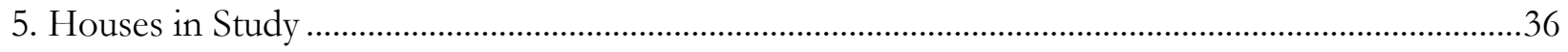

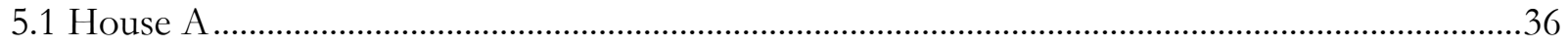

5.1.1. Specifications for House A in HOT2000 ................................................................................ 
5.1.2. Specifications for House A in EnergyPlus ................................................................................39

5.1.3. E+ Calibrated Model for House A ……...............................................................................

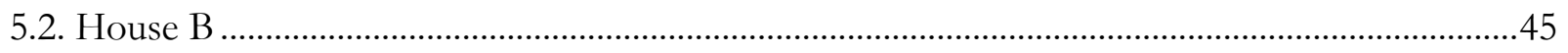

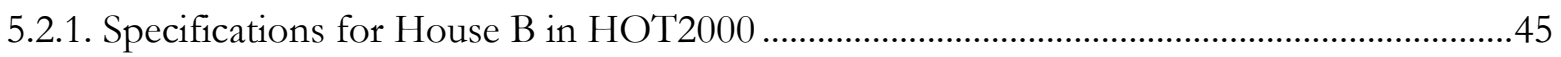

5.2.2. Specifications for House B in EnergyPlus ..................................................................................48

5.2.3. E+ Calibrated Model for House B ..........................................................................................

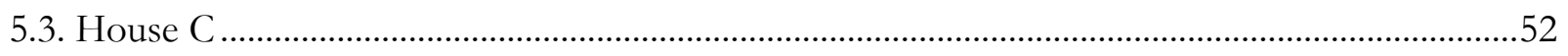

5.3.1. Specifications for House C in HOT2000 ……......................................................................52

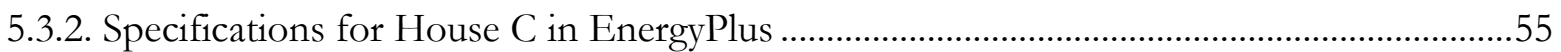

5.3.3. E+ Calibrated Model for House C...............................................................................................56

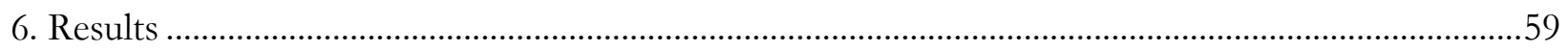

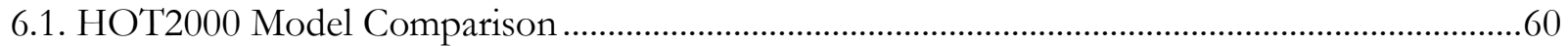

6.1.1. HOT2000 Model EnerGuide Comparison ..........................................................................63

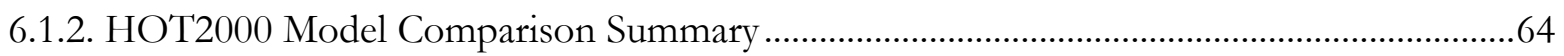

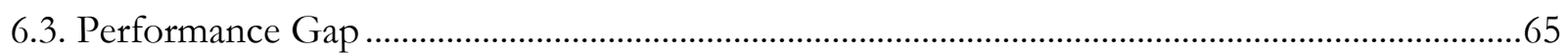

6.3.1. Performance Gap of House A ……………...................................................................................69

6.3.2. Performance Gap of House B ............................................................................................. 72

6.3.3. Performance Gap of House C .............................................................................................. 74

6.4. EnerGuide Rating Comparison...................................................................................................

6.4.1. EnerGuide Rating Comparison for House A .............................................................................77

6.4.2. EnerGuide Rating Comparison for House B ......................................................................... 79

6.4.3. EnerGuide Rating Comparison for House C ...........................................................................81

6.4.4. EnerGuide Rating Comparison Summary...............................................................................82

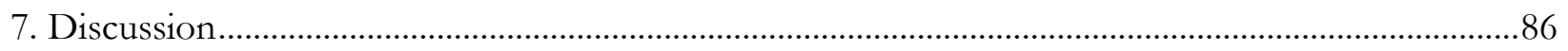

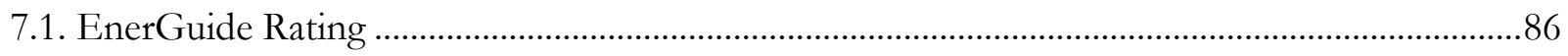

7.1.1. EnerGuide Rating Compared to Energy Use and Carbon Intensity.....................................86

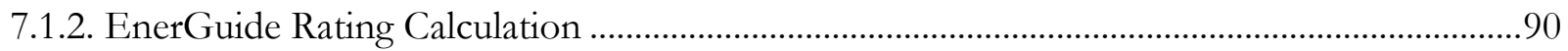

7.1.3. EnerGuide Base Load Assumptions ..........................................................................................91

7.2. Energy Program Comparison ................................................................................................... 93

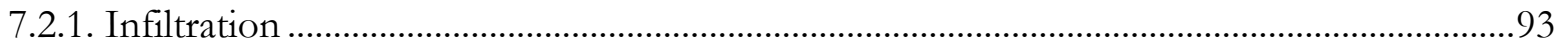

7.2.2. Manufacture specifications for heat pumps …….................................................................95 
7.2.3. PV Generation and the Shading Effect of Arrays................................................................... 96

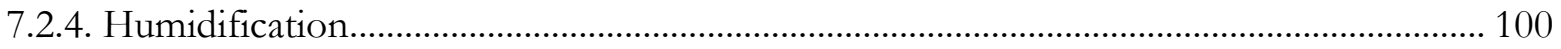

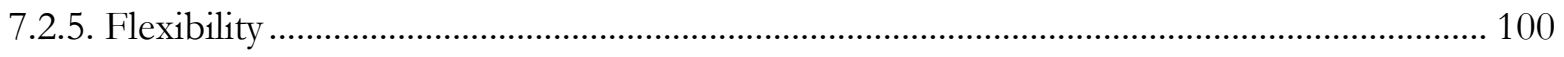

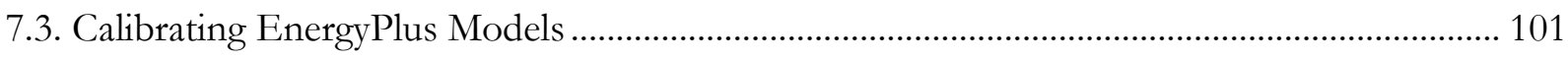

7.3.1. End-Use Energy Consumption Breakdown ......................................................................... 102

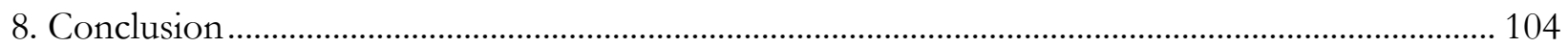

8.1. Energy Performance Gap for LEED Certified Residential Homes ......................................... 104

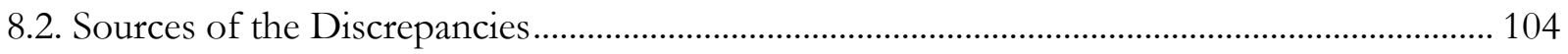

8.3. Added Value of Using a Dynamic Energy Simulation Program ............................................... 105

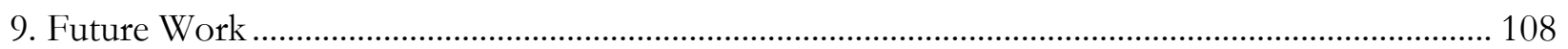

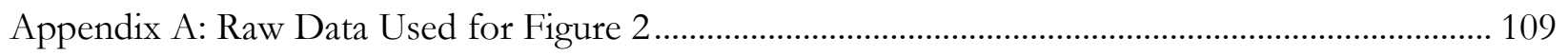

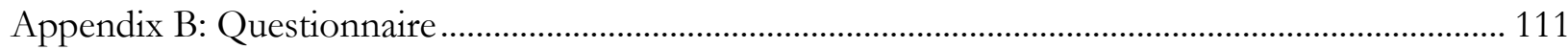

Appendix C: Energy Consumption Outputs from Energy Modeling for All Homes........................ 120

Appendix D: Energy and Carbon Intensity Data for All Homes...................................................... 126

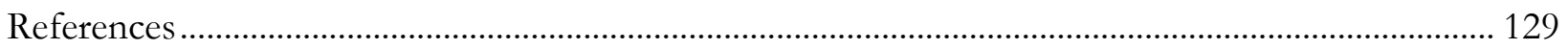




\section{List of Figures}

Figure 1: Comparison of the designed energy use and the actual total energy use of a building.........12

Figure 2: Comparison between the design and actual energy use intensity of 3 residential buildings.14

Figure 3: Diagram showing the types of analyses present in the literature.

Figure 4: Diagram showing the comparisons made between the models and the actual energy consumption. .20

Figure 5: Flow chart of steps taken in the methodology for each home...............................................21

Figure 6: Energy model comparisons made and the aim of the analysis................................................33

Figure 7: Simulated electricity consumption compared to actual electricity consumption of House A.

Figure 8: Simulated natural gas consumption in comparison to the actual natural gas consumption for House A.

Figure 9: Simulated electricity consumption compared to the actual electricity consumption for

House B.

Figure 10: Simulated natural gas consumption compared to the actual natural gas consumption for House B.

Figure 11: Simulated electricity consumptions for House C compared to the actual electricity consumption. .58

Figure 12: Energy model total energy consumption output overview and compared against the actual energy consumption for the 3 homes.

Figure 13: H2K v1 and H2K v2 model end use energy consumption output comparison for all homes in study. .60

Figure 14: Total energy use comparison between HOT2000 models and E+ calibrated.

Figure 15: End-use energy consumption comparison between $\mathrm{H} 2 \mathrm{~K}$ v1, H2K v3 and E+ calibrated

for House A.

Figure 16: End-use energy consumption comparison between $\mathrm{H} 2 \mathrm{~K}$ v1, H2K v3 and E+ calibrated

for House B.

Figure 17: End-use energy consumption comparison between $\mathrm{H} 2 \mathrm{~K}$ v1, H2K v3 and E+ calibrated

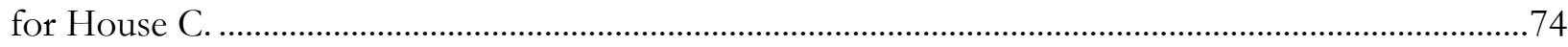

Figure 18: EnerGuide rating calculation values for House A. ................................................................78

Figure 19: EnerGuide calculation values for energy models of House B. .............................................80

Figure 20: EnerGuide calculation values for energy models of House C. ..............................................81

Figure 21: EnerGuide rating with carbon intensity for House A. .........................................................8

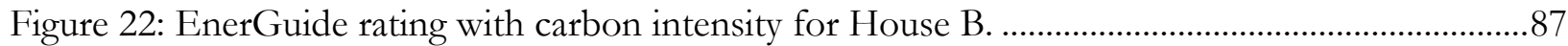

Figure 23: EnerGuide rating and carbon intensity from all models.....................................................8

Figure 24: Approximate carbon intensities for EnerGuide ratings for the homes...............................89

Figure 25: Interior lighting electricity consumption comparison. ......................................................92

Figure 26: PV electricity generation predicted by HOT2000 and EnergyPlus compared against the

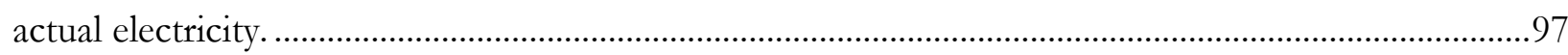

Figure 27: A monthly breakdown of the PV generation of the PV panels on House B......................98 


\section{List of Tables}

Table 1: Base-load assumptions of HOT2000.

Table 2: The percentage of water consumption used by old and updated fixtures that is heated

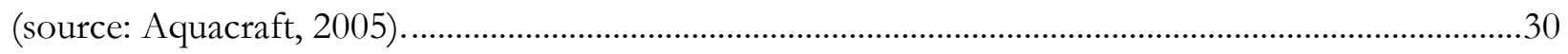

Table 3 Hot water and total water consumption by water fixtures..........................................................31

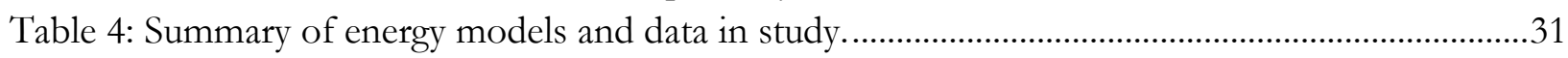

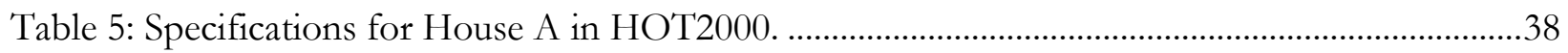

Table 6: Heat pump and ground heat exchanger specifications for House A......................................41

Table 7: CV(RMSE) and NMBE percentages of energy consumption outputs from the calibrated EnergyPlus model in comparison to the actual energy consumptions for House A............................44

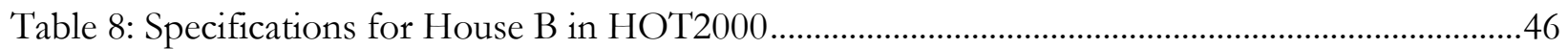

Table 9: Heat pump and ground heat exchanger specifications for House B ......................................49

Table 10: CV(RMSE) and NMBE percentages of the energy consumption outputs from the calibrated EnergyPlus model for House B in comparison to the actual..................................................52

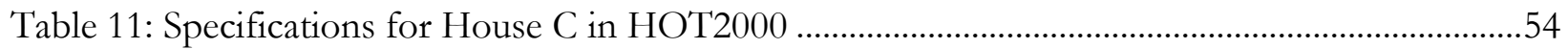

Table 12: Heat pump and ground heat exchanger specifications for House C.....................................56

Table 13: CV(RMSE) and NMBE percentages of the electricity consumption output from the calibrated EnergyPlus model for House $\mathrm{C}$ in comparison to the actual.................................................58

Table 14: End-use energy consumption predicted in $\mathrm{H} 2 \mathrm{~K}$ v1 and 2 for all homes, with differences in

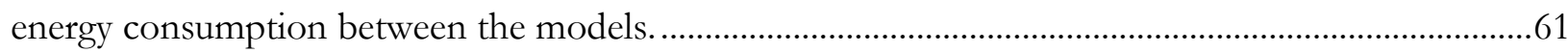

Table 15: EnerGuide rating from H2K v1 and H2K v2 for all homes...............................................63

Table 16: Performance gap summary. ………….....................................................................................67

Table 17: Annual space heating summary for House C..........................................................................68

Table 18: "Energy \& Atmosphere" points earned from their respective EnerGuide rating values....76

Table 19: Summary of EnerGuide ratings from energy models for each of the homes.......................84

Table 20: Caron dioxide equivalent emission intensity by energy type..................................................86

Table 21: Space heating and cooling energy consumption from the E+ v1 model of House B with

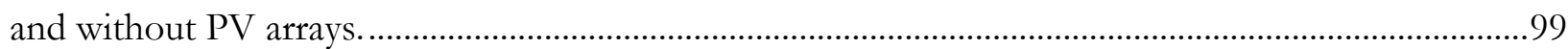

Table 22: Humidifier electricity consumption in each of the homes included in the study.............. 100 Table 23: Raw data for the energy use intensity of residential buildings used in figure 2. Data obtained from CarbonBuzz. Buildings with both design and actual data were plotted on figure 2. 109 Table 24: Raw data for the annual energy consumption of the residential buildings........................ 110

Table 25: Energy model energy consumption outputs for House A.................................................. 120

Table 26: EnerGuide calculation values for House A energy models. ................................................ 121

Table 27: Energy model energy consumption outputs for House B. ................................................ 122

Table 28: EnerGuide calculation values for House B energy models................................................. 123

Table 29: Energy model energy consumption outputs for House C. .................................................. 124

Table 30: EnerGuide calculation values for House C energy models................................................... 125

Table 31: Energy and carbon intensity values for House A................................................................. 126

Table 32: Energy and carbon intensity values for House B. ................................................................ 127

Table 33: Energy and carbon intensity values for House C................................................................ 128 


\author{
List of Abbreviations \\ ASHRAE - American Society of Heating, Refrigerating and Air-Conditioning Engineers \\ BPE - Building performance evaluation \\ CBE - Center for the Built Environment \\ CVRMSE - Coefficient of variation of the root mean square error \\ DHW - Domestic hot water \\ EPS - Expanded Polystyrene foam insulation \\ GHG - Greenhouse gas (consisting of water vapor, carbon dioxide, methane, nitrous oxide and \\ ozone) \\ HRV - Heat recovery ventilator \\ HVAC - Heating ventilation and air conditioning \\ LEED - Leadership in Energy and Environmental Design \\ NMBE - Normalized mean bias error \\ NRCan - Natural Resources Canada \\ POE - Post-occupancy evaluation \\ PROBE - Post-Occupancy Review of Buildings and their Engineering \\ PV - Photovoltaic \\ WHO - World Health Organization \\ XPS - Extruded Polystyrene foam insulation
}




\section{Nomenclature}

$B_{D E} \quad$ Base efficiency for electric DHW (energy factor $=0.88$ )

$B_{D F} \quad$ Base efficiency for fossil fuel DHW (energy factor $=0.57$ )

$B_{S E} \quad$ Base efficiency for electric space heating (100\%)

$B_{S F} \quad$ Base efficiency for fossil fuel space heating (80\%)

$D D \quad$ Number of long-term average degree days relative to a base of $18^{\circ} \mathrm{C}(3659.333$ used for calculations, which is the average number of heating degree days between 2011 and 2014)

$D_{E} \quad$ Estimated DHW electrical energy consumption (in MJ)

$D_{F} \quad$ Estimated DHW fossil fuel energy consumption (in MJ)

$n \quad$ Number of data points or period considered

$p \quad$ Number of parameters or terms in the baseline model ( $p=1$ for modeling uncertainty)

$S \quad$ Coefficient for space heating (4.5MJ for fossil fuel powered space heating systems; or 3.6MJ for electric space heating systems)

$S_{E} \quad$ Estimated space heating electrical energy consumption, including fans (in MJ)

$S_{F} \quad$ Estimated space heating fossil-fuel energy consumption (in MJ)

TW Local water mains or deep-soil temperature in degrees Celsius $\left(9^{\circ} \mathrm{C}\right.$ used for calculations)

$V \quad$ Heated volume of the home (in $\mathrm{m}^{3}$ )

W Coefficient for DHW (6.19MJ for fossil fuel fired DHW systems; or 3.87MJ for electric DHW systems)

$y_{i} \quad$ Utility data used for calibration (monthly or bi-monthly)

$\bar{y} \quad$ Arithmetic mean of the sample of $n$ observations

$\hat{y}_{i} \quad$ Simulation predicted data (monthly or bi-monthly) 


\section{Introduction}

Developed countries around the globe are committed to reducing the energy consumptions and greenhouse gas (GHG) emissions from buildings - although the extent and success of their commitments vary. The building sector in Canada uses $28 \%$ of total energy use, and over half of that is used within the residential sector (NRCan, 2013). In terms of GHG emissions, the residential sector is responsible for 14\% of total emissions in Canada (NRCan, 2013). From 1990 to 2010, a 6\% increase of residential energy use was observed due to the increases in; the average living space, the number of households and interior equipment (NRCan, 2013).

Over the past several years, new buildings that are labeled "green" or energy-efficient have grown in numbers. These buildings go through a rigorous certification process of green rating systems such as LEED (Leadership in Energy and Environmental Design) and Passive House certification. These green rating systems address energy consumption, GHG emissions, among other criteria in regards to the indoor environment and the impacts on the planet. However, the buildings that receive the certification are reviewed during the design process, and follow-up assessments are not required after the building has been occupied (with the exception of the "Living Building Challenge" and "LEED Existing Buildings Rating System"). Without such assessments, there is no confirmation on whether the buildings are performing as intended in their design.

There is however a move towards holding building owners accountable for their building's performance in cities throughout North America (e.g. New York City, San Francisco and Seattle), by requiring large buildings to report their annual energy consumption and benchmarking them with other similar building types. In the United Kingdom small scale residential buildings are also included and are required to have an Energy Performance Certificate when a home is built, sold or 
rented, which contains information regarding the property's energy use along with an energy efficiency rating (UK Government, 2015).

Transparency in energy use of buildings is important, however stakeholders still need to look at their final product and compare that to the predicted performance of the building envisioned during the design stage. This research compared the predicted and "actual" energy performance of 3 LEED certified homes in the Southern Ontario region to complete the feedback loop that is generally neglected in the industry. The energy modeling program used by consultants to predict a building's energy usage during the design stage is analyzed and compared to a dynamic simulation program.

\subsection{Building Evaluation of "Green" Buildings}

The interest of evaluating the performance of "green" buildings grew from the PROBE studies (Post-Occupancy Review of Buildings and their Engineering). The PROBE studies investigated the performance of 23 exemplar buildings in the United Kingdom and highlighted the problems with these buildings while providing feedback for the stakeholders so that mistakes are not repeated (Bordass B. , Cohen, Standeven, \& Leaman, 2001). Numerous studies since PROBE have found that while most buildings that are certified to be "green" or energy-efficient perform better than their conventional counter parts, there are some that do not out-perform their counterparts or not performing as designed (Carbon Trust, 2011; Hall, et al., 2013; Newsham, et al., 2012 \& Turner, 2006).

\subsection{Building Performance Evaluation}

Building performance evaluation (BPE) is a systematic process that evaluates the performance of a building once it has been completed and occupied for at least a whole calendar year, comparing it against the expectations of the building and providing valuable information regarding how the building is used. It is a form of a post-occupancy evaluation (POE) but the focus 
is placed on the building's performance (energy, water, indoor environmental quality and environmental impacts), as opposed to the emphasis on the occupants' needs such as safety security and aesthetic quality (Federal Facilities Council, 2002).

Leaman, et al. (2010) list three perspectives of performance that buildings should be evaluated upon:

1. Needs of the occupants

2. Environmental performance (energy and water)

3. Economic sense

In this study, the energy performance (environmental) is evaluated for each of the homes, and touching upon the occupant behaviour aspect (human factor) and how it affects the energy consumption of a home. The economic perspective of the homes was not explored, but it is recognized as an important factor in a building's overall performance.

BPE studies are predominantly empirical field work, where researchers study real buildings in the real world and interact with real people; involving walkthroughs of the building, measuring the performance of the building through metered data, occupancy questionnaires and interviews (Leaman, Stevenson, \& Bordass, 2010). The performance of a building is monitored and stakeholders are engaged to identify and solve problems regarding the building (from the design phase to post-occupancy), and feed back information to improve productivity of occupants and building management. Case studies of buildings provide in-depth analysis of both qualitative and quantitative data to provide a better understanding of the performance of the building, and communicate lessons learned to support changes in the building industry (Leaman, Stevenson, \& Bordass, 2010). BPE studies also allow for benchmarking of "green" buildings and measure the progress of "green" building design towards sustainable and regenerative design (Cooper, 2001). 
How these evaluation processes are utilized in the field is analyzed in the literature review. 


\section{Literature Review}

\subsection{Evaluation of Commercial and Institutional Buildings}

As mentioned earlier, the PROBE studies conducted a series of extensive evaluations of 23 exemplar commercial and institutional buildings in the United Kingdom that brought attention to the assessment of "green" buildings. The researchers analyzed each of the buildings' performance and conducted occupant surveys. The performance of the buildings was benchmarked against the "Energy Consumption Guide 19". The "Energy Consumption Guide 19" is a guide for which researchers can compare the energy consumption, energy cost, and carbon dioxide emissions of the building in question against the typical and good practice benchmarks for office buildings (BRECSU, 2000). While occupant satisfaction was evaluated using the "Building Use Studies" (BUS) methodology. The BUS methodology is a questionnaire that gathers quantitative and qualitative data from occupants to gain valuable insight from the occupants regarding the building (Building Use Studies Ltd., 2015). The results from the questionnaire can be benchmarked against similar building types from a large database to rate the occupancy satisfaction level, and they can also be used to improve upon the occupant experience (Building Use Studies Ltd., 2015).

Many of the buildings studied under PROBE, consumed more energy and scored low satisfaction levels compared to standards. For some of the buildings that were studied, the actual performances were compared to the design estimation and there were very few similarities found between the two (Bordass B. , Cohen, Standeven, \& Leaman, 2001). The difference in; operational hours, operating efficiencies, and the energy consumption of unregulated loads contributed to a significant difference between the designed estimates and the actual energy consumption (Bordass B. , Cohen, Standeven, \& Leaman, 2001). Each case study included a list of design lessons learned from the analysis that stakeholders could learn from for their future developments. The detailed analysis for each building was thorough and provided valuable information. But unfortunately the 
studies did not include the analysis of residential buildings, and only conducted on buildings in the United Kingdom.

Since the PROBE studies, which was conducted from 1995 to 2002, Newsham et al. evaluated the performance of "green" buildings in Canada and Northern U.S.A., and compared them to conventional buildings (2012), but once again residential building types were not included in their study. "Green" buildings in their study were found to perform better in terms of indoor environmental quality, occupant well-being and organizational satisfaction (Newsham, et al., 2012). On average, they reported that energy performance of "green" buildings were better than their conventional counterparts, where "green" buildings had 18-39\% less energy use intensity per floor area (Newsham, et al., 2012). However, 28-35\% of the "green" buildings were using more energy than their conventional counterparts (Newsham, et al., 2012). Unfortunately, the reasons why these "green" buildings were underperforming were not investigated.

Similarly, the members at Keen Engineering conducted POEs of 7 "green" institutional buildings in British Columbia. The POE included the use of the Occupant Satisfaction Survey by the Center for the Built Environment at the University of California Berkeley, along with metered energy and water use data for the buildings, in order to assess whether the buildings achieved the usability and sustainability design goals (Hydes, McCarry, Mueller, \& Hyde, 2004). The "green" buildings included in the study by Keen Engineering had lower energy consumptions compared to the average building in British Columbia with similar occupancy loads, and occupancy satisfaction with indoor air quality and lighting were found to be well above benchmark standards (Hydes, McCarry, Mueller, \& Hyde, 2004).

The energy and water use performance of the building in the study by Keen Engineering were compared to averages of similar buildings, and not to the initial design estimations as done by 
Turner (2006) for 11 LEED certified buildings in Portland. The POE study done by Turner (2006) included commercial, institutional and multi-unit residential buildings. Of the 11 buildings, 6 were found to use less energy than the design predictions, but none of the building's actual energy consumptions fell within $20 \%$ its design predictions (Turner C. , 2006).

Numerous evaluations of commercial and institutional buildings have been done beyond these studies, but very few assessments of residential buildings have been done in comparison.

\subsection{Evaluation of Residential Buildings}

Hall, et al. (2013) at GGLO LLC conducted BPEs of multi-family dwellings in the Seattle area and analyzed the energy and water performance of the residential buildings. They do not have an extensive report that includes their detailed methodology and findings, but they report that variations in potable water and electrical energy consumptions between the actual and model predictions are thought to be due to water use assumptions made in the model and occupant behaviour (Hall, Uhlig, \& Bertolet, 2013).

Molin, et al. (2011) evaluated the performance of a Passive House in Sweden and conducted an interesting parametric study using a dynamic energy simulation program. Their aim of the parametric case study was to identify "strong and weak parameters related to energy use" (Molin, Rohdin, \& Moshfegh, 2011). Internal gains were found to have the greatest impact on energy use through the parametric study. They also point out potential improvements or careful considerations required in low-energy housing developments, such as; deficiencies in the insulation and air tightness.

In New Zealand, the Household Energy End-use Study (HEEP) was conducted which gathered energy consumption, income data and monitored indoor and outdoor temperature data in 400 homes (Isaacs, Saville-Smith, Camilleri, \& Burrough, 2010). Space heating was found to represent $34 \%$ of the total energy consumption, and hot water energy consumption represented 
$29 \%$ of the total on average (Isaacs, Saville-Smith, Camilleri, \& Burrough, 2010). However, the indoor temperatures during the heating season were below World Health Organization's (WHO) healthy indoor temperature range of $18-24^{\circ} \mathrm{C}$ (Isaacs, Saville-Smith, Camilleri, \& Burrough, 2010). Isaacs et al. (2010) investigated when, where and how much heating is used in New Zealand homes that were included in the HEEP study. Indoor temperatures were found to be dependent on the heating equipment used in homes and the income of the household (Isaacs, Saville-Smith, Camilleri, \& Burrough, 2010). The findings from the HEEP study contributed to changes in important residential policies in New Zealand, such has changes in the mandatory insulation level, and a focus on indoor conditions over energy savings for retrofitting homes (Isaacs, Saville-Smith, Camilleri, \& Burrough, 2010). The study identified issues with space heating in New Zealand homes and the change in policies indicated a commitment by the government to follow through on their part and welcome feedback from researchers.

Mlecnik, et al. (2012) analyzed the occupants' satisfaction in various energy-efficient housing types, including low-energy, passive and net-zero energy houses in Germany, Austria and Switzerland. The greatest concerns in these types of houses were found to be in regards to summer comfort, air quality, noise protection, humidity level control, odour removal, simplicity and userfriendliness of control systems (Mlecnik, Schutze, Jansen, Vries, Visscher, \& Hal, 2012). Assessments of the buildings' performance in terms of energy and water consumption were not included in their research.

Measured energy usage and energy model prediction for residential homes were analyzed by Karlsson, et al. (2007) and Saunders, et al. (2012). A low energy house in southern Sweden and a solar house in Pittsburgh U.S.A. were modeled, respectively, using various energy modeling programs. Karlsson et al. (2007) found the average error rate, between actual and model predictions, 
to be $50 \%$, and with the programs chosen by Saunders et al. (2012) the average error rate was 59\%. Both researches point out incorrect parameters set in the energy models and conclude that understanding occupant behaviour and more accurate inputs are important factors when creating an energy model to predict the energy performance of a home.

Saunders, et al. state that "if building energy cannot be accurately predicted, then the efficacy of energy modeling will be in question and broader implications, including the value of LEED..." (2012) but in their research they do not critique the energy modeling program and energy rating scale used in the industry for LEED for Homes (in the U.S.A.).

Case studies of 5 award winning homes in Australia were conducted by Williamson et al. (2010) to assess whether the homes would meet the Building Code of Australia (BCA) which was brought into effect after the homes were built. All the homes were found to have energy consumptions below that of the average, but would receive ratings below the requirement of BCA and would not have been permitted to be built due to the homes not meeting the thermal comfort standard of the BCA. When interviewed, the occupants did not mention thermal discomfort during the year and it was realized that the temperature and humidity of the homes were not confined to the standard values of thermal comfort by the occupants. Williamson et al. (2010) suggest changes in the rating system and the simulation assumptions for homes in Australia that are designed with specific occupants in mind to be energy efficient.

There are a small but growing number of studies done on the performance of "green" residential buildings, but none were found to have been done on residential buildings in Canada.

\subsection{Occupant Surveys and Behaviour}

Occupant behaviours and schedules have an impact on the performance of the building, and so, how occupants are using the building requires attention. Occupant surveys have been used by 
many researchers to measure occupancy satisfaction levels, but it can also be a tool to obtain information on occupant behaviours and schedule.

The BUS methodology mentioned earlier includes a questionnaire that has been developed and tested for over 30 years (Building Use Studies Ltd., 2015). The respondents are asked to rate various aspects of the performance of the building on a 1-7 scale to provide the commissioner feedback from the occupants (Building Use Studies Ltd., 2015). Aspects of the building performance covers areas such as thermal comfort, indoor air quality, lighting, personal control, noise, and the occupants' perception of the building design, space and needs (Building Use Studies Ltd., 2015). The results are benchmarked against other comparable buildings within the BUS methodology database (Building Use Studies Ltd., 2015). The BUS methodology has been mainly utilized in commercial and institutional buildings, a residential version was recently developed to assess the comfort and satisfaction of occupants in residential buildings (Gill et al., 2010).

The Occupant Satisfaction Surveys for building evaluation by the Center for the Built Environment (CBE) at the University of California Berkeley is also a widely used survey to gain invaluable information regarding the performance of the building from the occupants - it was used in the above mentioned study by Keen Engineering (2004). The survey has been primarily used in office buildings, but they have expanded their questionnaire to include other building types such as residential buildings and schools (CBE, 2015). This survey is web-based and the results are generated on a website that can accessed by the researcher (CBE, 2015). The CBE survey covers similar aspects of indoor environment as the BUS methodology and the results can also be benchmarked (CBE, 2015). Beyond the objective of evaluating the building performance, the survey from CBE provides diagnoses to enhance occupant satisfaction and productivity (CBE, 2015). 
Zalejska-Jonsson (2012) compared the perception of comfort and satisfaction of low-energy and conventional residential buildings in Sweden, and assessed the building performance from the occupants' point of view through surveys. They reported that there were ventilation and heating problems and concerns in both building types, but the same or less adjustments were made by tenants in low-energy buildings (Zalejska-Jonsson, 2012). They emphasized the importance of obtaining occupant feedback in terms of building performance to find areas of improvement that developers and housing managers should focus more on (Zalejska-Jonsson, 2012).

Menezes, et al. (2012) did not distribute questionnaires but instead monitored occupancy patterns and electricity consumption to calibrate an energy model for their case study building. With the monitoring data, the accuracy of the energy model was increased to be within $3 \%$ of the actual electricity consumption, emphasizing the importance of understanding how the building is used by the occupants and management staff (Menezes, Cripps, Bouchlaghem, \& Buswell, 2012).

Gill, et al. (2010) looked at the extent that user behaviours contribute to electricity, heating energy and water consumption. They found that energy efficient behaviours accounted for a variation of $51 \%$ in heating energy consumption, a $37 \%$ variation in electricity consumption and an 11\% variation in water consumption (Gill, Tiemey, Pegg, \& Allan, 2010). Their findings translates to the need for energy-efficient occupant behaviours and/or improved energy-efficient designs that are easy to use, they also emphasized the impact of occupant behaviour on the building performance (Gill, Tiemey, Pegg, \& Allan, 2010).

In another study, Gill, et al. (2011) found that unregulated loads were found to contribute the most in terms of overall carbon emissions from low energy/carbon affordable housing development in southern United Kingdom. These unregulated loads are used and controlled by occupants, and are generally not accounted for in regulations and design targets. They are also a 
source of discrepancies between the designed and actual energy use, which is explored in the following section.

\subsection{The Performance Gap}

The discrepancy between the designed and actual measured performance of the building is called the "performance gap". Figure 1 visually shows how the designed energy use of a building does not account for the various factors that contribute towards the total energy use. The same principles could be applied to water use and other performance factors of a building.

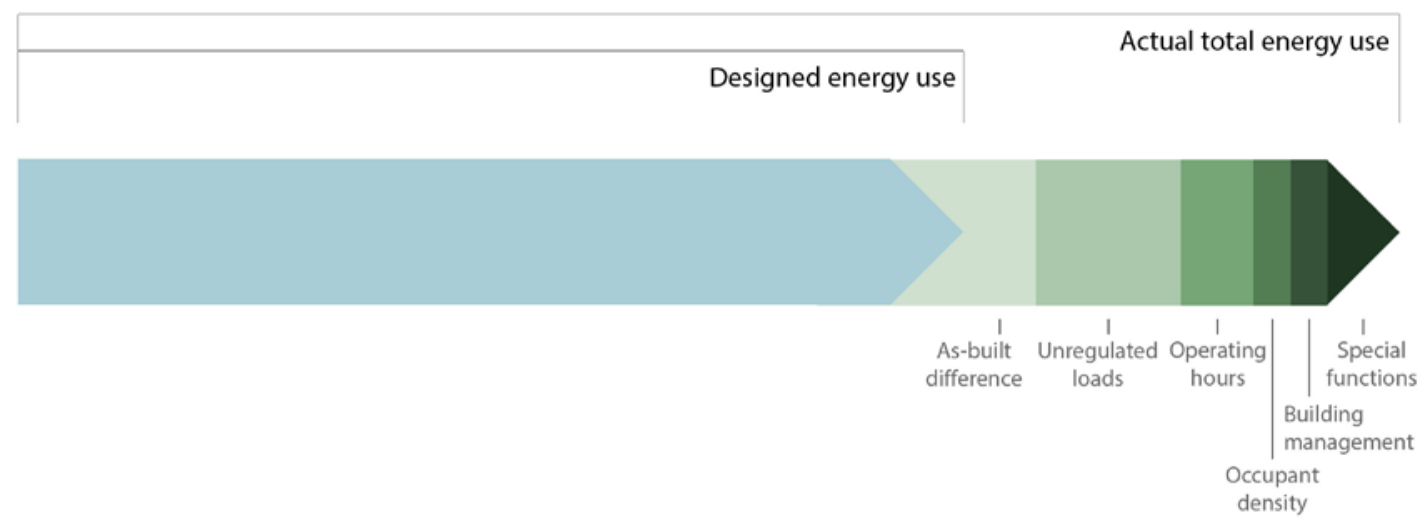

Figure 1: Comparison of the designed energy use and the actual total energy use of a building

[Adapted from CarbonBuzz (2013)]

The "As-built difference" within Figure 1 includes the changes made to the design during the construction to handover stage that affects the performance of the building (CarbonBuzz, 2013). "Unregulated loads" are plug-loads, equipment and machines that are generally excluded from the energy model created in the design stage and make up a large portion of the excluded energy use as seen in Figure 1 (CarbonBuzz, 2013). The "Operating hours" and "Occupant density" are changes in the building use that could not have been foreseen or excluded during the design stage. How the building is managed affects the efficiencies of the systems in the building and in turn can waste energy if poorly managed (Menezes, Cripps, Bouchlaghem, \& Buswell, 2012). "Special functions" 
are components and activities within a building that increases the energy consumption, such as; swimming pools and medical equipment (CarbonBuzz, 2013).

Menezes et al. (2012) lists additional causal factors for the performance gap. Causal factors affecting the predicted performance to be inaccurate include; oversimplified and/or unrealistic inputs for energy models and potential errors embedded within energy modeling programs that could lead to inaccurate outputs (Menezes, Cripps, Bouchlaghem, \& Buswell, 2012). On the other hand, factors that increase energy use of a building during operations could be due to construction quality (such as degraded insulation or imperfect air barrier) and occupant behaviour (Menezes, Cripps, Bouchlaghem, \& Buswell, 2012). Occupant behaviour can impact the energy consumption of a building in two ways; one is through the control of unregulated loads as mentioned earlier. The other is through intervention of building services and influencing the indoor climate, for example, by-passing lighting controls and opening windows (Menezes, Cripps, Bouchlaghem, \& Buswell, 2012).

Bordass et al. (2004) cited a comparison of the designed and actual annual carbon dioxide emissions of an environmental award-winning office two years after its completion, where the actual emissions were over double that of the designed estimates. From investigating the cause, they found several sources for the discrepancies, one of the major ones being that the electricity consumption in the computer and communication rooms were not included in the design estimates (Bordass, Cohen, \& John, 2004).

CarbonBuzz, a website where building owners can anonymously provide their building's design and actual energy consumption, has a small database of 13 residential buildings (as of February 2015). Unfortunately only 3 out of the 13 buildings have both design and actual data inputted in the platform. The data for these 3 buildings are presented in Figure 2 (the raw data for 
the figure is in Raw Data Used for Figure 2Appendix A). There is no trend that can be seen from the data, but it can be noted that there can be significant differences between the predicted and actual energy intensity.

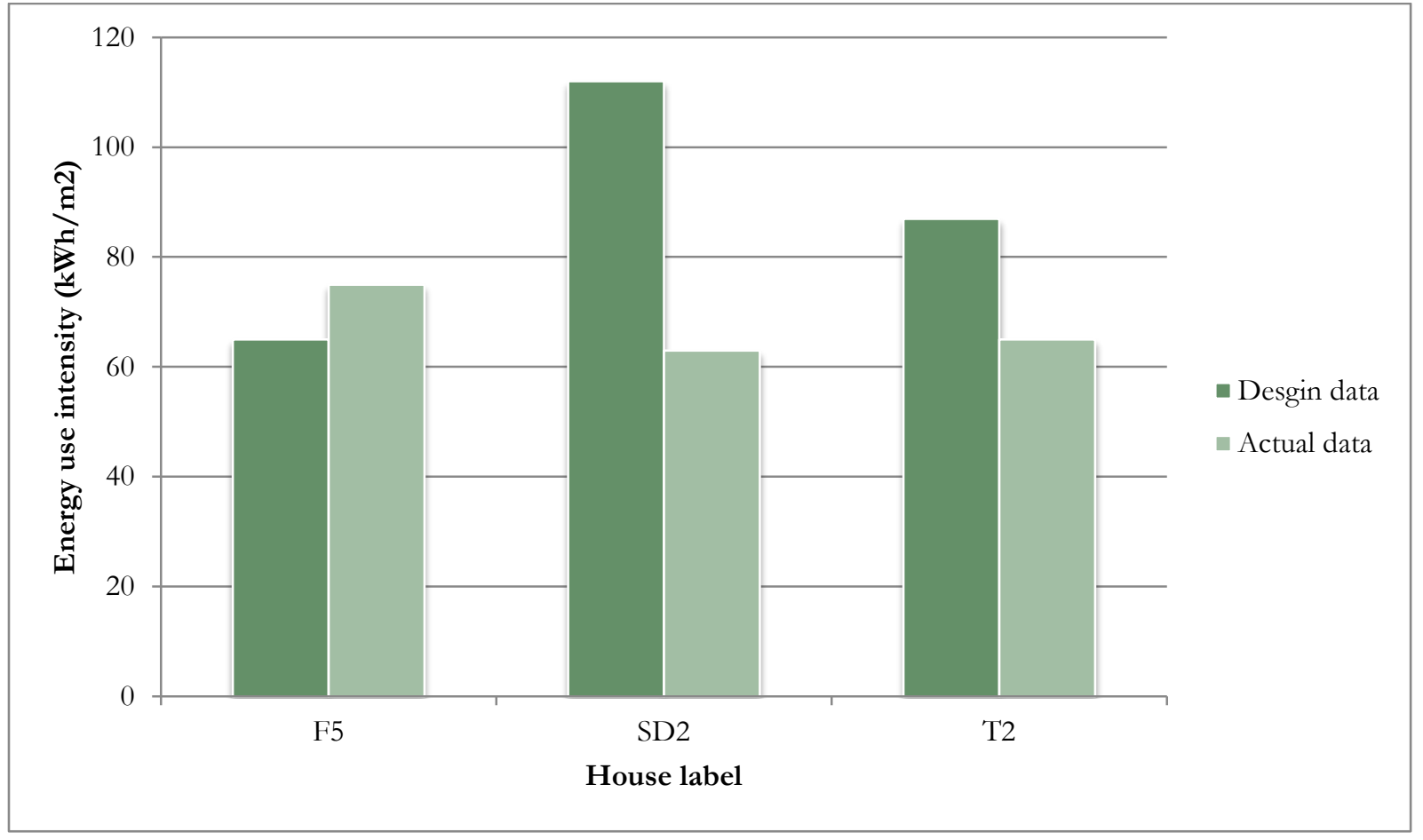

Figure 2: Comparison between the design and actual energy use intensity of 3 residential buildings.

F5 is a flat, SD2 is a semi-detached home, and T2 is a terraced home. Data from CarbonBuzz (2013).

As mentioned earlier, the commercial and multi-unit residential buildings in the study by Turner (2006) found that none of the actual energy use intensities fell within $20 \%$ of the design level. Carbon Trust reports that the performance gap is on average a 16\% variation (2011).

Several studies (Dall'O', et al. 2012; Hall, et al. 2013 \& Menezes, et al. 2012) compared the predicted and actual energy consumption of buildings. The predicted energy consumption for these cases is the energy consumption calculated or simulated based on the specifications of how the building should perform after construction and commissioning. The comparison of the predicted and measured performance of a building identifies issues with the building's operation (Hall, Uhlig, 
\& Bertolet, 2013). However, this does not look into the errors made during the design stages and the extent of the effects that the changes or errors made in the construction phase have on the final product. Figure 3 illustrates the difference between these two analyses.

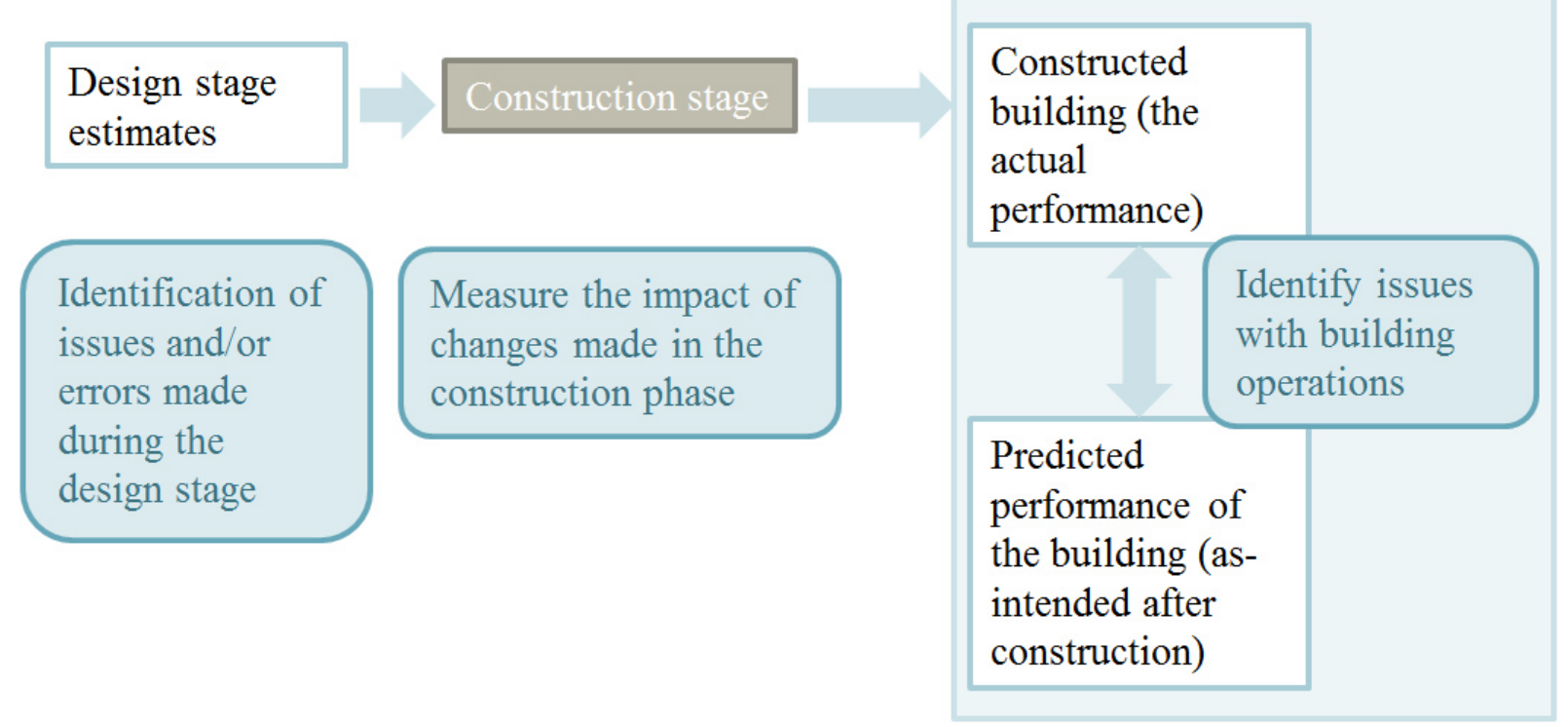

Figure 3: Diagram showing the types of analyses present in the literature.

The highlighted portion on the right is the type of study that Dall'O', et al. (2012), Hall, et al. (2013) \& Menezes, et al. (2012) conducted. This thesis focuses on the left portion of the diagram.

Designers and builders generally move on to their next project and do not ensure that the building they produced is operating the way it was intended to (Bordass, Cohen, \& John, 2004). Because they do not conduct follow-up assessments on their past projects, designers, consultants and builders do not realize the mistakes they have made and continue to repeat them in their next project (Bordass, Cohen, \& John, 2004). Databases like CarbonBuzz make stakeholders aware of the performance gap and encourage the investigation of the sources of discrepancies. Currently in Canada, the International Initiative for a Sustainable Built Environment (iiSBE) has teamed up with Universities to perform POE studies on award winning buildings throughout the country to identify the strengths and weakness of these buildings through key performance indicators. The lessons 
learned are then relayed back to various stakeholders with the hopes of improving the future of Canada's built environment.

\subsection{Summary of Findings}

The following points are the key findings from the literature review that influenced the development of the research questions:

- There was a lack of building performance evaluations done on residential buildings, and almost none were done on buildings in Canada.

- Several studies had compared the predicted and actual performance, but very few studies have investigated the sources of the discrepancies between the design estimates and actual performance.

- The efficacy of energy modeling programs have been in question but not targeting the programs used in the industry for the LEED for Homes certification process in Canada. 


\section{Conceptual Framework}

Given the number of studies done on residential buildings, and the lack of assessments done on these building types in Canada, building performance evaluations were performed on 3 LEED for Homes certified buildings in Southern Ontario. Of the three perspectives of BPE presented by Leaman, et al. (2010), the environmental performance (energy consumption) is covered in this research, and to an extent the human factor (occupant behaviour). The three case study homes were designed and built with energy efficiency in mind and all have been awarded LEED for Homes certification. For the certification process, the energy efficiency of the homes were evaluated but during occupancy, follow-up assessments were not performed to gain insight into how the buildings are being used and how the energy consumption of the home during occupancy may differ from the predicted values used in the energy efficiency rating for the home. The case study approach allows for an in-depth exploration of each of the homes utilizing multiple data sources and interacting with the occupants who live in the homes, to gain new knowledge that can be integrated and applied to improve upon the assessment process of energy efficient homes.

\subsection{Research Objectives}

The following were the overall research objectives:

1. To investigate whether there is an energy performance gap for LEED certified residential homes. If there is an energy performance gap, an additional objective to better understand the sources of discrepancies so that they may be minimized in future buildings.

2. To assess the impact of using a more versatile energy simulation program in place of the basic energy modeling program currently used for the LEED for Homes certification process.

\subsection{Research Questions}

The specific research questions of this research are as follows: 
1. How well does the design stage energy modeling, using a typical energy modeling program used to generate the EnerGuide rating, correlate with the actual energy use of a home?

2. What are the sources of discrepancies between the predicted and actual energy use of the homes in the study?

3. What is the added value of using a dynamic energy simulation program to predict energy use? In terms of the resulting EnerGuide ratings for the homes using the two different energy modeling programs, to assess whether the use of the current program is appropriate for energy efficient homes.

\subsection{Scope of the Research}

This research focuses on the energy consumption of the buildings, both electricity and natural gas consumption for both heating and cooling seasons, and does not include other building performance criteria such as; indoor environmental quality. The electricity and natural gas usage considered for a home includes consumptions through; space heating and cooling, fan and pumps associated with the HVAC system, ventilation, humidification, domestic hot water (DHW), lighting, exterior use, appliances and other electronics. Water consumption is considered only in terms of the energy consumption by the DHW system.

A study done by Guerra et al. (2009) found that the building's technical characteristics were responsible for $42 \%$ of the variation in energy consumption for homes in Netherland. In this study however, building integrity, choice in building design or construction were not considered besides the air tightness test results from the blower door test conducted by the consultants for the homes.

The study is limited to houses with LEED for Homes certification within the Southern Ontario region with homeowners who were willing to have their home be part of the study. The 
region was chosen for close proximity and the homes could be modeled with weather data that are similar.

\subsection{Value of Work}

This study provides feedback regarding the program used for LEED for Homes certification and the EnerGuide rating system so that the lessons learned from this research could inform future changes to the energy modeling programs and processes used. Additionally, very few analyses have been done on residential buildings in Canada, and this project is the first of its kind being done in Ontario. The data from this study can initiate the collection of data of energy efficient residential buildings in Ontario for benchmarking these building types with the cooperation of design teams and home owners. 


\section{Methodology}

Taking an investigative approach, this research analyzed the energy model created for the buildings in the design phase and compared that with the actual energy consumption of the building, and energy models of the homes created with a more sophisticated dynamic energy model. Figure 4 shows a simple diagram of the approach taken for this research. This thesis was not meant to understand the shortcomings of the buildings, but investigate the performance gap and see how it could be better understood and minimized. This study is similar to that of Karlsson, et al. (2007) and Saunders, et al. (2012), by analyzing the difference in the energy modeling programs, but putting it into the context of the LEED for Homes certification process. The intention of this study was to determine the sources of performance gaps in energy efficient homes, and the impact on the EnerGuide ratings when a dynamic energy simulation program is used in place of a basic energy modeling program.

\section{Predicted energy consumption \\ Energy consumption predicted by a steady state building energy simulation program for LEED for Home certification.} Dynamic energy model

Energy consumption estimation using a dynamic energy simulation program.

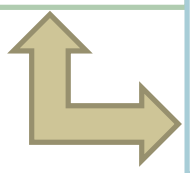




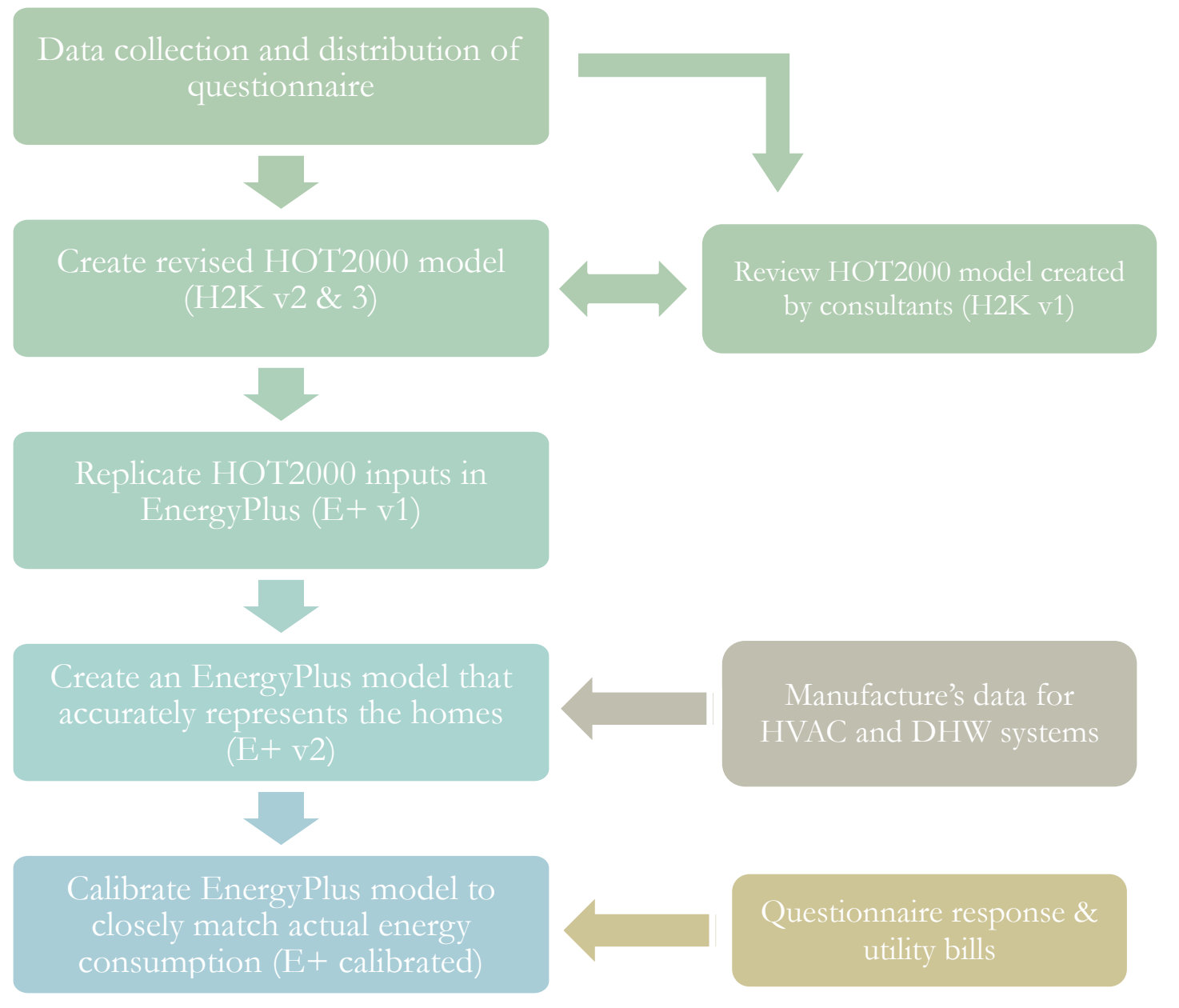

Figure 5: Flow chart of steps taken in the methodology for each home.

The steps taken in the methodology for each of the homes are shown in Figure 5. Energy models are created in both a steady state building energy simulation program and a dynamic energy simulation program. Questionnaires were distributed and the utility bills for the homes were obtained to gain insight regarding how the buildings were used by the occupants to calibrate the final energy model using EnergyPlus. The data collection, energy models and analysis approach for the research is explained in the following sections. 


\subsection{Data Collection}

\subsubsection{Physical Data Collection}

Detailed specifications of the homes were obtained from the designer and/or homeowner, including; wall, roof and foundation assemblies, window specifications, HVAC system make and models, and ground source heat pump specifications. The energy model used for the LEED submission was also obtained for all homes, and the outputs of those models were assumed to be the predicted energy consumption.

The energy and water consumption of the homes were gathered from utility bills provided by the homeowners since the homes are not sub-metered. The utility bills are generally billed on a monthly basis and so only monthly energy and water consumptions are available, but in some cases they are on a bi-monthly basis.

\subsubsection{Questionnaires}

Data regarding occupant behaviours was gathered through occupant questionnaires. The questionnaire format and questions were adapted from the Building Use Studies Methodology template (Usable Buildings, 2013). The questionnaires differ slightly for each home due to the home's characteristics and include specific questions regarding anomalies in their utility bills. The questions were developed after creating the energy model in the dynamic energy simulation program to understand what kind of information was required to calibrate the energy model, and were meant to obtain information regarding occupant behaviour that affect energy and water consumption. Each questionnaire was divided into 7 sections; background, air and temperature, lighting, energy use in the kitchen, energy use in all other rooms, domestic hot water use, and other questions.

The background section contained questions on when the homeowner moved into their home, occupancy number and when the home is generally occupied. The air and temperature section covered how often supplementary heating is used, additional heating/cooling equipment or 
methods used and frequency of use, and the set-point temperature during the heating and cooling season. The lighting section asked the homeowner how often electric lighting is used in their home and the wattage of lights in each room. The energy use sections posed questions regarding appliances and electronics used in the household and how frequently they are used. In the domestic hot water use section, homeowners were asked how frequently showers and baths were taken, and how often dishwashers and clothes washers were used. The final section, labeled "other", included questions regarding anomalies in the utility bills and if the home was vacated for an extended period of time during the year that would affect the energy and water consumptions. Each section included a comment box that allowed the respondents to include additional information or to elaborate on their answers.

The questionnaires were distributed electronically in a PDF form format where the homeowners could save their answers as they go and not be required to complete it in one sitting. A questionnaire that was distributed to one of the households is included in Appendix B.

\subsection{Whole Building Energy Simulation}

Whole building energy simulations have been done to predict the performance of energy efficient buildings as a part of green rating system processes. For the homes in this study, HOT2000 was used to model the homes and to calculate the EnerGuide rating number required for the LEED for Homes Energy \& Atmosphere 1.2 "Exceptional Energy Performance” credit.

HOT2000 is an easy to use simulation program developed by CanmetENERGY that has become the "Canadian standard for evaluating the energy performance of houses and multi-unit residential buildings" (NRCan, 2014). It is a steady state building energy simulation program that has various options to represent details of building designs for optimization and predicting the energy consumption of the building. The dynamic building energy simulation program chosen to be 
compared against HOT2000 for this study is EnergyPlus. EnergyPlus is a text-based program developed by the U.S. Department of Energy, and partnered organizations, that has been extensively tested and validated (Henninger \& Witte, 2014). The program was chosen for its flexibility and wide array of comprehensive inputs that could be utilized to model the homes with as much detail as possible.

The following sections describe the type of energy modeling done in the respective programs.

\subsubsection{HO'T2000 models}

There are three models made in HOT2000 that are analyzed within this study. The first is the model created by the consultants, the second is a revised version created by the author for the homes using the "EnerGuide" mode, and the third is done using the "General" mode in the program.

Weather data in HOT2000 for the respective cities that the homes are in were chosen for the simulations. The data is derived from the data produced by the Atmospheric Environmental Services of Environment Canada. The weather data in HOT2000 is on a monthly basis and is based mainly on Long Term Mean data.

\subsubsection{HOT2000 Consultant Model (H2K v1)}

The HOT2000 models that were created for the purpose of the LEED for Homes

submissions were provided by the consultants for each of the homes. Cooling operations were excluded from the models since it is not considered in the EnerGuide rating calculation. In later sections this HOT2000 model will be referenced as "H2K v1". 


\subsubsection{HOT'2000 Revised Model in EG Mode (H2K v2)}

After reviewing the HOT2000 models created by the consultants, a revised HOT2000 model for each of the home was created due to several reasons. One being that the energy models created by the consultants used an older version of the program (version 9.34c), the revised model was created using 10.51. The as-built homes were not always consistent with the models created during the design stage and some inaccuracies were identified in the H2K v1 models for the homes. For these reasons a revised version of the HOT2000 model was created for each home to be as accurate and a close representation of the buildings within the capabilities of the program. In situations where the correct system was not available within the list of inputs the closest option was chosen in the program. The full house report for each home was generated under the "EnerGuide Rating (new houses)" application mode within the HOT2000 program similar to H2K v1. In later sections, this revised HOT2000 model will be referenced as "H2K v2".

\subsubsection{HOT2000 Revised Model in General Mode (H2K v3)}

This version of the HOT2000 model for the homes is similar to the H2K v2 model in the previous section, but the outputs are generated under the "General" application mode within the HOT2000 program. The assumptions for base loads and heating are slighting different in the "General" mode and cooling is included for the whole year simulation. This model will be referenced as "H2K v3" in later sections.

\subsubsection{Energy Plus Models}

Three models of EnergyPlus were created for each home to be compared against the HOT2000 outputs. The description and the how they differ from each other is described in their respective sections below.

The weather data used for the simulations (Canadian Weather for Energy Calculations) were obtained from the U.S. DOE website, and produced by Numerical Logics in partnership with 
Environment Canada and the National Research Council of Canada, for each location. The hourly files were derived from the data sets of hourly weather information for Canada from 1953 to 1995 (U.S. DOE, 2014). The energy models were created using EnergyPlus version 8.1.

The homes were initially drafted in Google SketchUp based on the architectural drawings provided by the architects/homeowners. In EnergyPlus, the choice of using interior, exterior or centered dimensions of the building envelope has little impact on the simulation model. The outer wall measurements were used in all the EnergyPlus models to simplify the model where wall assembly thicknesses differed from the below ground walls to above ground walls. The thermal zones for all homes were modeled to match the exterior measurements of the building envelope. Minor changes were made to the geometry of the thermal zones to simplify the model and to avoid non-convex zones.

\subsubsection{EnergyPlus with HOT2000 HVAC and Base-load Input Model (E+v1)}

A basic EnergyPlus model with one zone was created for each home with the same or similar HVAC and DHW system as HOT2000. HVAC templates were used in EnergyPlus to set up the HVAC system with the same specification inputs as HOT2000. "ZoneHVAC" parameters were used in this energy model type, such as;

- ZoneHVAC:EnergyRecoveryVentilator

- ZoneHVAC:WaterToAirHeatPump

- ZoneHVAC:Baseboard:Convective:Electric

- ZoneHVAC:HighTemperatureRadiant (for the fireplaces)

Where inputs were required, but not an applicable field in HOT2000, the field would be auto-sized by the program if possible or set to the manufacturer's specifications. Inputs such as electronics, lighting and exterior lighting energy consumption and hot water consumption were matched in 
order to have the same outputs as HOT2000. Table 1 lists the values for the base-load assumptions in HOT2000 that were matched in the EnergyPlus model.

Table 1: Base-load assumptions of HOT2000.

These are the default values within the program that are used for all the homes (regardless of size).

\begin{tabular}{|l|l|}
\hline Component & Value \\
\hline Interior equipment electricity consumption & $5110 \mathrm{kWh} /$ year \\
\hline Lighting electricity consumption & $1095 \mathrm{kWh} /$ year \\
\hline Exterior lighting electricity consumption & $1460 \mathrm{kWh} /$ year \\
\hline Other electricity consumption & $1095 \mathrm{kWh} /$ year \\
\hline Total base load electricity consumption & $8760 \mathrm{kWh} /$ year \\
\hline Hot water consumption & $225 \mathrm{~L}(365 \mathrm{~L}$ for double occupancy) \\
\hline
\end{tabular}

This model was created to mimic HOT2000 inputs and compare the two programs in terms of output. In later sections this EnergyPlus model will be referenced as "E+ v1".

\subsubsection{EnergyPlus with HOT2000 Base-load Input and Actual HVAC Model (E+ v2)}

After creating the revised HOT2000 model, it was clear that the program did not have the capabilities of precisely modeling these homes since the HVAC and DHW systems used in the homes were not available input options within the program. The second EnergyPlus model was created with HVAC and DHW systems actually installed within the homes, but still with the setpoint temperature, occupancy and operation schedules, base-load assumptions (appliance, electronic, lighting and exterior lighting electricity consumption) and hot water consumption as in HOT2000 (the EnerGuide assumptions). The occupancy value and scheduling were also made to match those that were used in HOT2000. Unlike the previous model, multiple zones were created for this model to work in tandem with the HVAC system. The heating and cooling set-points used in the model were set to 21 and $25^{\circ} \mathrm{C}$ respectively.

For the heat pump inputs in the energy model, the pre-process parametric spreadsheets were obtained from the EnergyPlus website and the required fields were put in from the manufacturers' 
specification sheet to generate the coefficients to be used in the simulation parameter. Where applicable, the manufacturers' specifications for the mechanical equipment were used for the inputs of the parameters used.

This second EnergyPlus model represents what the outputs would be if a program like EnergyPlus, that has the versatility to model complex or unique HVAC and DHW systems, was used instead to predict the energy consumption of LEED certifiable homes. This version of the EnergyPlus model will be referenced as "E+ v2" in later sections.

\subsubsection{EnergyPlus Calibrated Model}

The third EnergyPlus model is essentially the previous model calibrated with the questionnaire responses to closely match the actual energy and water consumption of the homes obtained from the utility bills. The calibrated model used the responses from the questionnaire to adjust parameters within the model to closely reflect the occupants' behaviours and how they use their home. Parameters such as occupancy number and scheduling, heating and cooling set-point temperatures, which were described by occupants, were set and parameters with some uncertainty were adjusted within the range of realistic values for the output of the simulation model to closely match the values from the utility bills. This latter group of parameters includes specifications that either could not be asked in the questionnaire since it would be too invasive or would make the questionnaire too long by asking too many questions. For electronics and appliances that are installed and used in the homes, the design level inputs (in watts) for the EnergyPlus model for each electric equipment was estimated using the average described by Energy Use Calculator (2015). Lighting (both for interior and exterior) was modeled based on the responses from the questionnaire on the number of light bulbs are in each room, the types of light bulbs used in the home and how frequently they are used. 
Phantom loads were also considered in the electricity consumption of the homes. Phantom load or plug load is the electricity consumption of electronics and appliances in the home that have been turned off and not in use by the occupants but still continue to draw electricity 24 hours a day unless they are completely unplugged. Each electronic may only draw a small amount on an hourly basis but with more electronics and appliances in a home the phantom load adds up and can accumulate. The design level input (in watts) for the phantom load for each home was established using the table created by the Lawrence Berkeley National Laboratory (2015), by summing up the average wattage of the standby power of the electronics and appliances available in the home.

Utility bills and the questionnaire responses were used to calibrate the energy model since these homes are not metered by the end-use energy consumptions. The utility bills were mostly on a monthly basis (one home was billed bi-monthly), and the monthly energy consumptions outputs from the simulation were compared to the figures from the normalized monthly utility bills. However, the model is not created with 100\% certainty and there are potential for errors and incorrect assumptions. ASHRAE has a guideline for whole building calibrated simulation compliance that dictates that, for a computer model calibrated to monthly data, the normalized mean bias error $(\mathrm{NMBE})$ should be within $+/-5 \%$, and the coefficient of variation of the root mean square error (CVRMSE) should be within +/-15\% (ASHRAE, 2002). The NMBE and CV(RMSE) are calculated using the following equations:

$$
N M B E=\frac{\sum\left(y_{i}-\hat{y}_{i}\right)}{(n-p) \times \bar{y}} \times 100
$$




$$
C V(R M S E)=100 \times \frac{\left[\frac{\sum\left(y_{i}-\hat{y}_{i}\right)^{2}}{(n-p)}\right]^{1 / 2}}{\bar{y}}
$$

For the home with bi-monthly utility bills, the percentages were assumed to be half of those for the monthly comparison, since inaccuracies are less forgiving for a greater time period.

The water bills were used to match the total water consumption for the DHW portion of the model. The data reported by Aquacraft (2005) was used to estimate the approximate hot water to total water ratio to calibrate the DHW energy consumption portion as realistic as possible. Table 2 lists the percentages of the hot water in respect to the total water consumption of the end-use that the author aimed for when modeling the DHW consumption. Table 3 includes the amount of hot water and total water used by water fixtures in a home on average, these values were used to compare the simulation outputs to ensure that water and hot water consumptions were in line with the norm where water bills were not available.

Table 2: The percentage of water consumption used by old and updated fixtures that is heated (source: Aquacraft, 2005).

For example, for water use of old shower fixtures, $64 \%$ of the water used in showers is heated and the remaining $36 \%$ is from the water mains. Old fixtures represent fixtures and appliances that generally have a higher flow rate, whereas the updated types are higher efficiency and low flow fixtures and appliances. These percentages were used as a reference to ensure the hot water consumption simulated in the models were reasonable.

\begin{tabular}{|lll|}
\hline Water end-use & Old fixture hot water percentage & $\begin{array}{l}\text { Updated fixture hot water } \\
\text { percentage }\end{array}$ \\
\hline Clothes washer & $20 \%$ & $14 \%$ \\
\hline Showers & $64 \%$ & $72 \%$ \\
\hline Sinks & $83 \%$ & $72 \%$ \\
\hline Dishwashers & $86 \%$ & $88 \%$ \\
\hline Leaks & $8 \%$ & $13 \%$ \\
\hline Total & $31 \%$ & $39 \%$ \\
\hline
\end{tabular}


Table 3 Hot water and total water consumption by water fixtures.

The values are derived from the gallons per day data gathered by Aquacraft (source: Aquacraft, 2005).

\begin{tabular}{|lllll|}
\hline Water end-use & \multicolumn{2}{l}{$\begin{array}{l}\text { Old fixture water consumption (in } \\
\mathrm{m}^{3} \text { /year) }\end{array}$} & $\begin{array}{l}\text { Updated fixtures water } \\
\text { consumption }\end{array}$ \\
& Hot water & Total & Hot water & Total \\
\hline Toilet & & 62 & & 28 \\
\hline Dishwasher & & 3 & 4 & 3 \\
\hline Clothes washer & 9 & 47 & 23 & 29 \\
\hline Shower & 22 & 38 & 21 & 33 \\
\hline Sink & 26 & 32 & 2 & 28 \\
\hline Leaks & 3 & 46 & 15 \\
\hline
\end{tabular}

The basement utility 3-dimensional ground heat transfer tool was used to calculate the exterior face temperature of the building surfaces below the ground, instead of using the default ground temperature for the outside surface temperature for the surfaces as done for the previous models.

This calibrated model is a means to evaluate the capability of EnergyPlus in modeling actual energy consumption given occupant behavioural patterns. At the same time it provides an approximate breakdown of the actual energy consumption by end-uses to compare against the other energy model outputs. In later sections this version of the EnergyPlus model will be referenced as "E+ calibrated".

Table 4 summarizes the energy models described in the above sections included in this study.

Table 4: Summary of energy models and data in study.

\begin{tabular}{|l|l|l|}
\hline Program & Model label & Description \\
\hline HOT2000 & H2K v1 & $\begin{array}{l}\text { HOT2000 model created by the consultants to predict the } \\
\text { energy consumption and energy efficiency of the homes for } \\
\text { the LEED for Homes certification. }\end{array}$ \\
\cline { 2 - 2 } & $\begin{array}{l}\text { A revised version of H2K v1 accounting for inaccuracies } \\
\text { and using the most current version of the program, but still } \\
\text { in the EnerGuide mode. }\end{array}$ \\
\hline
\end{tabular}




\begin{tabular}{|c|c|c|}
\hline Program & Model label & Description \\
\hline & $\mathrm{H} 2 \mathrm{~K}$ v3 & $\begin{array}{l}\text { Similar to H2K v2 but outputs generated using the } \\
\text { "General" mode within the program where base loads and } \\
\text { occupancy were altered for House C. }\end{array}$ \\
\hline \multirow[t]{3}{*}{ EnergyPlus } & $\mathrm{E}+\mathrm{v} 1$ & An EnergyPlus model that uses the same inputs as $\mathrm{H} 2 \mathrm{~K}$ v3. \\
\hline & $\mathrm{E}+\mathrm{v} 2$ & $\begin{array}{l}\text { A model with the same base load energy and water } \\
\text { consumption assumptions as the HOT } 2000 \text { models but } \\
\text { parameters for the HVAC and DHW were made to match } \\
\text { the actual systems in the homes. }\end{array}$ \\
\hline & $\mathrm{E}+$ calibrated & $\begin{array}{l}\mathrm{E}+\mathrm{v} 2 \text { model calibrated using the questionnaire responses } \\
\text { to closely match the actual energy consumption of the } \\
\text { home. }\end{array}$ \\
\hline Data & Label & Description \\
\hline $\begin{array}{l}\text { Actual energy } \\
\text { use }\end{array}$ & Actual & $\begin{array}{l}\text { Actual metered energy use gathered from utility metered } \\
\text { data. }\end{array}$ \\
\hline
\end{tabular}

\subsection{Data Analysis}

Figure 6 shows the comparisons made between the models described above. Initially, the $\mathrm{H} 2 \mathrm{~K}$ v1 and $\mathrm{H} 2 \mathrm{~K}$ v2 models for each of the homes were compared against each other to investigate inconsistencies between the original model assumptions by the consultants at the design stage and the final building. Through creating the $\mathrm{H} 2 \mathrm{~K}$ v2 models, the author learned the limitations of the HOT2000 program. Then the energy consumption outputs from each of the HOT2000 models (H2K v1 and H2K v3) were examined alongside the outputs from the E+ calibrated model to determine what the sources of the discrepancies are for the performance gap between the predicted and the energy model calibrated to actual energy consumptions. 


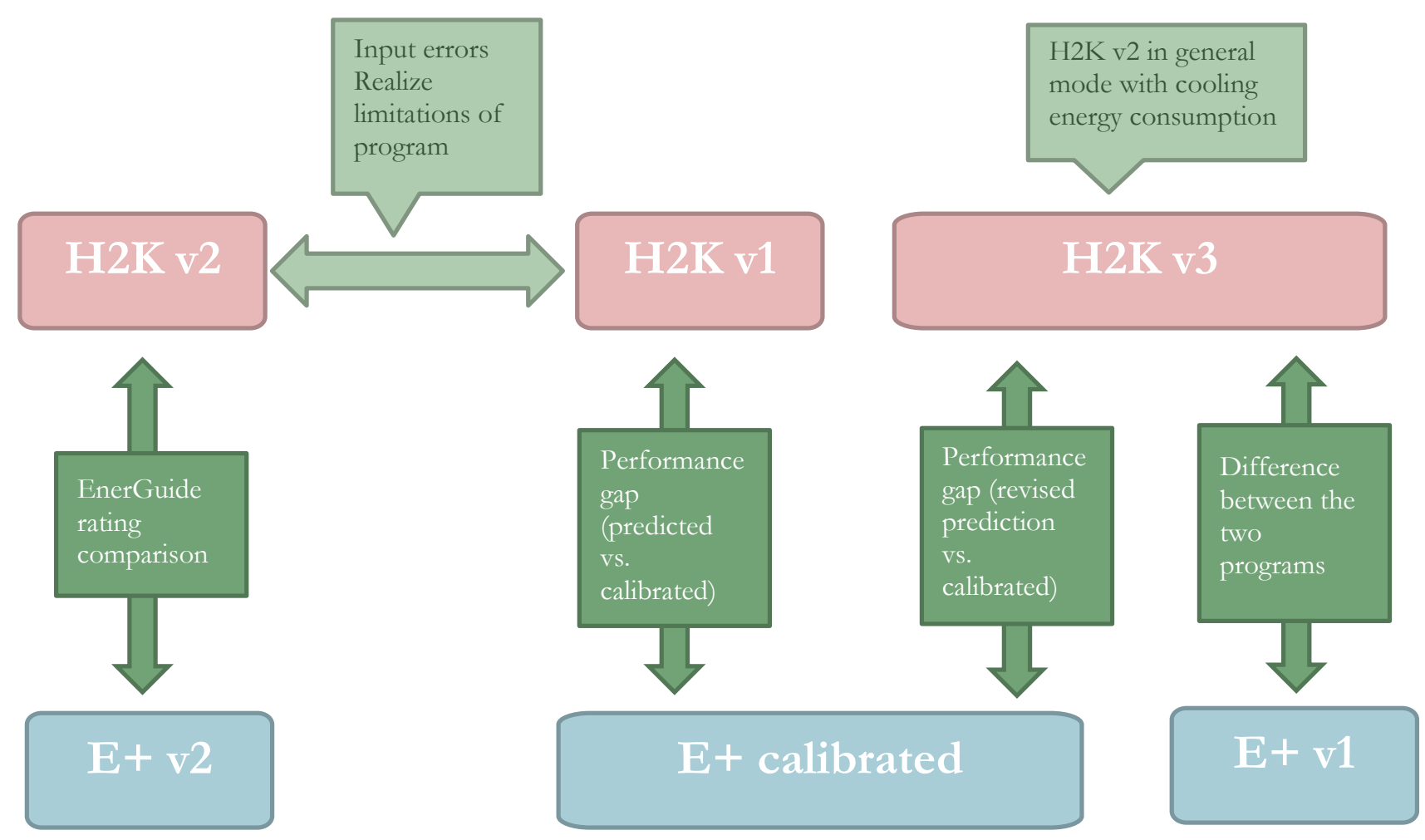

Figure 6: Energy model comparisons made and the aim of the analysis.

In order to answer the third research question, the EnerGuide rating number is calculated from the energy consumption outputs for each of the energy models created, and the differences (or the lack thereof) are analyzed. Since, for the LEED for Homes certification process, the EnerGuide rating number is what is considered for the certification process from the output of the energy model program. The EnerGuide rating is a standard measure that evaluates a home's energy performance on a scale of 0 to 100 , where a home with a 100 rating is an air tight, well insulated and ventilated home that requires no purchased energy (NRCan, 2005). The EnerGuide for Homes energy efficiency rating is calculated using the following equation:

Energy efficiency rating

$$
=100-\left(\frac{\text { Estimated total energy consumption }}{\text { Benchmark total energy consumption }}\right) \times 20
$$


The "estimated total energy consumption" portion of the above equation is calculated using the following equations:

$$
\begin{aligned}
& \text { Estimated total energy consumption } \\
& \qquad \begin{array}{l}
=(\text { Estimated space heating consumption }) \\
+(\text { Estimated occupancy consumption })
\end{array}
\end{aligned}
$$

The "space heating consumption" of the "estimated total consumption" is calculated using the following equation:

$$
\text { Estimated space heating consumption }=\left(S_{E} \times B_{S E}+S_{F} \times B_{S F}\right)
$$

Where, $S_{E}$ and $S_{F}$ are the estimated space heating electrical and fossil-fuel energy consumption respectively, and $B_{S E}$ and $B_{S F}$ are the base efficiencies for each energy type. The base efficiency values are $100 \%$ for electric space heating and for fossil fuel space heating the value ranges from 75 $90 \%$ depending on the fossil fuel used.

The "occupancy consumption" of the "estimated total consumption" is calculated using the following equation:

$$
\begin{aligned}
& \text { Estimated occupancy consumption } \\
& \qquad \begin{array}{l}
=(\text { Estimated DHW consumption }) \\
+(\text { Lights and appliance energy consumption })
\end{array}
\end{aligned}
$$

The "lights and appliance energy consumption" is assumed to be $31,536 \mathrm{MJ}$ per year (24kWh/day). The "estimated DHW consumption" is calculated using the following equation:

$$
\text { Estimated DHW consumption }=1.136 \times\left(D_{E} \times B_{D E}+D_{F} \times B_{D F}\right)
$$

Where, $D_{E}$ and $D_{F}$ are the estimated DHW electrical and fossil-fuel energy consumption respectively, and $B_{D E}$ and $B_{D F}$ are the base efficiencies for each. The base efficiency values are 0.88 for electric 
DHW and 0.57 for fossil fuel DHW. The DHW energy consumption is multiplied by 1.136 to adjust the DHW load to represent its share of the total energy consumption (NRCan, 2005).

The "benchmark total energy consumption" used in the energy efficiency rating calculation is the sum of space heating, DHW and base load benchmark.

$$
\begin{aligned}
& \text { Benchmark total energy consumption } \\
& \qquad \begin{array}{l}
=(\text { Space heating benchmark })+(\text { DHW benchmark }) \\
+(\text { Base load benchmark })
\end{array}
\end{aligned}
$$

The "base load benchmark" is the same value as the "lights and appliance energy consumption" in the "estimated total energy consumption", set at 31,536MJ per year (24kWh/day). The other two components are calculated using the following equations:

$$
\begin{gathered}
\text { Space heating benchmark }=3.6 \times\left(\frac{49 \times D D}{6000}\right) \times\left(40+\frac{V}{2.5}\right) \\
\text { DHW benchmark }=1136 \times 17082 \times\left(\frac{55-T W}{55-9.5}\right)
\end{gathered}
$$

Where, $D D$ is the number of long-term average degree days relative to a base of $18^{\circ} \mathrm{C}$, for the calculations the value 3659.333 was used. The heated volume of the home $(V)$ is also used in the space heating benchmark calculation. In the DHW benchmark calculation, $T W$ represents the local water mains or deep-soil temperature in degree Celsius. 


\section{Houses in Study}

The homes in the study were selected based on LEED for Homes certification (regardless of ranking). The homeowners were approached and they graciously allowed their home to be part of this study. The homes have been kept anonymous and labeled as House A, B \& C. The specifications of the homes are outlined in the following sections.

\subsection{House A}

House A is a single detached family 2 story (plus basement) home located in Toronto, with a floor area of approximately $274 \mathrm{~m}^{2}$, with 3 bedrooms. It has a prefabricated modular design, where parts of the building were created off-site and put together on-site to minimize construction errors, reduce construction waste and maintain a continuous air barrier. The above ground exterior walls and roofs are timber framed with polyurethane foam insulation (insulation RSI 3.52 in walls and RSI 8.62 for the roofs). The basement floor is a 6" concrete slab that sits on expanded polystyrene (EPS) rigid insulation (RSI 1.86). The foundation walls were constructed with 8" concrete surrounded on both sides with EPS rigid insulation (RSI 1.86 each). This home was certified LEED for Homes Gold status and has been occupied since March 2013, with electricity, natural gas and water consumption data available for 2 whole years (March 2013 to March 2015).

The HVAC system for this home consists of a ground source heat pump that provides heating and cooling through a forced air system and supplementing DHW loads. The DHW system is otherwise consists of an electric hot water tank. A heat recovery ventilator (HRV) is also equipped in this home to provide fresh air and reduce space heating energy consumption. Supplementary heating is provided on the main floor of the home through a natural gas powered fireplace. Additional natural gas usage on the property is through an outdoor barbeque set. A $5.5 \mathrm{~kW}$ photovoltaic (PV) solar panel array covers a large portion of the flat roof of this home. 


\subsubsection{Specifications for House A in HO'T2000}

Table 5 lists the specifications for House A used in its H2K v2 model. Base load inputs were left at default settings. For the HVAC system, a baseboard heater was selected under the "type 1" heating category and the ground source heat pump was selected for the "type 2" heating, with a supplementary heating element (a natural gas fueled fireplace). Due to the limitations in HOT2000, the user is unfortunately forced to select a heating source from the "type 1" category and the baseboard inclusion in the model was inevitable even when the home does not physically have baseboard heating. The baseboard output capacity was set to the lowest required according to the program with the inputs for the home, and with 100\% efficiency for it to have the lowest energy consumption possible. There were several changes made with the revised model ( $\mathrm{H} 2 \mathrm{~K}$ v2) from the model that the consultant had created:

1. The fireplace was initially modeled to be a "fireplace with pilot", but changed to a "fireplace with spark ignition”.

2. The specification for the fireplace that was installed in the home was used in the revised model, it was noticed that the heating capacity and the efficiency were left as the default.

3. Laundry equipment was not included in the initial model, and they were included in the revised model but it was noticed that there were no changes in the DHW consumption.

4. The tank type for the DHW system was set to "heat pump", but the description of the "heat pump" tank type in HOT2000 differs from a ground source heat pump and the actual DHW system in the home. A "conserver tank" type was used instead of a "heat pump" in the revised model.

5. The initial design of the House A was to have triple glazed windows, but during construction, plans were changed and double glazed windows were installed. The HOT2000 model 
created by the consultant was modeled with triple glazed windows, the revised model was modeled with double glazed windows.

Table 5: Specifications for House A in HOT2000.

(* Batt insulation was used in place of polyurethane foam since the polyurethane insulation option within HOT2000 did not meet the thickness and insulation value. ${ }^{* *}$ For the exterior wall insulation XPS was used in place of polyurethane for the same reason.)

\begin{tabular}{|c|c|c|}
\hline Feature & Value/description used in $\mathrm{H} 2 \mathrm{~K}$ v1 & Changes made in $\mathrm{H} 2 \mathrm{~K}$ v2 \& 3 \\
\hline $\begin{array}{l}\text { House internal } \\
\text { conditioned floor } \\
\text { area }\end{array}$ & $281.0 \mathrm{~m}^{2}$ & \\
\hline House volume & $913.3 \mathrm{~m}^{3}$ & \\
\hline $\begin{array}{l}\text { Brief description of } \\
\text { window type }\end{array}$ & $\begin{array}{l}\text { Triple glazed with low-e coating } \\
\text { Argon gas in between } \\
\text { Reinforced vinyl framing }\end{array}$ & $\begin{array}{l}\text { Double glazed with low-e coating } \\
\text { instead of triple glazed }\end{array}$ \\
\hline $\begin{array}{l}\text { Brief description of } \\
\text { the roof and its RSI- } \\
\text { values }\end{array}$ & $\begin{array}{l}\text { Roof rafters with } 2 \text { layers of batt } \\
\text { insulation* } \\
\text { Main floor }=9.30 \mathrm{~m}^{2} \mathrm{~K} / \mathrm{W} \\
\text { Second floor }=9.39 \mathrm{~m}^{2} \mathrm{~K} / \mathrm{W} \\
\text { Third floor }=9.28 \mathrm{~m}^{2} \mathrm{~K} / \mathrm{W}\end{array}$ & \\
\hline $\begin{array}{l}\text { Brief description of } \\
\text { the exterior walls } \\
\text { and the RSI-values }\end{array}$ & $\begin{array}{l}\text { Wood framing with extruded } \\
\text { polystyrene insulation }(\mathrm{XPS})^{* *} \\
\text { Main floor }=3.94 \mathrm{~m}^{2} \mathrm{~K} / \mathrm{W} \\
\text { Second floor }=3.89 \mathrm{~m}^{2} \mathrm{~K} / \mathrm{W} \\
\text { Third floor }=3.89 \mathrm{~m}^{2} \mathrm{~K} / \mathrm{W}\end{array}$ & \\
\hline $\begin{array}{l}\text { Below ground wall } \\
\text { and floor } \\
\text { construction brief } \\
\text { description of type }\end{array}$ & $\begin{array}{l}\text { Interior and exterior insulation on } \\
\text { below ground walls (RSI of } 1.86 \\
\mathrm{~m}^{2} \mathrm{~K} / \mathrm{W} \text { each) } \\
\text { Insulation below the foundation floor } \\
\left.\text { (RSI of } 1.86 \mathrm{~m}^{2} \mathrm{~K} / \mathrm{W}\right)\end{array}$ & \\
\hline $\begin{array}{l}\text { Blower door test } \\
\text { inputs }\end{array}$ & $\begin{array}{l}\text { Air change rate }=0.79 \text { at } 50 \mathrm{~Pa} \\
\text { Equivalent leakage area }=199.3 \mathrm{~cm}^{2} \text { at } \\
10 \mathrm{~Pa}\end{array}$ & \\
\hline $\begin{array}{l}\text { Heating set point } \\
\text { temperature }\end{array}$ & $21^{\circ} \mathrm{C}$ & \\
\hline $\begin{array}{l}\text { Cooling set point } \\
\text { temperature }\end{array}$ & $25^{\circ} \mathrm{C}$ & \\
\hline $\begin{array}{l}\text { Heating/cooling } \\
\text { system }\end{array}$ & $\begin{array}{l}\text { Type 1: } \\
\text { Baseboards/Hydronic/Plenum } \\
\text { heaters } \\
\text { Type 2: Ground Source Heat Pump } \\
\text { Supplementary Heating (natural gas } \\
\text { fueled fireplace) }\end{array}$ & \\
\hline Baseboard & Output capacity $=19 \mathrm{~kW}$ & \\
\hline
\end{tabular}




\begin{tabular}{|c|c|c|}
\hline Feature & Value/description used in $\mathrm{H} 2 \mathrm{~K}$ v1 & Changes made in $\mathrm{H} 2 \mathrm{~K}$ v2 \& 3 \\
\hline specifications & Efficiency $=100 \%$ & \\
\hline $\begin{array}{l}\text { Ground source heat } \\
\text { pump specifications }\end{array}$ & $\begin{array}{l}\text { Output capacity }=10.96 \mathrm{~kW} \\
\text { Heating efficiency }=4 \mathrm{COP} \\
\text { Cooling efficiency }=5.86 \mathrm{COP}\end{array}$ & \\
\hline $\begin{array}{l}\text { Supplementary } \\
\text { heating } \\
\text { specifications }\end{array}$ & $\begin{array}{l}\text { Energy source }=\text { natural gas } \\
\text { Equipment type }=\text { fireplace with pilot } \\
\text { (sealed) } \\
\text { Output heating capacity }=2 \mathrm{~kW} \\
\text { Efficiency }=30 \%\end{array}$ & $\begin{array}{l}\text { Equipment type }=\text { fireplace with } \\
\text { spark ignition (sealed) } \\
\text { Output heating capacity }=8.2 \mathrm{~kW} \\
\text { Efficiency }=87 \%\end{array}$ \\
\hline Fireplace schedule & $\begin{array}{l}\text { October }=1 \text { hour } / \text { day } \\
\text { November }=2 \text { hours } / \text { day } \\
\text { December }=3 \text { hours } / \text { day } \\
\text { January }=3 \text { hours } / \text { day } \\
\text { February }=3 \text { hours } / \text { day } \\
\text { March }=2 \text { hours } / \text { day } \\
\text { April }=1 \text { hour } / \text { day }\end{array}$ & \\
\hline HRV specifications & Efficiency $=61-62 \%$ & \\
\hline DHW & $\begin{array}{l}\text { Energy source }=\text { electricity } \\
\text { Tank type }=\text { heat pump } \\
\text { Tank volume }=0 \mathrm{~L}\end{array}$ & $\begin{array}{l}\text { Tank type }=\text { conserver tank } \\
\text { Tank volume }=189.3 \mathrm{~L}\end{array}$ \\
\hline PV system & $\begin{array}{l}\text { Array area }=34.8 \mathrm{~m}^{2} \\
\text { Slope }=15 \text { degrees } \\
\text { Azimuth }=0 \text { degrees } \\
\text { Module efficiency }=11.9 \% \\
\text { Miscellaneous array losses }=3 \% \\
\text { Other power conditioning losses }= \\
5 \% \\
\text { Inverter efficiency }=96 \% \\
\text { Grid absorption rate }=100 \%\end{array}$ & \\
\hline
\end{tabular}

\subsubsection{Specifications for House A in EnergyPlus}

For the E+ v1 model, an HVAC template for a water-to-air heat pump was used. HVAC

templates were used to generate inputs required for certain HVAC systems with limited input requirements, but it is only applicable for use in single zone buildings. HVAC templates were used in the $\mathrm{E}+\mathrm{v} 1$ models to mimic the basic input requirements in HOT2000 for the HVAC systems. The following zone HVAC input parameters were included in the E+ v1 model for House A:

- ZoneHVAC:EnergyRecoveryVentilator represents the HRV

- ZoneHVAC:Water'ToAirHeatPump represents the ground source heat pump 
- ZoneHVAC:Baseboard:Convective:Electric represents the baseboard heater

- ZoneHVAC:HighTemperatureRadiant represents the supplementary space heating fireplace

Each HVAC component was to have the same inputs used in HOT2000. The

ZoneHVAC:WaterToAirHeatPump includes a cooling and heating heat pump, along with a supplementary heating electric heating coil. But the electric heating coil was set to have a nominal capacity of $0 \mathrm{~W}$ to not contribute to the electricity consumption in the model. For the DHW system, a WaterHeater:Mixed component was used to model the electric water heater with the same inputs as HOT2000. A high temperature radiant parameter (fireplace) is included for supplementary heating similar to the HOT2000 model.

The other two EnergyPlus models (E+v2 \& E+ calibrated) for House A were modeled to include the actual HVAC and DHW systems in the home. The models have 4 thermal zones plus a thermal zone that represents the garage that is not connected to the HVAC system. Each of the thermal zones are serviced with an AirTerminal:SingleDuct:Uncontrolled. The main air loop supplying the zones (AirLoopHVAC) includes and outdoor air system, water-to-air unitary heat pump and a humidifier. The outdoor air system portion of the air loop contains the heat exchanger. Under the water-to-air unitary heat pump is the; fan, water-to-air heat pump (for cooling and heating) and an electric heating coil. The specifications for the heat pumps are listed in Table 6 . The electric heating coil was set to have a capacity of $0 \mathrm{~W}$ to not contribute to the electricity consumption. The condenser loop consists of the ground heat exchanger; Table 6 also lists the specifications for the ground heat exchanger for House A. The ground heat exchanger is connected to the water-to-air heat pump for cooling and a water-to-water heat pump for heating. Another plant loop exists where the water-to-water heat pump for heating supplies water for the water-to-air heat pump for space heating, and a stratified water heater (this was done to model the heat pump to supplement the 
DHW supply). A high temperature radiant parameter (fireplace) is placed in the main floor thermal zone and set to be the last in the sequence for providing space heating.

Table 6: Heat pump and ground heat exchanger specifications for House A

\begin{tabular}{|l|l|l|}
\hline EnergyPlus component & Input parameters & Value \\
\hline $\begin{array}{l}\text { Heat pump for cooling (water- } \\
\text { to-air) }\end{array}$ & $\begin{array}{l}\text { Gross rated total cooling } \\
\text { capacity }\end{array}$ & $16,412 \mathrm{~W}$ \\
\cline { 2 - 3 } & $\begin{array}{l}\text { Gross rated sensible cooling } \\
\text { capacity }\end{array}$ & $10,111 \mathrm{~W}$ \\
\cline { 2 - 3 } & Gross rated cooling COP & 5.86 \\
\hline $\begin{array}{l}\text { Heat pump for heating (water- } \\
\text { to-air) }\end{array}$ & Gross rated heating capacity & $18,756 \mathrm{~W}$ \\
\cline { 2 - 3 } & Gross rated heating COP & 4.0 \\
\cline { 2 - 3 } & $\begin{array}{l}\text { Rated heating power } \\
\text { consumption }\end{array}$ & $3,850 \mathrm{~W}$ \\
\hline \multirow{2}{*}{ Ground heat exchanger } & Number of bore holes & 3 \\
\cline { 2 - 3 } & Bore hole length & $150 \mathrm{~m}$ \\
\cline { 2 - 3 } & Bore hole radius & $0.2032 \mathrm{~m}$ \\
\hline
\end{tabular}

\subsubsection{E+ Calibrated Model for House A}

The E+ calibrated model has the same parameters as E+ v2 but certain inputs were adjusted in order for the modeled total energy consumption to closely match the actual energy consumption of the home. Some of the notable changes that were made for the E+ calibrated model for House A based on occupant information are:

- The HRV is turned off during summer.

- There was a higher occupancy during certain months during the calibration time period.

- A higher cooling set point temperature is set by the occupants to reduce the cooling energy consumption.

- Natural ventilation is also utilized to reduce the cooling demand for the home.

- Compact fluorescent and LED lightbulbs are used throughout the home.

- There is no dryer usage in the summer season.

- Cold water is used for the clothes washer throughout the year. 
Figure 7 compares the electricity consumption simulated by E+ calibrated (broken down by base-load, HVAC and DHW electricity consumption) to the actual electricity consumption for House A. The monthly electricity consumption for this home was calculated from the hourly electricity consumption data from the electricity company servicing their home since the utility bills are delivered on a bi-monthly basis. Deducing the approximate breakdown of electricity for base load, DHW, space heating and space cooling consumption was difficult since July and August had the lowest electricity consumption during the year which is unusual since the shoulder seasons would be expected to have the lowest electricity consumption with a low space heating or cooling demand. The energy consumption trend was easily achieved with the questionnaire responses. Indeed there is space cooling in the home during the summer, but the simulated HVAC electricity consumption for July and August are lower as a result of several points; occupants have set high set point temperatures (ranging from 25.5 to $30^{\circ} \mathrm{C}$ depending on the time of day), and the $\mathrm{HRV}$ is turned off from June to August. The simulated DHW electricity consumption is also lower during this period since the ground source heat pump is providing most of the DHW demand and the water heater is not required to do as much work compared to the heating season when the heat pump is mainly required to supply space heating. For this home, the base load is relatively consistent throughout the year, except for March and April where there was a higher occupancy in the home (resulting in a higher base load), and July and August when the dryer is not in use (equating to a lower base load). 


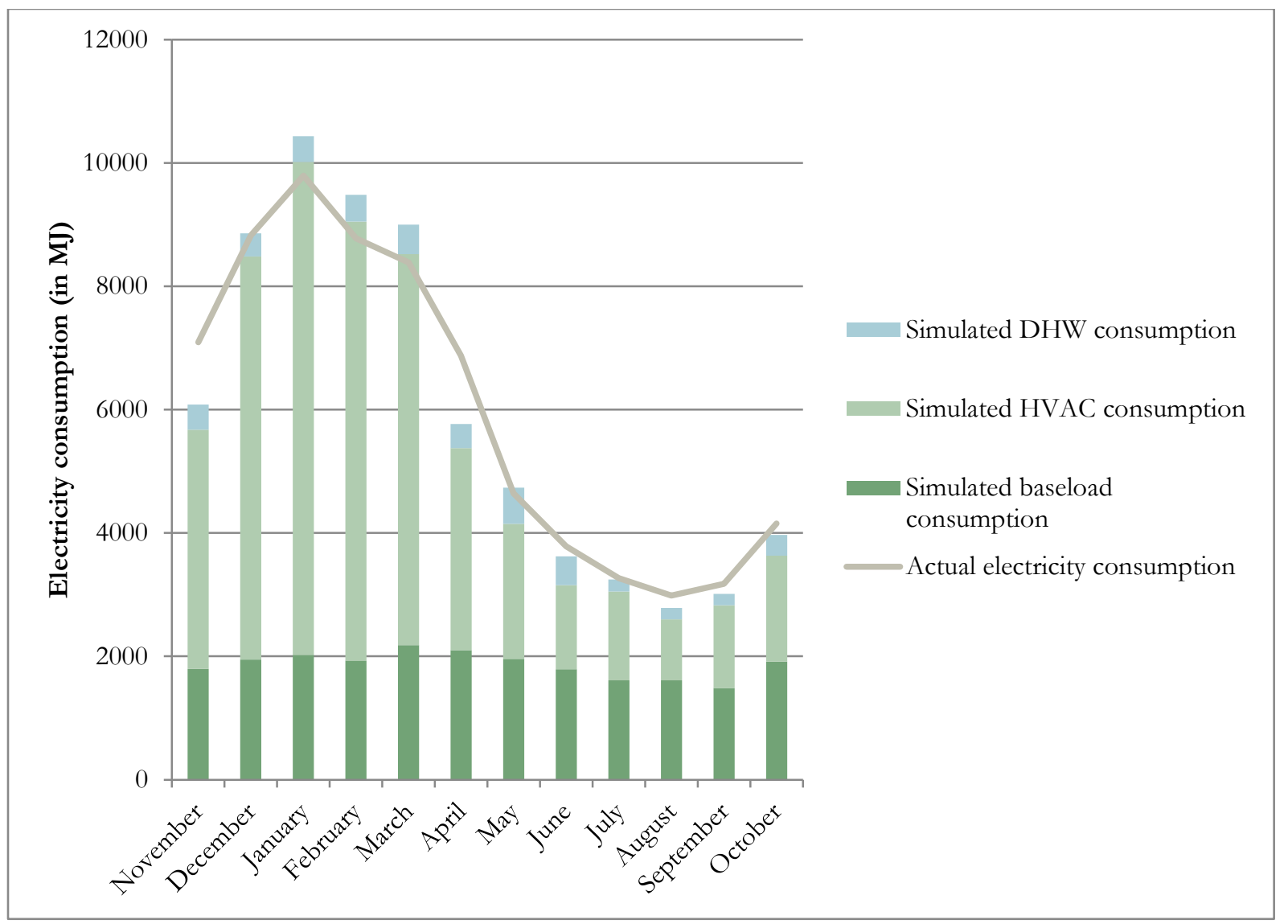

Figure 7: Simulated electricity consumption compared to actual electricity consumption of House A.

Figure 8 compares natural gas consumption simulated in E+ calibrated to the actual billed natural gas consumption for House A. The natural gas consumption was obtained from the bimonthly bills the homeowner receives; a narrower time frame of total consumption was not available. For this home, natural gas in the heating season is used by the fireplace for supplementary space heating, and outside the heating season, the outdoor barbeque set is the sole natural gas consumer. When the billed data is looked at it is clear when the fireplace was used and when the barbeque was used for cooking meals. The scheduling for the fireplace and barbeque were set to those specified by the homeowner in the questionnaire, then adjustments were made for the outputs to closely match the values from the natural gas bills. 


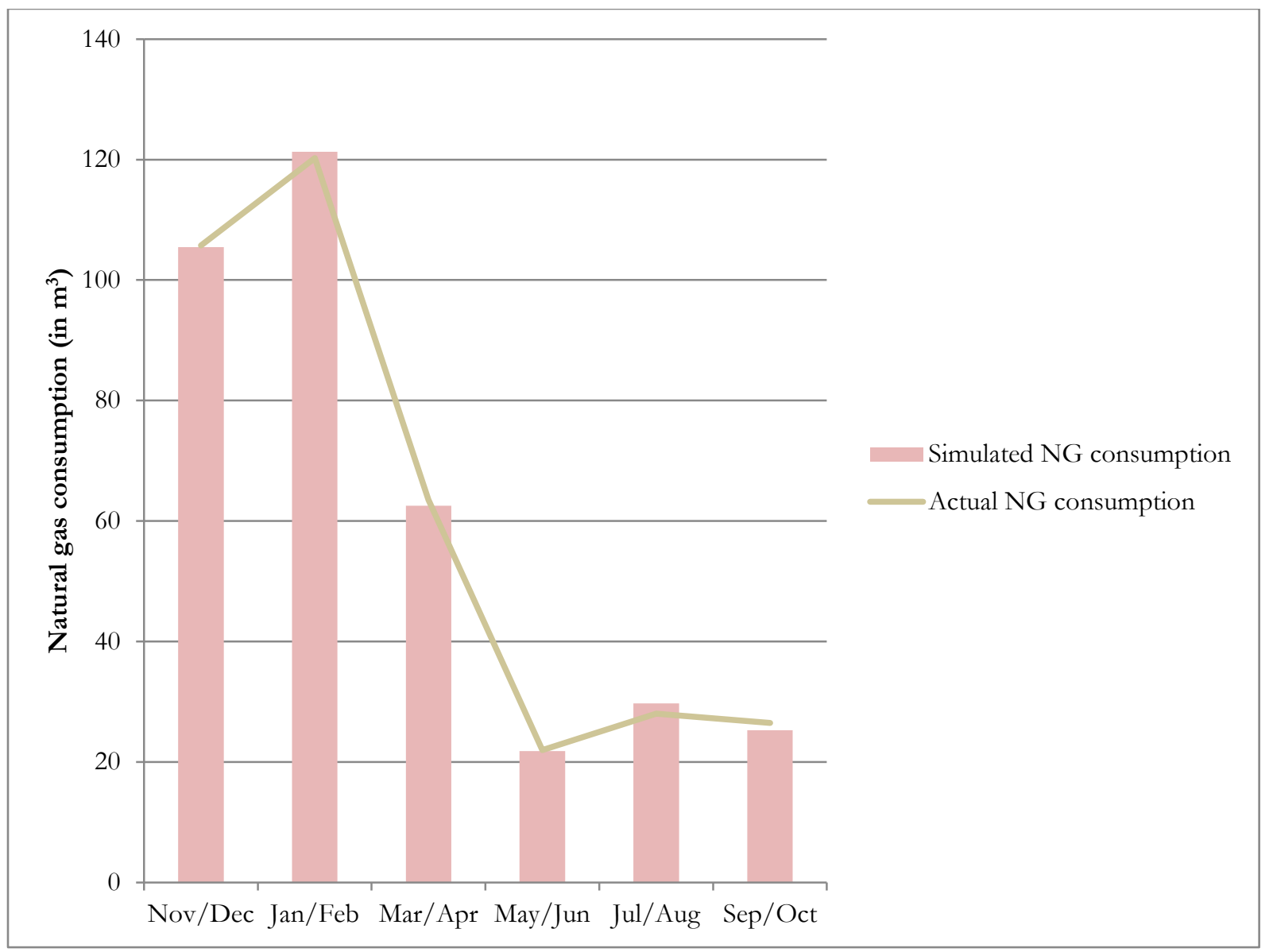

Figure 8: Simulated natural gas consumption in comparison to the actual natural gas consumption for House A.

The CV(RMSE) and NMBE percentages for the above electricity and natural gas energy modeling outputs from the $\mathrm{E}+$ calibrated model for House A are in Table 7. For this home, the natural gas bills are distributed on a bi-monthly basis and so the target percentages for the $\mathrm{CV}(\mathrm{RMSE})$ and NMBE for this home were half that of the monthly percentage requirements. The final calibrated model for this home exceeded the targets for both indices.

Table 7: CV(RMSE) and NMBE percentages of energy consumption outputs from the calibrated EnergyPlus model in comparison to the actual energy consumptions for House $\mathrm{A}$

\begin{tabular}{|l|l|l|}
\hline Energy source & CV(RMSE) & NMBE \\
\hline Electricity consumption & $9.39 \%$ & $1.17 \%$ \\
& $($ Target $=$ with $+/-15 \%)$ & $($ Target $=$ within $+/-5 \%)$ \\
\hline Natural gas consumption & $1.92 \%$ & $0.04 \%$ \\
& $($ Target $=$ within $+/-7.5 \%)$ & $($ Target $=$ within $+/-2.5 \%)$ \\
\hline
\end{tabular}




\subsection{House B}

House B is a 3 story (with basement) single detached house located in Toronto which has a LEED for Homes Platinum certification and utility data for the home is available since June 2011. The home has 3 bedrooms with a floor area of approximately $425 \mathrm{~m}^{2}$. The home is constructed with wood framing with polyurethane foam in between (RSI 5.8), and additional EPS insulation (RSI 0.53) on the exterior side of the framing. The basement slab sits on EPS insulation (RSI 3.52), and the basement walls are insulated in the interior with spray foam insulation (RSI 3.7). This home has a ground source heat pump for heating through a radiant floor system and cooling through a forced air system. An HRV and a humidifier are also connected to the forced air system. Supplementary heating is provided by natural gas powered fireplaces in most rooms in the home. The DHW system utilizes a natural gas powered instantaneous water heater. PV solar panels $(7 \mathrm{~kW})$ that total $31.59 \mathrm{~m}^{2}$ in array area are also installed on the roof of this home.

\subsubsection{Specifications for House B in HOT2000}

Table 8 lists the specifications for House B used in the H2K v2 model. Similar to House A, the base loads inputs were left at the default settings. For the HVAC system, the baseboard heater was selected for the "type 1" heating element and the ground source heat pump for the "type 2" heating category. The home actually has two heat pump units supplying the radiant floor heating and so the heating output capacity for the ground source heat pump was doubled. The option for radiant floor heating is available in HOT2000 but cannot be coupled with the ground source heat pump and so a forced air system is modeled in HOT2000. Two supplementary heating components (natural gas fueled fireplaces) were also added to represent 2 out of the 4 fireplaces that were installed in the home.

Several changes were made to the HOT2000 model created by the consults in the revised version created by the author: 
1. The HRV specifications were updated in the revised version to match those of the manufacturer's specification for the model installed in the home.

2. The specifications for the fireplaces physically in the home were inputted instead of the default specifications built into HOT2000.

3. Initially, overhangs and exposed floors were excluded, this was changed in the revised model.

4. The basement below ground style was changed to match the actual construction of the home.

a. A walkout configuration is used as opposed to a basement configuration, where one wall is exposed and not below ground. This increased the heat loss from the basement from $31,471 \mathrm{MJ}$ to $45,951 \mathrm{MJ}$ (H2K v1 compared to $\mathrm{H} 2 \mathrm{~K}$ v2).

Table 8: Specifications for House B in HOT2000

\begin{tabular}{|c|c|c|}
\hline Feature & $\begin{array}{l}\text { Value/description used in } \mathrm{H} 2 \mathrm{~K} \\
\text { v1 }\end{array}$ & Changes made in $\mathrm{H} 2 \mathrm{~K}$ v $2 \& 3$ \\
\hline $\begin{array}{l}\text { House internal } \\
\text { conditioned floor area }\end{array}$ & $424.9 \mathrm{~m}^{2}$ & \\
\hline House volume & $1431.3 \mathrm{~m}^{3}$ & \\
\hline $\begin{array}{l}\text { Brief description of } \\
\text { window type }\end{array}$ & $\begin{array}{l}\text { Triple glazed with low-e coating } \\
\text { Argon gas in between } \\
\text { Aluminum clad wood framing }\end{array}$ & \\
\hline $\begin{array}{l}\text { Brief description of the } \\
\text { roof and its RSI-values }\end{array}$ & $\begin{array}{l}\text { Isocyanurate insulation and } \\
\text { polyurethane insulation over wood } \\
\text { purlins } \\
3^{\text {rd }} \text { floor }=11.35 \mathrm{~m}^{2} \mathrm{~K} / \mathrm{W} \\
4^{\text {th }} \text { floor }=11.35 \mathrm{~m}^{2} \mathrm{~K} / \mathrm{W}\end{array}$ & \\
\hline $\begin{array}{l}\text { Brief description of the } \\
\text { exterior walls and the } \\
\text { RS-values }\end{array}$ & $\begin{array}{l}\text { Wood framing construction with } \\
\text { polyurethane foam insulation, } \\
\text { additional EPS exterior insulation } \\
\text { Main floor }=3.16 \mathrm{~m}^{2} \mathrm{~K} / \mathrm{W} \\
3^{\text {rd }} \text { floor }=3.11 \mathrm{~m}^{2} \mathrm{~K} / \mathrm{W} \\
4^{\text {th }} \text { floor }=3.24 \mathrm{~m}^{2} \mathrm{~K} / \mathrm{W}\end{array}$ & \\
\hline $\begin{array}{l}\text { Below ground wall and } \\
\text { floor constructions brief } \\
\text { description of type }\end{array}$ & $\begin{array}{l}\text { Foundation label }=\text { Foundation- } 1 \\
\text { Interior insulation on below ground } \\
\text { walls (RSI of } 3.7 \mathrm{~m}^{2} \mathrm{~K} / \mathrm{W} \text { ) } \\
\text { Insulation below the foundation } \\
\left.\text { floor (RSI of } 3.52 \mathrm{~m}^{2} \mathrm{~K} / \mathrm{W}\right)\end{array}$ & Foundation label $=$ Walkout-4 \\
\hline Exposed floor area & $0 \mathrm{~m}^{2}$ & $54.81 \mathrm{~m}^{2}$ \\
\hline
\end{tabular}




\begin{tabular}{|c|c|c|}
\hline Feature & $\begin{array}{l}\text { Value/description used in } \mathrm{H} 2 \mathrm{~K} \\
\text { v1 }\end{array}$ & Changes made in $\mathrm{H} 2 \mathrm{~K}$ v2 \& 3 \\
\hline Blower door test inputs & $\begin{array}{l}\text { Air change rate }=3 \text { at } 50 \mathrm{~Pa} \\
\text { Equivalent leakage area }= \\
1754.8 \mathrm{~cm}^{2} \text { at } 10 \mathrm{~Pa}\end{array}$ & \\
\hline $\begin{array}{l}\text { Heating set point } \\
\text { temperature }\end{array}$ & $21^{\circ} \mathrm{C}$ & \\
\hline $\begin{array}{l}\text { Cooling set point } \\
\text { temperature }\end{array}$ & $25^{\circ} \mathrm{C}$ & \\
\hline Heating/cooling system & $\begin{array}{l}\text { Type 1: } \\
\text { Baseboards/Hydronic/Plenum } \\
\text { heaters } \\
\text { Type 2: Ground Source Heat Pump } \\
\text { Supplementary heating } 1 \text { (natural } \\
\text { gas fueled fireplace) } \\
\text { Supplementary heating } 2 \text { (natural } \\
\text { gas fueled fireplace) }\end{array}$ & \\
\hline $\begin{array}{l}\text { Baseboard } \\
\text { specifications }\end{array}$ & $\begin{array}{l}\text { Output capacity }=24 \mathrm{~kW} \\
\text { Efficiency }=100 \%\end{array}$ & \\
\hline $\begin{array}{l}\text { Ground source heat } \\
\text { pump specifications }\end{array}$ & $\begin{array}{l}\text { Output capacity }=16.06 \mathrm{~kW} \\
\text { Heating efficiency }=3.1 \mathrm{COP} \\
\text { Cooling efficiency }=4.8 \mathrm{COP}\end{array}$ & \\
\hline $\begin{array}{l}\text { Supplementary heating } \\
\text { specifications }\end{array}$ & $\begin{array}{l}\text { Energy source }=\text { natural gas } \\
\text { Equipment type }=\text { fireplace with } \\
\text { spark ignition (sealed) } \\
\text { Output heating capacity for } \\
\text { fireplace } 1 \& 2=2 \mathrm{~kW} \\
\text { Efficiency for fireplace } 1 \& 2= \\
30 \%\end{array}$ & $\begin{array}{l}\text { Output heating capacity for } \\
\text { fireplace } 1=18.9 \mathrm{~kW} \\
\text { Output heating capacity for } \\
\text { fireplace } 2=11.7 \mathrm{~kW} \\
\text { Efficiency for fireplace } 1=80 \% \\
\text { Efficiency for fireplace } 2=65 \%\end{array}$ \\
\hline Fireplace schedule & $\begin{array}{l}\text { October }=1 \text { hour } / \text { day } \\
\text { November }=2 \text { hours } / \text { day } \\
\text { December }=3 \text { hours } / \text { day } \\
\text { January }=3 \text { hours } / \text { day } \\
\text { February }=3 \text { hours } / \text { day } \\
\text { March }=2 \text { hours } / \text { day } \\
\text { April }=1 \text { hour } / \text { day }\end{array}$ & \\
\hline HRV specifications & Efficiency $=60-70 \%$ & Efficiency $=58-59 \%$ \\
\hline DHW specifications & $\begin{array}{l}\text { Energy source = natural gas } \\
\text { Tank type }=\text { instantaneous } \\
\text { Tank volume }=\text { not applicable }\end{array}$ & \\
\hline PV system & $\begin{array}{l}\text { Array area }=31.6 \mathrm{~m}^{2} \\
\text { Slope }=31 \text { degrees } \\
\text { Azimuth }=20 \text { degrees } \\
\text { Module efficiency }=15.7 \%\end{array}$ & \\
\hline
\end{tabular}




\begin{tabular}{|l|l|l|}
\hline Feature & $\begin{array}{l}\text { Value/description used in H2K } \\
\mathbf{v 1}\end{array}$ & Changes made in H2K v2 \& 3 \\
\hline & Miscellaneous array losses $=4 \%$ & \\
& Other power conditioning losses $=$ & \\
$5 \%$ & \\
& Inverter efficiency $=96.8 \%$ & \\
Grid absorption rate $=99 \%$ & \\
\hline
\end{tabular}

\subsubsection{Specifications for House B in EnergyPlus}

For the E+ v1 model, the outputs from the HVAC template for the water-to-air heat pump were used. This version of the EnergyPlus model included a ZoneHVAC:EnergyRecoveryVentilator, ZoneHVAC:WaterToAirHeatPump, ZoneHVAC:Baseboard:Convective:Electric and two sets of ZoneHVAC:HighTemperatureRadiant. All the HVAC components have the same inputs as used in the HOT2000 model for this home. For the DHW system, a WaterHeater:Mixed was put in which uses natural gas with the same inputs as HOT2000.

The other two EnergyPlus models (E+v2 \& E+ calibrated) for House B were modeled to have the actual HVAC and DHW systems in this home. The models have 5 thermal zones and each zone is serviced by an uncontrolled single duct air terminal. The air loop for House B includes an outdoor air system (with the HRV), a fan, an evaporator coil and an electric humidifier. The condenser loop contains the ground heat exchanger that supplies water for two sets of water-towater heat pump for heating and the evaporator coil for cooling. The specifications for the heat pumps and the ground heat exchanger are listed in Table 9. Then a plant loop connects the two heat pumps to the low temperature radiant floors in each thermal zone. The water heater parameter is unchanged as it was modeled to represent the unit present in the home. Finally, 4 high temperature radiant parameters are included to represent the 4 fireplaces in the home. 
Table 9: Heat pump and ground heat exchanger specifications for House B

\begin{tabular}{|l|l|l|}
\hline EnergyPlus component & Input parameters & Value \\
\hline $\begin{array}{l}\text { Heat pump for heating (water- } \\
\text { to-water) }\end{array}$ & $\begin{array}{l}\text { Rated heating capacity (for each } \\
\text { heat pump) }\end{array}$ & $14,360 \mathrm{~W}$ \\
\cline { 2 - 3 } & $\begin{array}{l}\text { Rated heating power } \\
\text { consumption (for each heat } \\
\text { pump) }\end{array}$ & $3,630 \mathrm{~W}$ \\
\hline Ground heat exchanger & \begin{tabular}{l} 
Number of bore holes \\
\cline { 2 - 4 }
\end{tabular} & 6 \\
\hline & Bore hole length & $55 \mathrm{~m}$ \\
\hline & Bore hole radius & $0.10795 \mathrm{~m}$ \\
\hline
\end{tabular}

\subsubsection{E+ Calibrated Model for House B}

In the $\mathrm{E}+$ calibrated model, an additional plant loop is included to model the drive way snow melting system that exists for the site. An additional zone was created to contain a low temperature radiant floor system. The water source is heated by a boiler fueled by natural gas.

The notable changes that were made for the E+ calibrated model for House B are as follows:

- A lower usage of the fireplaces.

- A higher slab temperature for the radiant floor heating set by the occupant.

- LED lightbulbs are used throughout the home.

- There are 3 refrigerators in the home.

Figure 9 graphs the simulated electricity consumption against the actual electricity consumption for House B. For this home, the electricity consumption consists of the base load electricity consumption (excluding the stove top) and the HVAC system. The cooling for this home is provided through evaporator coils within a forced air system connected to the ground source heat pump, and consumes very little energy. During the cooling season the HVAC portion of the electricity consumption consists of fans, pumps and the HRV consumptions. It was deduced that the total electricity consumption minus the HVAC electricity consumption during the cooling 
season would equate to the base load electricity consumption for the home. The radiant floor heating set points for each slab in the thermal zones were scheduled to mimic the temperatures in the actual home. Minor adjustments were made to the control temperature to closely match the electricity consumptions for each month in the heating season and the shoulder seasons.

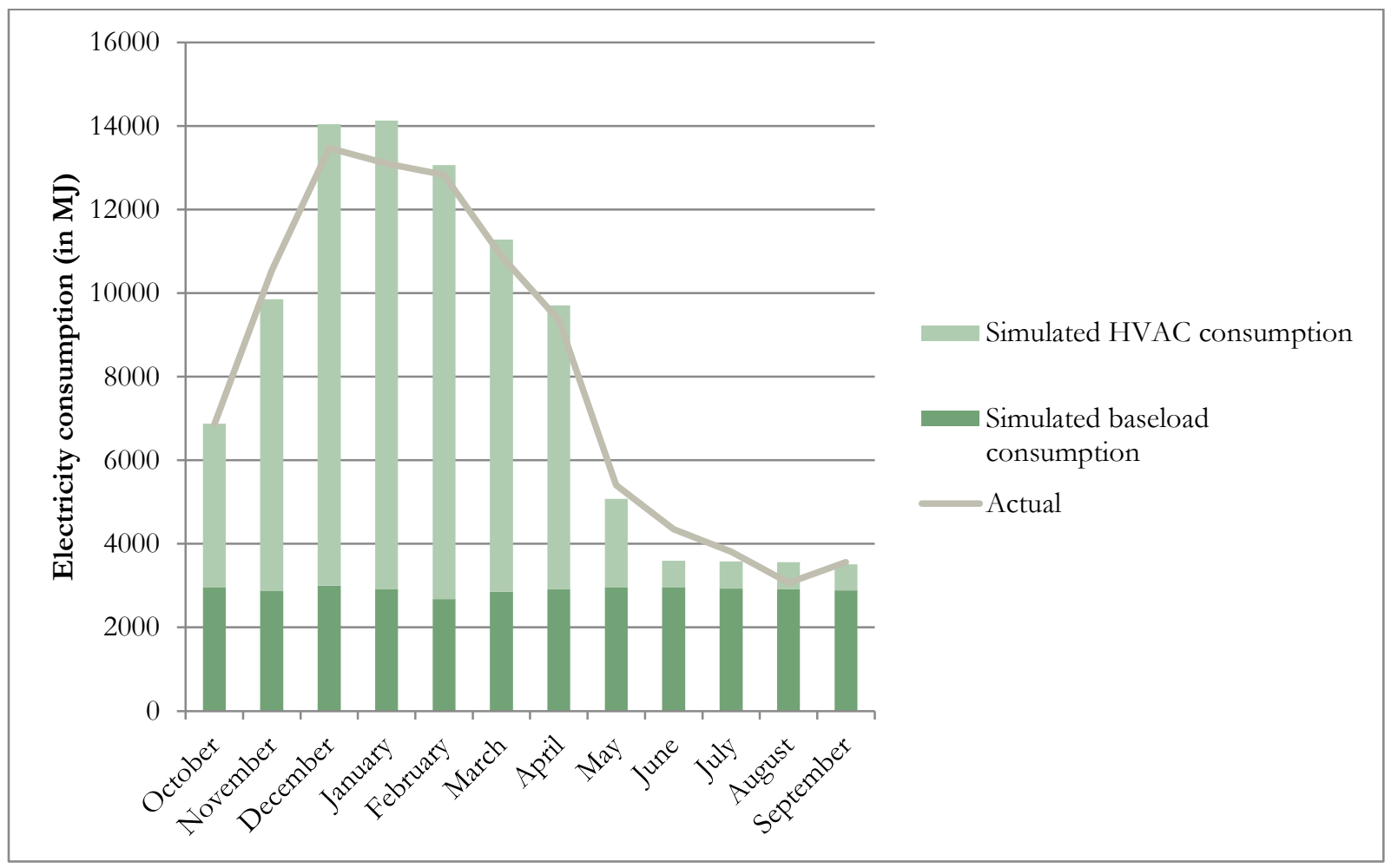

Figure 9: Simulated electricity consumption compared to the actual electricity consumption for House B.

Figure 10 graphs the simulated natural gas consumption against the actual natural gas consumption for House B. The natural gas consumption for this home includes stove top usage, DHW, fireplaces and the boiler for the driveway's snow melting system. It was established that during the cooling season the majority of the natural gas consumption would be attributed to the DHW system. The stove top natural gas consumption was negligible as the homeowner expressed that it is not used on a daily basis (at most several times a month). However, higher natural gas consumptions are seen in April and May beyond the DHW natural gas consumption seen in the cooling season. The model was adjusted to allow the boiler and fireplaces to operate during these 
months but with the weather file used, the two systems were not called upon to operate. In order to increase the natural gas consumption for these two months the DHW consumption was increased to match the natural gas consumption. The boiler was set to operate when the driveway slab temperature dropped below $0^{\circ} \mathrm{C}$ and very minor changes were made to the water temperature and the control temperature to replicate the high natural gas consumption during the heating season. It was mentioned by the occupant that the fireplaces are not used frequently, as the radiant floor system is able to provide sufficient space heating. The fireplace natural gas consumption was assumed to fill in the gaps between the simulated and actual natural gas consumption once the boiler and DHW consumptions were accounted for, while still maintaining the usage pattern described by the homeowner.

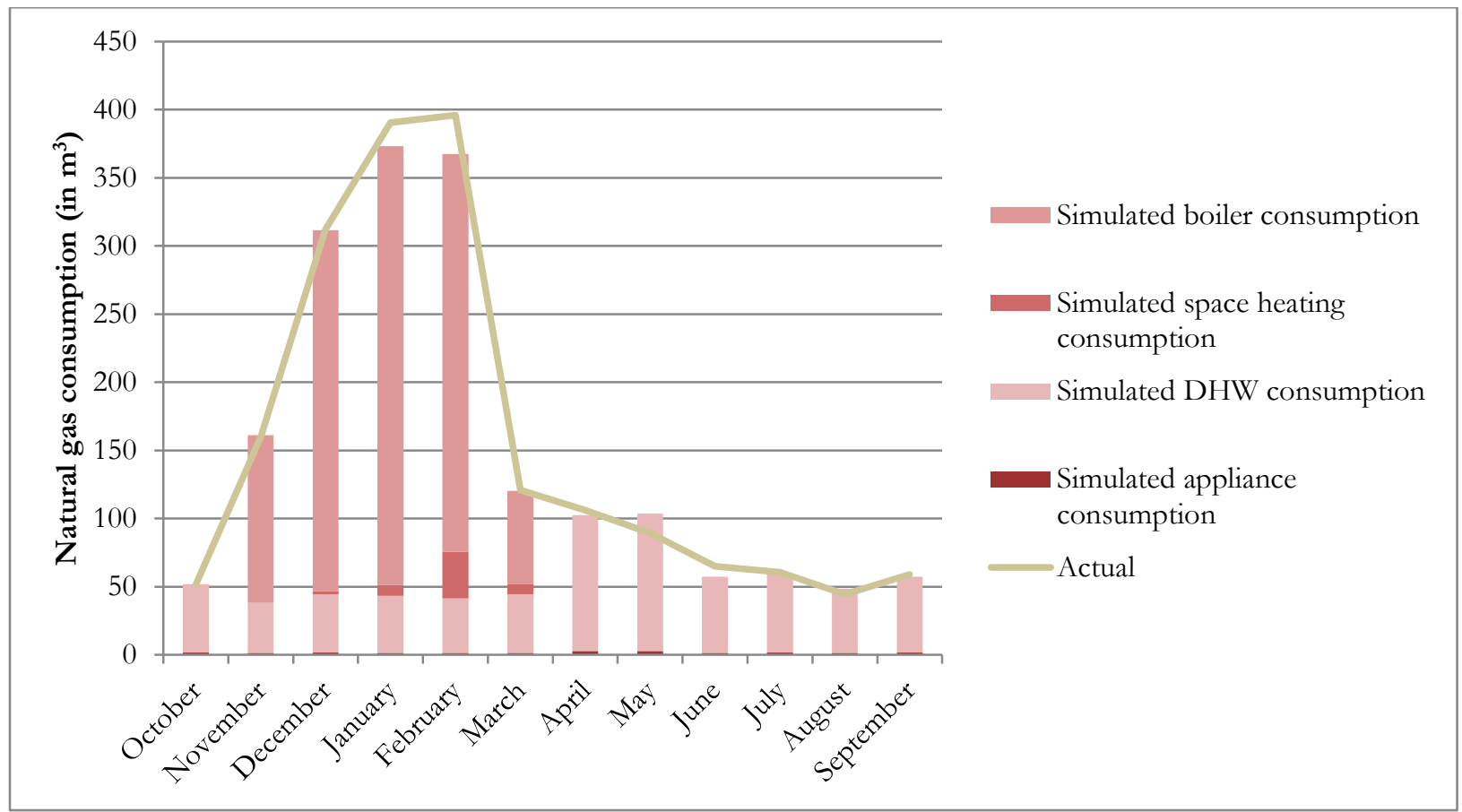

Figure 10: Simulated natural gas consumption compared to the actual natural gas consumption for House B.

The CV(RMSE) and NMBE percentages for the electricity and natural gas consumptions of House B are shown in Table 10. The electricity and natural gas bills for this home are distributed on 
a monthly basis, and the monthly targets were the basis for the calibration. The targets were exceeded for both electricity and natural gas consumption for House B.

Table 10: CV(RMSE) and NMBE percentages of the energy consumption outputs from the calibrated EnergyPlus model for House B in comparison to the actual.

\begin{tabular}{|l|l|l|}
\hline Energy source & $\begin{array}{l}\text { CV }(\text { RMSE) } \\
{[\text { Target = within }+/-15 \%]}\end{array}$ & $\begin{array}{l}\text { NMBE } \\
{[\text { Target = within }+/-5 \%]}\end{array}$ \\
\hline Electricity consumption & $6.25 \%$ & $-0.28 \%$ \\
\hline Natural gas consumption & $6.47 \%$ & $2.62 \%$ \\
\hline
\end{tabular}

\subsection{House C}

House $\mathrm{C}$ is also LEED for Homes Platinum certified and has been occupied since September 2010. It consists of a pair of semi-detached homes, located in Ottawa and each has 3 storeys and a basement, totaling approximately $329 \mathrm{~m}^{2}$ of treated floor area. The building as a whole is studied in this research. It has a timber frame construction, and the exterior wall stud cavities are filled with polyurethane spray foam insulation (RSI 3.70) with additional polyisocyanurate rigid insulation (RSI 3.87) on the exterior. The third floor roof is a green roof over polyisocyanurate rigid insulation (RSI 1.76) on polyurethane insulation (RSI 10.03) filled wood I-joists. The foundation floor sits on layers of XPS insulation (RSI 5.28), and the foundation walls are insulated similarly with XPS insulation (RSI 5.28). The ground source heat pump supplies heated fluid for the radiant floor heating and supplements the DHW system. The DHW system otherwise consists of an electric water heater. There is no built in cooling equipment for the building. A $33.4 \mathrm{~m}^{2}$ PV array sits on the south side of the roof of this building.

\subsubsection{Specifications for House C in HOT2000}

Table 11 lists the specifications for House C as used in the HOT2000 models for this home. For the HVAC system, the baseboard heater was selected for the "type 1" heating component and the ground source heat pump was selected for the second type. Since the building is a pair of semi- 
detached homes there are two heat pump units, one for each household, the heating output capacity for the ground source heat pump was doubled that of one unit to match the total of two. Like the situation for House B, the radiant floor system cannot be modeled to be coupled with the ground source heat pump in HOT2000 and so it is modeled as a forced air system.

Several changes were made to the HOT2000 model created by the consultant in the revised version created by the author:

- Since the whole building, including both units were modeled as one, the following inputs were doubled to account for two households:

o Occupancy

O Electric appliances

o Lighting

o Other electric

o Exterior use

o Hot water load (this is automatically adjusted by the program with the occupancy change)

- The heating output capacity was changed to $10 \mathrm{~kW}$ from $14 \mathrm{~kW}$. The output capacity for the direct expansion heat pumps are $5 \mathrm{~kW}$ each and this was doubled to $10 \mathrm{~kW}$ represent the two units in the building. The $14 \mathrm{~kW}$ output capacity was used in $\mathrm{H} 2 \mathrm{~K}$ v1 since HOT2000 does not have the capabilities of modeling a direct expansion heat pump, but the justification for the exact value is not known.

- For the DHW tank type, conserver tanks were used in place of conventional tanks to represent the energy efficient water heater installed in the home. 
- The PV generation inputs were adjusted to have the inputs below. These changes were made to be in line with the other two homes. As all three houses have a similar array area for the PV system, yet it was noticed that the predicted electricity generation from the PV arrays for House $\mathrm{C}$ was significantly lower than the other homes $(1,840 \mathrm{MJ} /$ year in $\mathrm{H} 2 \mathrm{~K}$ v1 for House C compared to $16,487 \mathrm{MJ} /$ year and $22,314 \mathrm{MJ} /$ year in $\mathrm{H} 2 \mathrm{~K}$ v1 for House A and B respectively).

0 Azimuth $=0$ degrees (PV arrays facing south)

o Miscellaneous array losses $=4 \%$

O Other power conditioning losses $=4 \%$

o Grid absorption rate $=99 \%$

Table 11: Specifications for House C in HOT2000

\begin{tabular}{|c|c|c|}
\hline Feature & Value/description used in $\mathrm{H} 2 \mathrm{~K}$ v1 & Changes made in $\mathrm{H} 2 \mathrm{~K}$ v2 \& 3 \\
\hline $\begin{array}{l}\text { House internal } \\
\text { conditioned floor } \\
\text { area }\end{array}$ & $328.5 \mathrm{~m}^{2}$ & \\
\hline House volume & $993.0 \mathrm{~m}^{3}$ & \\
\hline Occupancy & $\begin{array}{l}2 \text { adults, } 50 \% \text { at home } \\
2 \text { children, } 50 \% \text { at home }\end{array}$ & $\begin{array}{l}4 \text { adults, } 50 \% \text { at home } \\
4 \text { children, } 50 \% \text { at home }\end{array}$ \\
\hline Base loads & $\begin{array}{l}\text { Electric appliances }=9 \mathrm{kWh} / \text { day } \\
\text { Lighting }=3.4 \mathrm{kWh} / \text { day } \\
\text { Other electric }=7.6 \mathrm{kWh} / \text { day } \\
\text { Exterior use }=4 \mathrm{kWh} / \text { day }\end{array}$ & $\begin{array}{l}\text { Electric appliances }=18 \mathrm{kWh} / \text { day } \\
\text { Lighting }=6.8 \mathrm{kWh} / \text { day } \\
\text { Other electric }=15.2 \mathrm{kWh} / \text { day } \\
\text { Exterior use }=8 \mathrm{kWh} / \text { day }\end{array}$ \\
\hline Hot water load & $225 \mathrm{~L} / \mathrm{day}$ & 365L/day \\
\hline Window type & $\begin{array}{l}\text { Triple glazed with low-e coating } \\
\text { Argon gas filled } \\
\text { Fiberglass framing }\end{array}$ & \\
\hline Roof RSI-values & $\begin{array}{l}3^{\text {rd }} \text { floor }=9.88 \mathrm{~m}^{2} \mathrm{~K} / \mathrm{W} \\
4^{\text {th }} \text { floor }=10.03 \mathrm{~m}^{2} \mathrm{~K} / \mathrm{W}\end{array}$ & \\
\hline Wall RSI-values & $\begin{array}{l}\text { Main floor }=8.46 \mathrm{~m}^{2} \mathrm{~K} / \mathrm{W} \\
3^{\text {rd }} \text { floor }=8.51 \mathrm{~m}^{2} \mathrm{~K} / \mathrm{W} \\
4^{\text {th }} \text { floor }=8.53 \mathrm{~m}^{2} \mathrm{~K} / \mathrm{W}\end{array}$ & \\
\hline $\begin{array}{l}\text { Below ground wall } \\
\text { and floor } \\
\text { constructions }\end{array}$ & $\begin{array}{l}\text { Interior and exterior insulation on } \\
\text { below ground walls (RSI of } 0.25 \\
\mathrm{~m}^{2} \mathrm{~K} / \mathrm{W} \text { and } 5.28 \mathrm{~m}^{2} \mathrm{~K} / \mathrm{W} \text { respectively) } \\
\text { Insulation below the foundation floor }\end{array}$ & \\
\hline
\end{tabular}




\begin{tabular}{|c|c|c|}
\hline Feature & Value/description used in $\mathrm{H} 2 \mathrm{~K}$ v1 & Changes made in $\mathrm{H} 2 \mathrm{~K}$ v2 \& 3 \\
\hline & (RSI of $2.64 \mathrm{~m}^{2} \mathrm{~K} / \mathrm{W}$ ) & \\
\hline $\begin{array}{l}\text { Blower door test } \\
\text { inputs }\end{array}$ & $\begin{array}{l}\text { Air change rate }=0.52 \text { at } 50 \mathrm{~Pa} \\
\text { Equivalent leakage area }=186.4 \mathrm{~cm}^{2} \text { at } \\
10 \mathrm{~Pa}\end{array}$ & \\
\hline $\begin{array}{l}\text { Heating set point } \\
\text { temperature }\end{array}$ & $21^{\circ} \mathrm{C}$ & \\
\hline $\begin{array}{l}\text { Cooling set point } \\
\text { temperature }\end{array}$ & $25^{\circ} \mathrm{C}$ & \\
\hline Heating system & $\begin{array}{l}\text { Type 1: } \\
\text { Baseboards/Hydronic/Plenum heaters } \\
\text { Type 2: Ground Source Heat Pump }\end{array}$ & \\
\hline $\begin{array}{l}\text { Baseboard } \\
\text { specifications }\end{array}$ & $\begin{array}{l}\text { Output capacity }=13 \mathrm{~kW} \\
\text { Efficiency }=100 \%\end{array}$ & \\
\hline $\begin{array}{l}\text { Ground source heat } \\
\text { pump } \\
\text { specifications }\end{array}$ & $\begin{array}{l}\text { Output capacity }=14.07 \mathrm{~kW} \\
\text { Heating efficiency }=3.3 \mathrm{COP}\end{array}$ & $\begin{array}{l}\text { Output capacity }=10 \mathrm{~kW} \\
\text { Heating efficiency }=3.28 \mathrm{COP}\end{array}$ \\
\hline HRV specifications & Efficiency $=72-78 \%$ & \\
\hline $\begin{array}{l}\text { DHW } \\
\text { specifications }\end{array}$ & $\begin{array}{l}\text { Energy source }=\text { electricity } \\
\text { Tank type }=\text { conventional tank } \\
\text { Tank volume }=189.3 \mathrm{~L} \\
\text { (The secondary tank also has the same } \\
\text { inputs) }\end{array}$ & Tank type $=$ conserver tank \\
\hline PV system & $\begin{array}{l}\text { Array area }=33.4 \mathrm{~m}^{2} \\
\text { Slope }=45 \text { degrees } \\
\text { Azimuth }=180 \text { degrees (north) } \\
\text { Module efficiency }=13 \% \\
\text { Miscellaneous array losses }=20 \% \\
\text { Other power conditioning losses }= \\
20 \% \\
\text { Inverter efficiency }=95 \% \\
\text { Grid absorption rate }=27 \%\end{array}$ & $\begin{array}{l}\text { Azimuth }=0 \text { degrees (south) } \\
\text { Miscellaneous array losses }=4 \% \\
\text { Other power conditioning losses } \\
=4 \% \\
\text { Grid absorption rate }=99 \%\end{array}$ \\
\hline
\end{tabular}

\subsubsection{Specifications for House C in EnergyPlus}

Similar to the previous homes, the $\mathrm{E}+\mathrm{v} 1$ model for House $\mathrm{C}$ utilized the outputs from the HVAC template for the water-to-air heat pump to replicate the forced air ground source heat pump system in HOT2000. The energy recovery ventilator and baseboard components were also included.

All the HVAC components in the E+ v1 model have the same inputs as the ones used in HOT2000.

For the DHW system, a WaterHeater:Mixed component was put in to model the electric water heater for the home with the same inputs as HOT2000. 
The second and third EnergyPlus models (E+v2 \& E+ calibrated) for House C were set up to include the actual HVAC and DHW systems in this home. The models have 14 thermal zones in total (7 for each household) and each household has its own air loop and plant loop for the radiant floor heating. The air loops for House $\mathrm{C}$ each include an outdoor air system (with HRVs), a fan, and an electric humidifier. The condenser loop contains the ground heat exchanger that supplies the two water-to-water heat pumps that provide space heating through a radiant floor system for each household. The specifications for the heat pumps and the ground heat exchanger are listed in Table 12. The pipe thermal conductivity for the ground heat exchanger was set to be $390 \mathrm{~W} / \mathrm{m} * \mathrm{~K}$ to represent copper to model a direct expansion system instead of the usual plastic pipes used in the conventional heat pump system (Maritime Geothermal, 2015). Each heat pump is assigned to be in a plant loop that supplies the fluid for the low temperature radiant floors in each thermal zone. Within each plant loop is also a stratified water heater, to supplement the DHW load, otherwise the water heater in each household operates electrically.

Table 12: Heat pump and ground heat exchanger specifications for House C

(*The actual ground heat exchanger data was not available to the author, instead the bore hole data for House A were used since the homes were similar in size. A simulation was run with the bore hole data for House B to test the impact of the change in input data, but the change did not make a significant difference in space heating energy consumption.)

\begin{tabular}{|c|c|c|}
\hline EnergyPlus component & Input parameters & Value \\
\hline \multirow[t]{2}{*}{$\begin{array}{l}\text { Heat pump for heating } \\
\text { (water-to-water) }\end{array}$} & $\begin{array}{l}\text { Rated heating capacity (for each } \\
\text { heat pump) }\end{array}$ & $6,273 \mathrm{~W}$ \\
\hline & $\begin{array}{l}\text { Rated heating power } \\
\text { consumption (for each heat } \\
\text { pump) }\end{array}$ & $1,561 \mathrm{~W}$ \\
\hline \multirow[t]{3}{*}{ Ground heat exchanger } & Number of bore holes* & 3 \\
\hline & Bore hole length* & $150 \mathrm{~m}$ \\
\hline & Bore hole radius & $0.2032 \mathrm{~m}$ \\
\hline
\end{tabular}

\subsubsection{E+ Calibrated Model for House C}

Some of the notable changes that were made for the E+ calibrated model for this home are:

- Frequent use of kitchen appliances. 
- Daily washer and dryer usage.

- High computer and printer usage.

- $\quad H R V$ is turned off for the majority of the cooling season.

- Portable air conditioning unit put in to operate during the cooling season.

- LED lightbulbs are used throughout the home.

Figure 11 compares the electricity consumption that was simulated in E+ calibrated, to the actual electricity consumption for House C. The author only had access to the yearly electricity consumption for one of the two households residing in the building and so the actual electricity consumption graphed represents double that of one household. Similarly, in the E+ calibrated model, the inputs for one household were replicated for the other half of the building, assuming the same building usage and occupancy behaviours. During the cooling season (with the exception of July) the electricity consumptions consist of mainly DHW and base load electricity consumptions because this home is not equipped with a cooling system. The water consumptions were not available for this home, therefore the Aquacraft report was used as a reference to model the DHW portion of the model and the resulting DHW electricity consumption would be subtracted from the total electricity consumption during the cooling season to deduce the approximate base load consumption for this home. Since the homeowner uses the home as an office there is a higher than average base load electricity consumption due to computers and printers being constantly on. The base load was assumed to be lower in December and January due to the holidays. There is a higher HVAC electricity consumption in July due to the use of a portable air conditioning unit for very hot days. The DHW electricity consumption fluctuates since it is supplemented by the ground source heat pump. When space heating is required, the heat pumps in the building do not have a high enough capacity to supplement the water heater significantly, causing the water heaters to do more 
work, resulting in higher DHW electricity consumptions in the peak of the heating season. Once the basis for the DHW and base load consumptions were determined, the difference in the heating season is assumed to be the space heating consumption.

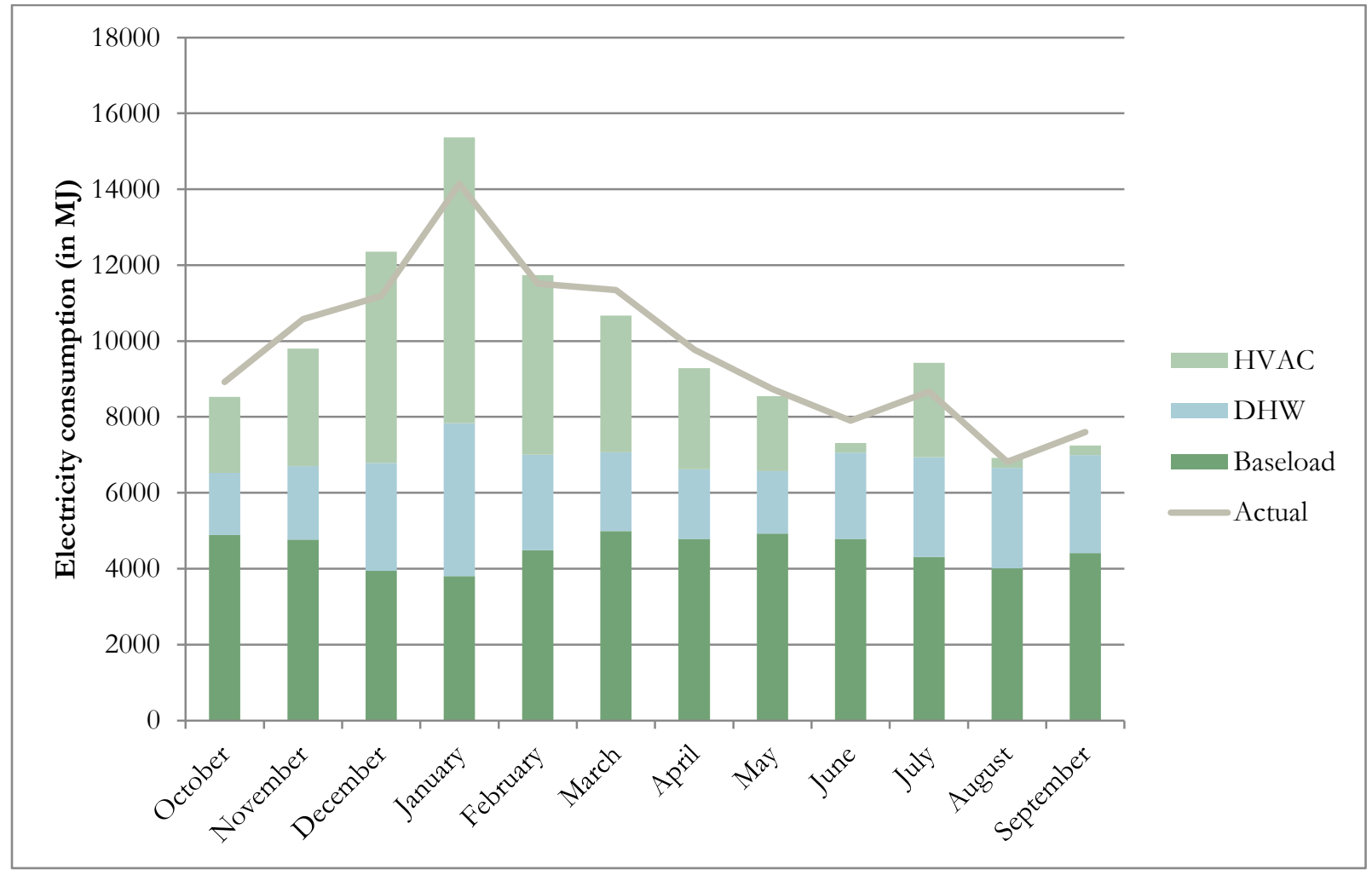

Figure 11: Simulated electricity consumptions for House $\mathrm{C}$ compared to the actual electricity consumption.

The CV(RMSE) and NMBE percentages for the electricity consumption from the E+ calibrated model are listed in Table 13. This home does not have natural gas consumptions, and so only the electricity consumption outputs were considered. Similar to the other homes, the targets were not only met but exceeded for both indices.

Table 13: CV(RMSE) and NMBE percentages of the electricity consumption output from the calibrated EnergyPlus model for House $\mathrm{C}$ in comparison to the actual.

\begin{tabular}{|l|l|l|}
\hline Energy source & $\begin{array}{l}\text { CV }(\text { RMSE }) \\
{[\text { Target }=\text { within }+/-15 \%]}\end{array}$ & $\begin{array}{l}\text { NMBE } \\
{[\text { Target = within }+/-5 \%]}\end{array}$ \\
\hline Electricity consumption & $6.65 \%$ & $-0.02 \%$ \\
\hline
\end{tabular}




\section{Results}

The energy consumption outputs from all the energy models are in Appendix C. The energy use intensities from the 6 energy models and the actual energy consumption of the three homes are shown in Figure 12. The bars represent the actual energy consumptions for the homes. The E+ calibrated models were to have outputs similar to those of the actual energy consumptions, and the points (dark blue rectangles) are fairly close to the top of the bars. The outputs from H2K v1\& 2 models (red and dark pink rectangles) were generally found to have total energy consumptions that were significantly lower than the actual. The following sections will take portions of the data to analyze and answer the research questions posed.

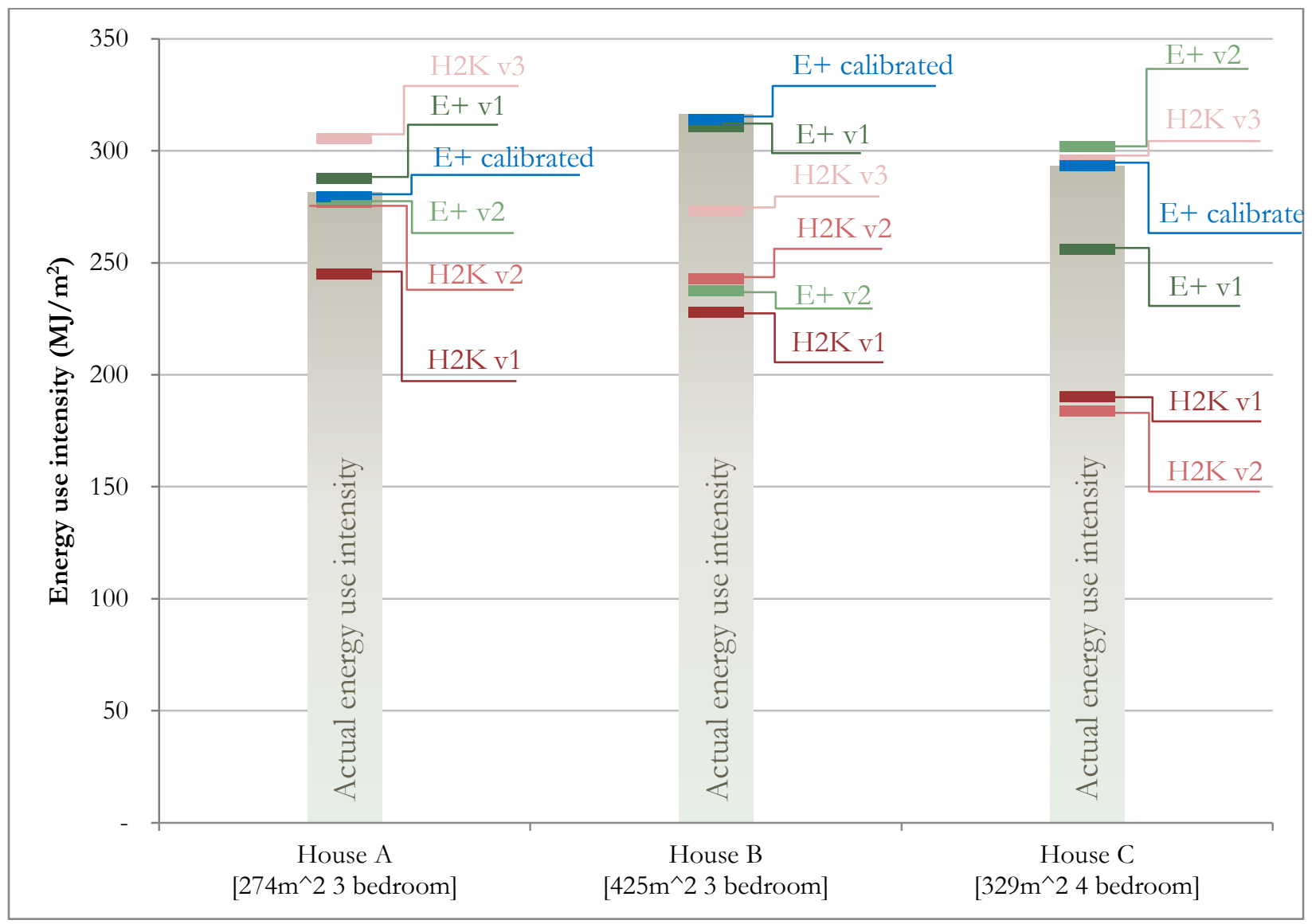

Figure 12: Energy model total energy consumption output overview and compared against the actual energy consumption for the 3 homes. 


\subsection{HO'T2000 Model Comparison}

The following section will review the differences seen with the revised HOT2000 models (H2K v2) compared to those done by the consultants (H2K v1) for each home and how the changes affect the resulting EnerGuide rating number for the homes. Figure 13 compares the annual energy use predictions from the $\mathrm{H} 2 \mathrm{~K}$ v1 consultant models with the $\mathrm{H} 2 \mathrm{~K}$ v2 revised model for all the homes $(\mathrm{H} 2 \mathrm{~K}$ v3 is compared against $\mathrm{H} 2 \mathrm{~K}$ v1 for House $\mathrm{C}$ since the EnerGuide assumptions do not apply to two households). Table 14 contains the values used in Figure 13 for comparison of values that are not as clearly visible in the graph.

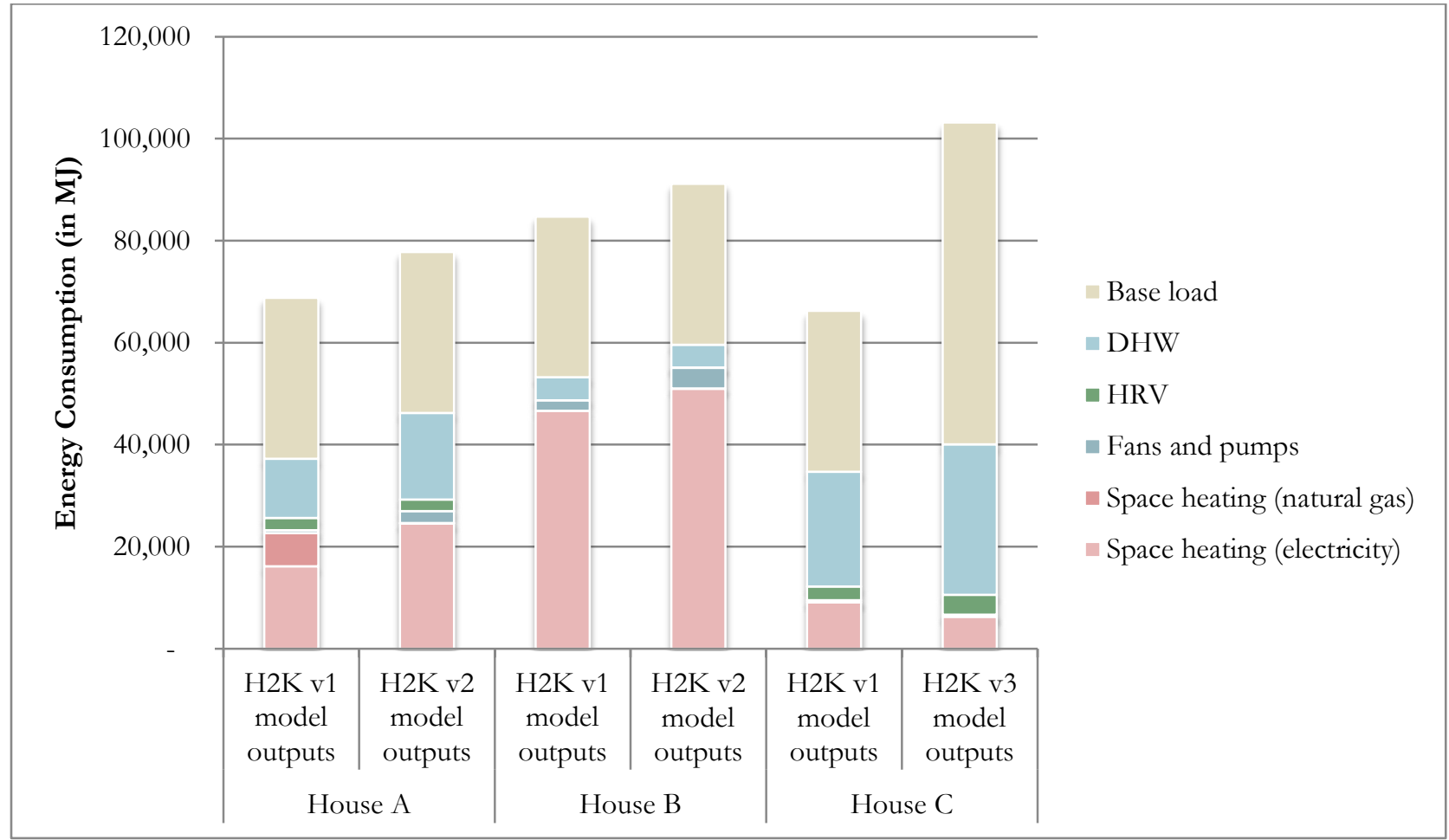

Figure 13: $\mathrm{H} 2 \mathrm{~K}$ v1 and $\mathrm{H} 2 \mathrm{~K}$ v2 model end use energy consumption output comparison for all homes in study. 
Table 14: End-use energy consumption predicted in $\mathrm{H} 2 \mathrm{~K}$ v1 and 2 for all homes, with differences in energy consumption between the models.

\begin{tabular}{|c|c|c|c|c|c|c|c|c|c|}
\hline \multirow{3}{*}{$\begin{array}{l}\text { End-use } \\
\text { category }\end{array}$} & \multicolumn{3}{|c|}{ House A } & \multicolumn{3}{|c|}{ House B } & \multicolumn{3}{|c|}{ House C } \\
\hline & $\begin{array}{l}\mathrm{H} 2 \mathrm{~K} \\
\mathrm{v} 1 \\
\text { model } \\
\text { outputs }\end{array}$ & $\begin{array}{l}\mathrm{H} 2 \mathrm{~K} \\
\mathrm{v} 2 \\
\text { model } \\
\text { outputs }\end{array}$ & Difference & $\begin{array}{l}\mathrm{H} 2 \mathrm{~K} \\
\text { v1 } \\
\text { model } \\
\text { outputs }\end{array}$ & $\begin{array}{l}\mathrm{H} 2 \mathrm{~K} \\
\mathrm{v} 2 \\
\text { model } \\
\text { outputs }\end{array}$ & Difference & $\begin{array}{l}\text { H2K } \\
\text { v1 } \\
\text { model } \\
\text { outputs }\end{array}$ & $\begin{array}{l}\mathrm{H} 2 \mathrm{~K} \\
\mathrm{v} 2 \\
\text { model } \\
\text { outputs }\end{array}$ & Difference \\
\hline & MJ & MJ & $M J$ & MJ & MJ & $M J$ & MJ & MJ & MJ \\
\hline $\begin{array}{l}\text { Space heating } \\
\text { (electricity) }\end{array}$ & 16,191 & 24,571 & $+8,380$ & 46,704 & 50,991 & $+4,288$ & 9,086 & 6,286 & $-2,800$ \\
\hline $\begin{array}{l}\text { Space heating } \\
\text { (natural gas) }\end{array}$ & 6,462 & 61 & $-6,400$ & 0 & 68 & +68 & 0 & 0 & 0 \\
\hline $\begin{array}{l}\text { Fans and } \\
\text { pumps }\end{array}$ & 584 & 2,339 & $+1,755$ & 2,044 & 4,031 & $+1,987$ & 464 & 435 & -29 \\
\hline HRV & 2,415 & 2,266 & -149 & 0 & 76 & +76 & 2,666 & 3,879 & $+1,213$ \\
\hline DHW & 11,628 & 17,033 & $+5,405$ & 4,468 & 4,468 & 0 & 22,499 & 29,499 & 7,000 \\
\hline Base load & 31,536 & 31,536 & 0 & 31,536 & 31,536 & 0 & 31,536 & 63,072 & $+31,536$ \\
\hline Total & 68,815 & 77,806 & $+8,991$ & 84,751 & 91,170 & $+6,419$ & 66,251 & 103,171 & $+36,920$ \\
\hline
\end{tabular}

For House A, the space heating electricity consumption is significantly higher in $\mathrm{H} 2 \mathrm{~K}$ v2 due to the changes in the window specifications from triple glazed to double glazed. The home has a fair amount of glazing on the north and east façade (approximately $41 \%$ and $37 \%$ of the building surface is covered by glazing respectively), and when the glazing was updated to reflect what was actually installed, the heat loss through the windows increased resulting in a higher heating demand. The space heating through natural gas on the other hand was significantly reduced with the fireplace equipment type change in $\mathrm{H} 2 \mathrm{~K} v 2$. The space heating natural gas consumption in $\mathrm{H} 2 \mathrm{~K} v 1$ for House A is mainly the energy consumption by the pilot light which constantly drew energy, this was eliminated in $\mathrm{H} 2 \mathrm{~K}$ v2 since the equipment type was changed to spark ignition. The majority of the heating demand was met with the ground source heat pump and baseboard heater, and the fireplace is assumed to be used minimally (61MJ of energy consumption predicted for the fireplace annually). The fan mode was set to auto and the power consumption was left to be calculated by the program for both models, but with the increase in heating demand the fan is required to do more work and 
an increase in the electricity consumption by the fan is seen in $\mathrm{H} 2 \mathrm{~K}$ v2 (584MJ in $\mathrm{H} 2 \mathrm{~K}$ v1 to 2,339MJ in $\mathrm{H} 2 \mathrm{~K} v 2$ ). Additionally, an increase in DHW electricity consumption is observed with the change in the tank type, from heat pump to conserver tank (an increase of 5,405MJ). Otherwise, the other components were equivalent or the changes were very minimal.

In the case of House B, a slight increase in the space heating through electricity is seen in the $\mathrm{H} 2 \mathrm{~K}$ v2 model, this is a result of the higher heating demand with exposed floors being included in the model. With the inputs in $\mathrm{H} 2 \mathrm{~K} v 1$, the program did not require the supplementary heating from the fireplace, but with the changes made in the $\mathrm{H} 2 \mathrm{~K}$ v2 model, the natural gas consumption for space heating increased from 0 to $68 \mathrm{MJ}$. As previously seen in the case of House A, the fan electricity consumption is increased with the higher heating supply. In the H2K v1 model, the HRV electricity consumption is zero, potentially due to the ventilation system energy credit of $667 \mathrm{kWh}$. With the specifications changed for the HRV (lower efficiency values) the electricity consumption by the HRV is increased but still a major portion of it offset by the energy credit. The remaining end-use energy consumptions remained the same since the changes made in the H2K v2 model did not affect them.

The $\mathrm{H} 2 \mathrm{~K}$ v1 model for House $\mathrm{C}$ is compared against $\mathrm{H} 2 \mathrm{~K}$ v3 which was modeled in the "General" mode of the program, where occupancy and base loads could be doubled (since it consists of 2 semi-detached homes) to model two households instead of one, which cannot be adjusted under the "EnerGuide Rating" mode. When the base loads were doubled the usable internal gains in the home increased from $24,551 \mathrm{MJ}$ to $39,215 \mathrm{MJ}$ which in turn reduced the heating demand for the home significantly, resulting in the decrease in the space heating electricity consumption in $\mathrm{H} 2 \mathrm{~K}$ v3. The DHW electricity consumption is increased with the changes in the occupancy resulting in a higher daily hot water usage, but the increase is not drastic since the DHW 
tank type was changed from a conventional to conserver tank which has a reduced stand-by loss. As mentioned earlier, the daily base load electricity consumptions were doubled, accounting for the difference in the base load consumption.

\subsubsection{HO'T2000 Model EnerGuide Comparison}

The EnerGuide ratings from the HOT2000 models are shown in Table 15, for two out of the three homes there is a decrease in the EnerGuide rating.

Table 15: EnerGuide rating from $\mathrm{H} 2 \mathrm{~K}$ v1 and $\mathrm{H} 2 \mathrm{~K}$ v2 for all homes.

(*The EnerGuide rating from the outputs of $\mathrm{H} 2 \mathrm{~K}$ v3 used as a comparison for House C.)

\begin{tabular}{|l|l|l|l|}
\hline & House A & House B & House C \\
\hline H2K v1 & $89(89.09)$ & $89(88.87)$ & $87(87.06)$ \\
\hline H2K v2 & $87(87.06)$ & $88(87.78)$ & $89(88.94)^{*}$ \\
\hline
\end{tabular}

The EnerGuide rating number for H2K v1 for House A was 89 (89.09), and with the revisions made to closely match the constructed home in $\mathrm{H} 2 \mathrm{~K}$ v2, the EnerGuide rating decreases to 87 (87.06). With the increase in both space heating and DHW energy consumptions the "Estimated total energy consumption" for the home is increased for the H2K v2 model, (68,162MJ for $\mathrm{H} 2 \mathrm{~K}$ v1 and 77,788MJ for H2K v2) lowering the EnerGuide rating for the home. The two point decrease in the EnerGuide rating does also equates to one and a half fewer points in the "Energy \& Atmosphere" category for the LEED for Homes certification.

The EnerGuide rating for the H2K v1 of House B was 89 (88.87), then with the changes in $\mathrm{H} 2 \mathrm{~K}$ v2, the EnerGuide rating is reduced to 88 (87.78). The increase in the space heating energy consumption and the fan electricity consumption for space heating in $\mathrm{H} 2 \mathrm{~K}$ v2 results in a higher “estimated space heating consumption” (48,748MJ for H2K v1 compared to 55,158MJ for H2K v2). The reduction in the EnerGuide rating translates to a decrease in the "Energy \& Atmosphere" points for the LEED for Home certification by 1 (from 20 points to 19). 
For the EnerGuide rating calculation from the outputs of the $\mathrm{H} 2 \mathrm{~K}$ v3 model for House $\mathrm{C}$ the "Domestic Hot Water Benchmark" and "Base Load Benchmark" portion of the "Benchmark Total Energy Consumption" calculation were changed to account for two households, otherwise the EnerGuide rating would be calculated against a benchmark which assumes only one household in the building. The "Space Heating Benchmark" was not altered since the calculation is based on the heated volume of the home and this remains unchanged. For the DHW benchmark calculation the value of 17,082 was doubled to 34,164 , assuming it is the benchmark energy consumption for DHW. Then the base load benchmark was also doubled from $31,536 \mathrm{MJ}$ to $63,072 \mathrm{MJ}$. With the adjustments made for the EnerGuide rating calculation to level the playing field to compare the two EnerGuide rating values, the $\mathrm{H} 2 \mathrm{~K}$ v1 model EnerGuide rating was calculated to be 87 (87.06) and the rating for H2K v3 was 89 (88.94). The EnerGuide rating for House $\mathrm{C}$ increases by two points with the calculation adjustment accounting for two households, and with the updated inputs for PV generation. The PV generation predicted by the program increased from 1,840MJ/year in H2K v1 to $20,141 \mathrm{MJ} /$ year in $\mathrm{H} 2 \mathrm{~K}$ v3 when the above mentioned inputs for PV generation were adjusted. Without the adjustments for the EnerGuide calculation however, the rating for this building H2K v3 goes down to 83 .

\subsubsection{HOT2000 Model Comparison Summary}

From creating the revised version of the HOT2000 models for all the homes in the study, there were several inconsistencies found between the H2K v1 models and the final constructed buildings. When the inconsistencies were accounted for in the $\mathrm{H} 2 \mathrm{~K}$ v2 models the predicted energy consumptions increased which in turn lowered the EnerGuide rating for two of the homes. Attention is required in every input and choice made when modeling homes in HOT2000 for the model to closely reflect the building being assessed. This was an issue in both House A and B, with the inputs for glazing properties, DHW tank type, fireplace specifications and exposed floors. But at 
the same time there are limitations to the program in being able to model the insulation type, and the HVAC and DHW systems installed in the home, where consultants and the author were required to choose an input that would more or less resemble the components of the actual building. Beyond the input discrepancies of the HOT2000 models, to address the limitations of the program, the homes were modeled using EnergyPlus to assess the impact of using a dynamic energy simulation program that has the flexibility to model complex assemblies and systems in homes.

\subsection{Performance Gap}

The performance gap, as explained earlier is the difference between the predicted energy consumption and the actual energy consumption of the building. For this study, the outputs from the $\mathrm{H} 2 \mathrm{~K}$ v1 and H2K v3 models are the "predicted" values and these are compared against those from the E+ calibrated model for each home. The E+ calibrated models have been fine-tuned to closely match the total energy consumption of each of the homes. The end-use energy consumption breakdowns from the $\mathrm{E}+$ calibrated models was a means to approximate the breakdown of the actual energy consumption using the questionnaire responses, since the homes are not sub-metered. Both HOT2000 models are compared to the calibrated EnergyPlus model since H2K v1 is the model that was created by the consultants for the intention of predicting the energy efficiency of the home, and H2K v3 models the homes using HOT2000 to the best of its abilities.

Table 16 summarizes the energy consumption gap between $\mathrm{H} 2 \mathrm{~K}$ v1 and E+ calibrated, and $\mathrm{H} 2 \mathrm{~K} v 3$ and $\mathrm{E}+$ calibrated for all the homes in the study, and Figure 14 graphs the total energy uses from the energy models to visually see the difference. 


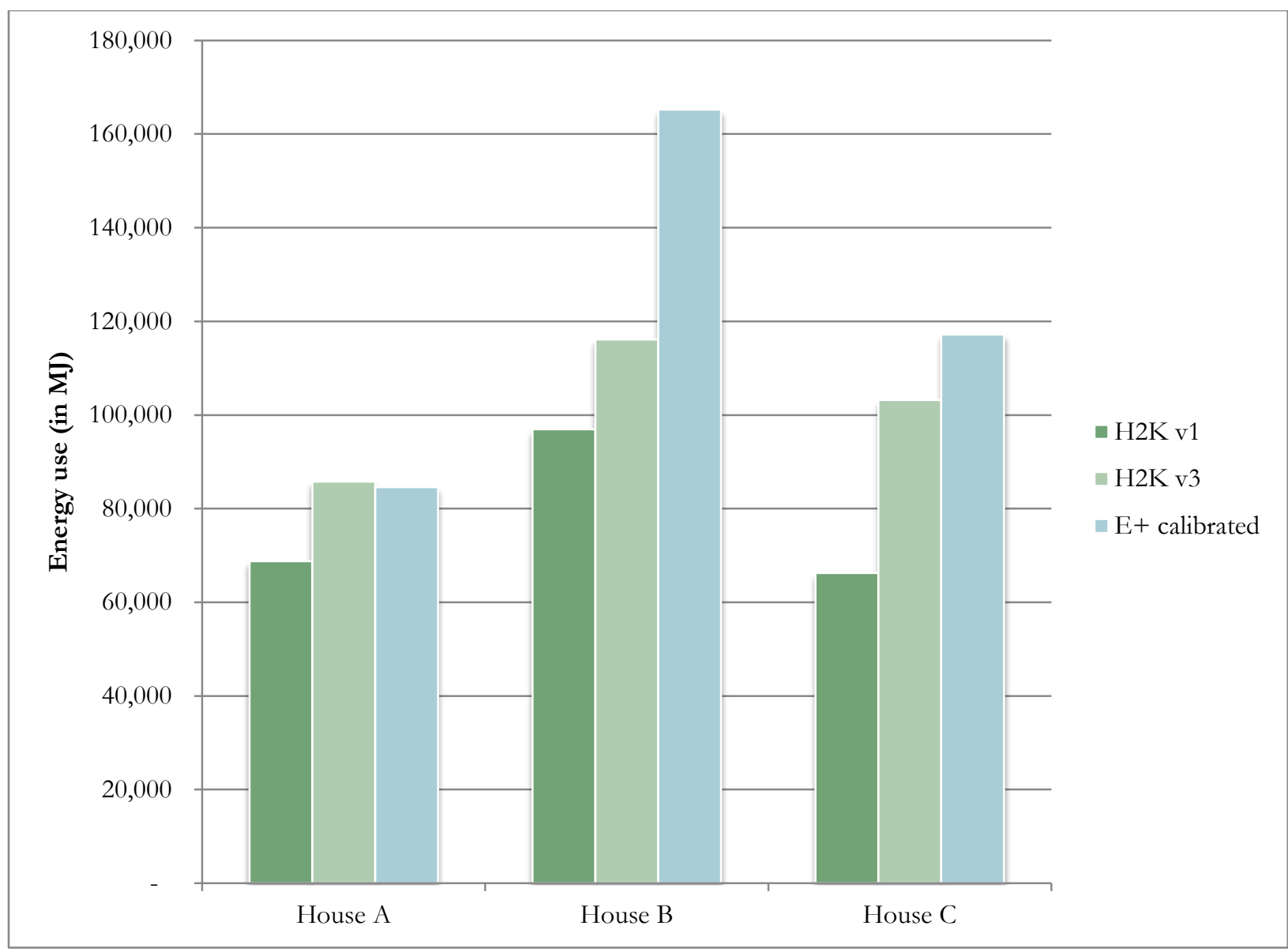

Figure 14: Total energy use comparison between HOT2000 models and E+ calibrated. 
Table 16: Performance gap summary.

\begin{tabular}{|c|c|c|c|c|}
\hline & & House A & House B & House C \\
\hline H2K v1 & $\begin{array}{l}\text { Total energy use } \\
\text { (in MJ) }\end{array}$ & 68,815 & 96,915 & 66,251 \\
\hline H2K v3 & $\begin{array}{l}\text { Total energy use } \\
\text { (in MJ) }\end{array}$ & 85,772 & 116,115 & 103,171 \\
\hline E+ calibrated & $\begin{array}{l}\text { Total energy use } \\
\text { (in MJ) }\end{array}$ & 84,613 & 165,197 & 117,184 \\
\hline \multirow{2}{*}{$\begin{array}{l}\mathrm{H} 2 \mathrm{~K} \text { v1 } \\
\text { compared to } \mathrm{E}+ \\
\text { calibrated }\end{array}$} & $\begin{array}{l}\text { Difference in } \\
\text { MJ }\end{array}$ & $15,797 \mathrm{MJ}$ & $68,282 \mathrm{MJ}$ & $50,932 \mathrm{MJ}$ \\
\hline & $\begin{array}{l}\% \text { difference } \\
\text { (from } \mathrm{H} 2 \mathrm{~K} \text { v1 } \\
\text { to } \mathrm{E}+ \\
\text { calibrated) }\end{array}$ & $+23 \%$ & $+70 \%$ & $+77 \%$ \\
\hline \multirow{2}{*}{$\begin{array}{l}\mathrm{H} 2 \mathrm{~K} \text { v3 } \\
\text { compared to } \mathrm{E}+ \\
\text { calibrated }\end{array}$} & $\begin{array}{l}\text { Difference in } \\
\text { MJ }\end{array}$ & $1,160 \mathrm{MJ}$ & 49,082MJ & $14,012 \mathrm{MJ}$ \\
\hline & $\begin{array}{l}\% \text { difference } \\
\text { (from } \mathrm{H} 2 \mathrm{~K} \text { v3 } \\
\text { to } \mathrm{E}+ \\
\text { calibrated) }\end{array}$ & $-9 \%$ & $+42 \%$ & $+14 \%$ \\
\hline \multirow{4}{*}{\multicolumn{2}{|c|}{ Source of gap }} & $\begin{array}{l}\text { Space heating } \\
\text { (window } \\
\text { specification in } \\
\text { H2K v1) }\end{array}$ & $\begin{array}{l}\text { Space heating } \\
\text { (overhangs, } \\
\text { exposed floors, } \\
\text { set point } \\
\text { temperature) }\end{array}$ & $\begin{array}{l}\text { Space heating } \\
\text { (difference in } \\
\text { system, basement } \\
\text { tool, internal gain } \\
\text { components) }\end{array}$ \\
\hline & & \multirow[t]{3}{*}{ DHW system } & HRV & HRV \\
\hline & & & Additional loads & \multirow[t]{2}{*}{ Additional loads } \\
\hline & & & $\begin{array}{l}\text { DHW } \\
\text { consumption }\end{array}$ & \\
\hline
\end{tabular}

There were several commonalities amongst the performance gaps for each home. The first notable source of discrepancy was that the buildings as constructed did not match the assumptions that were made for the H2K v1 model during the design stage. The use of windows, HVAC and DHW system specifications that were installed in the home affected the energy consumption of a home significantly. Even details such as exposed floors and over hangs will affect the heating demand for the home, as seen in the case of House B. Secondly, it was realized that HOT2000 underutilizes the fireplaces put in for supplementary space heating. When fireplaces were included for House A and B, HOT2000 assumed that they were rarely used, almost as if they would be used 
for aesthetic purposes and not for space heating. In these homes, however, the fireplaces are meant to accompany the space heating system and provide additional heating when needed by the occupants. The fireplaces may have been overshadowed by the baseboard heaters included in the models but not in the actual homes. As seen in Figure 1, there were additional loads and special functions that made up the total energy consumption in a home that could not have been included in the HOT2000 model using the EnerGuide mode. The HOT2000 EnerGuide mode has preset assumptions for the base load and occupancy that does not apply to semi-detached homes when the whole building is being simulated, as seen in the case of House $C$, since the assumptions apply to only one household. When the base load daily energy consumptions were increased in HOT2000 for House $\mathrm{C}$ to account for two households in $\mathrm{H} 2 \mathrm{~K} v 3$, the usable internal gain increased as a result, significantly lowering the space heating demand for the home. Table 17 shows the gross space heating load for both $\mathrm{H} 2 \mathrm{~K}$ v1 and $\mathrm{H} 2 \mathrm{~K}$ v3 for House $\mathrm{C}$, and the usable internal and solar gains that contributed to lower the auxiliary space heating energy required (space heating system load).

Table 17: Annual space heating summary for House C.

\begin{tabular}{|l|l|l|}
\hline & H2K v1 & H2K v3 \\
\hline Gross space heating load & $84,843 \mathrm{MJ}$ & $86,622 \mathrm{MJ}$ \\
\hline Usable internal gains & $23,352 \mathrm{MJ}$ & $39,216 \mathrm{MJ}$ \\
\hline Usable solar gains & $37,751 \mathrm{MJ}$ & $31,573 \mathrm{MJ}$ \\
\hline Space heating system load & $\mathbf{2 3 , 7 4 0 M J}$ & $\mathbf{1 5 , 8 3 3 M J}$ \\
\hline
\end{tabular}

The user is unable to alter the amount of energy emitted by the added base load for it to not drastically impact the space heating system load in a home. This inability to customize inputs was one of the limitations in the HOT2000 program. Another limitation of the program was its ability to accurately represent the HVAC and DHW systems in these homes. Whereas EnergyPlus has the capabilities to integrate HVAC and DHW components to replicate the energy efficient systems installed in the homes, along with the flexibility to alter radiant heating from electric equipment, and 
able to specify wattages for lighting and electric equipment to match the fixtures, equipment and additional loads physically in the homes.

The following sections analyze the performance gap between the predicted annual energy consumption by HOT2000 and the calibrated EnergyPlus model for each of the homes in greater detail.

\subsubsection{Performance Gap of House A}

Figure 15 compares the energy consumption distribution between $\mathrm{H} 2 \mathrm{~K}$ v1, H2K v3 and the outputs from the E+ calibrated model in EnergyPlus. Between $\mathrm{H} 2 \mathrm{~K}$ v1 and E+ calibrated, there is over a $15,000 \mathrm{MJ}$ difference (a 23\% increase) between the predicted and calibrated models. The major differences between these two models are seen in space heating, humidification and DHW energy consumption. As discussed earlier, $\mathrm{H} 2 \mathrm{~K}$ v1 predicted lower space heating electricity consumption due to the glazing specification. 


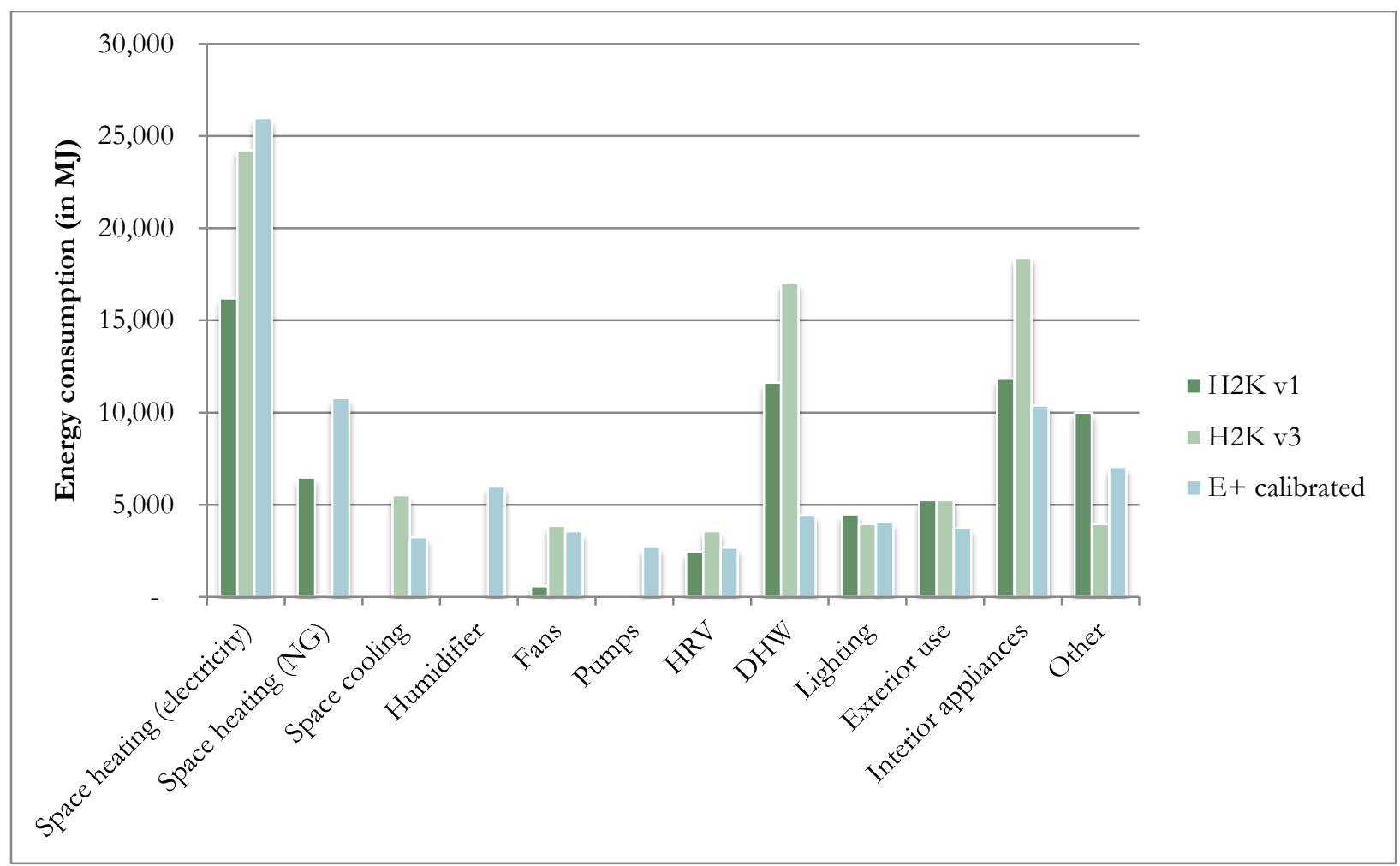

Figure 15: End-use energy consumption comparison between $\mathrm{H} 2 \mathrm{~K}$ v1, H2K v3 and E+ calibrated for House A.

The natural gas consumption for space heating in $\mathrm{H} 2 \mathrm{~K} v 1$ is mainly from the pilot light energy consumption, and only a small portion of it was for supplementary heating as seen in the natural gas consumption for space heating from the H2K v3 model (61MJ). In the actual home however, the fireplace is used frequently during the heating season to supplement the main heating system $(10,780 \mathrm{MJ})$, which HOT2000 was not able to predict. Space cooling is not considered in the EnerGuide calculation and so the energy consumption for it is excluded in the H2K v1 output, but is accountable for $3,240 \mathrm{MJ}$ in electricity consumption in the E+ calibrated model. Humidification, to the author's knowledge, is not considered in the HOT2000 program, and for this home the humidifier is responsible for $5,990 \mathrm{MJ}$ of electricity consumption according to the calibrated EnergyPlus model. The fan in the E+ calibrated model is required to do more work with a higher heating demand, and it also includes the fan electricity consumption during the cooling season. Finally, the E+ calibrated DHW energy consumption is lower than the DHW energy consumption 
predicted by the H2K v1 model due to EnergyPlus being able to correctly model the DHW system in place in House A - an electric tank that is supplemented by the ground source heat pump. With the connection to the ground source heat pump, the water heater is not required to work as , much as predicted in HOT2000.

The initial overall performance gap was 15,797MJ (a difference of 23\%), this was decreased to $1,160 \mathrm{MJ}$ ( $9 \%$ difference) when revisions were made to the HOT2000 model. But when the breakdown of the energy consumption is inspected, there are still notable differences in the space heating through natural gas and DHW energy consumption. HOT2000 is able to model the HVAC system in place for this particular home correctly, and so the space heating (electricity) consumption is similar between the two models. The minor difference may be due to the difference in the weather files used in the programs. The $\mathrm{E}+$ calibrated model does have a lower space cooling energy consumption since the occupants have set a higher cooling set-point on their thermostat and take advantage of natural ventilation over the cooling system. Similar to the other HOT2000 model for this home, the program underestimated the use of the fireplace for supplementary heating and the gap still remains. The HRV electricity consumption difference is not significant, but the E+ calibrated model is slightly lower since the HRV is turned off by the occupants during the cooling season. Looking at the DHW energy consumption, the gap between $\mathrm{H} 2 \mathrm{~K}$ v3 and E+ calibrated is increased, compared to the gap between $\mathrm{H} 2 \mathrm{~K}$ v1 and $\mathrm{E}+$ calibrated, with the change in the tank type for the home (from a heat pump tank type to a conserve tank type). The higher DHW energy consumption for $\mathrm{H} 2 \mathrm{~K} v 3$ is offset by the lower natural gas space heating and humidifier energy consumption to almost balance out the total energy consumption of the two models. The performance gap between these two models may be minimal but the energy consumption breakdown is not accurately represented by the HOT2000 program. 


\subsubsection{Performance Gap of House B}

Figure 16 compares the end-use energy consumption from the H2K v1 and H2K v3 outputs to the $\mathrm{E}+$ calibrated outputs for House B. When the total energy consumptions of the H2K v1 and $\mathrm{E}+$ calibrated are compared, there is over a $68,000 \mathrm{MJ}$ difference (a $70 \%$ increase) between the predicted and calibrated models. This gap is slightly narrowed with the revisions in H2K v3 (a 68,282MJ difference to 49,082MJ).

The calibrated model has a slightly higher space heating electricity consumption compared to the H2K v1 model, this could be the result of a combination of the overhangs and exposed floors being excluded in the H2K v1 model, and a higher heating set-point temperature assigned by the occupants. Since humidification is not considered in HOT2000, the humidifier itself adds a 4,260MJ gap between the models. The DHW system in all three models are modeled to be instantaneous natural gas fueled water heaters, but the home has a higher than average hot water consumption, resulting in an $8,389 \mathrm{MJ}$ difference. 


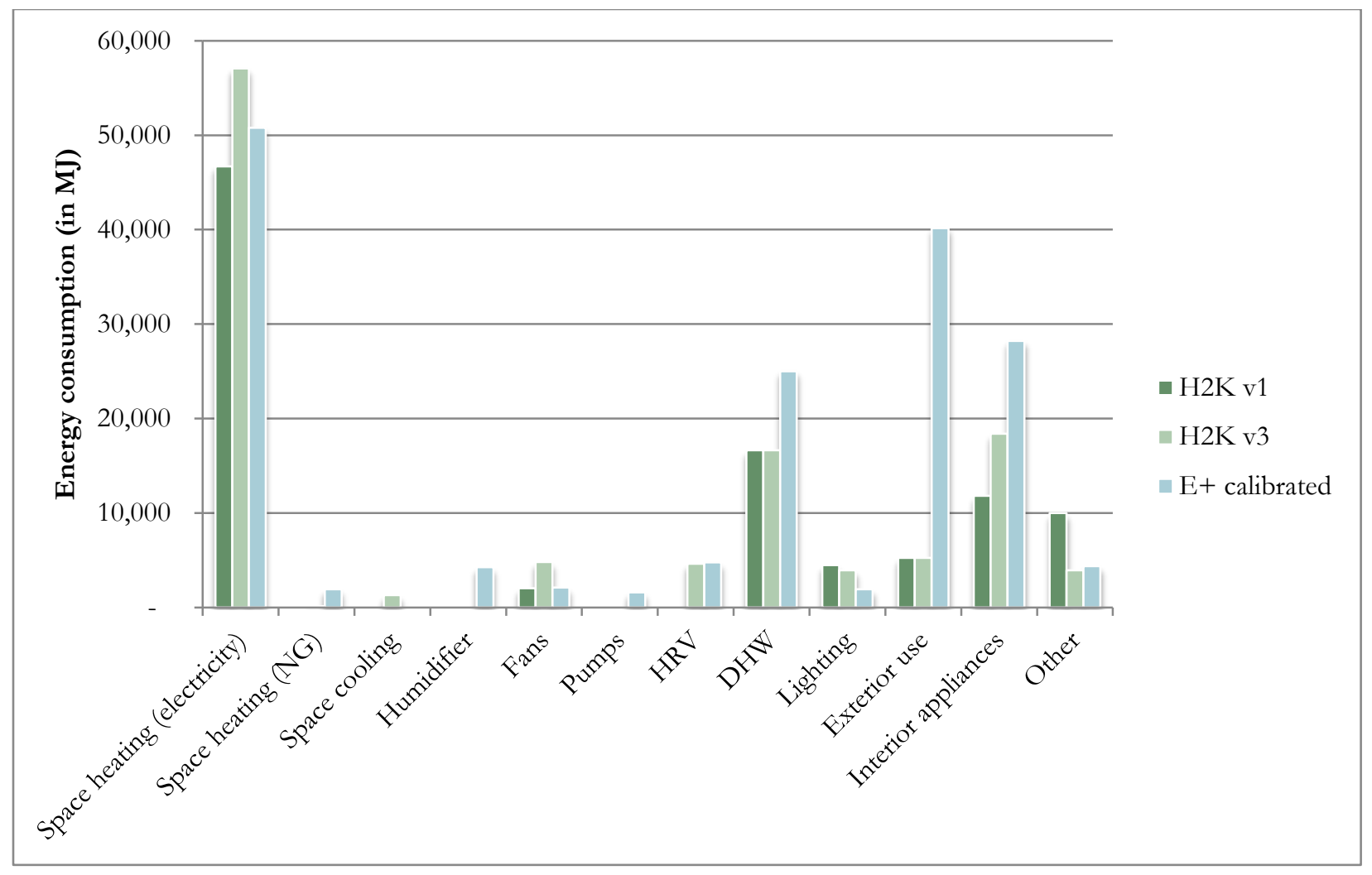

Figure 16: End-use energy consumption comparison between $\mathrm{H} 2 \mathrm{~K}$ v1, H2K v3 and E+ calibrated for House B.

The difference may be minimal compared to the other end-uses, but the lighting electricity consumption is lower in the E+ calibrated model since the home mostly has LED lightbulbs installed throughout the home. The exterior use energy consumption for the $\mathrm{E}+$ calibrated model includes the energy consumption of a boiler providing heated water to melt the snow off the driveway during the winter, which accounts for the 34,918MJ difference between the HOT2000 models and the E+ calibrated model. Additionally, the home has 2 additional refrigerators beyond the assumed interior appliances energy consumption in the HOT2000 models, contributing to higher interior appliances energy consumption in the E+ calibrated model.

If the boiler energy consumption and the additional appliances are taken out of the picture for this home, the E+ calibrated total energy consumption turns out to be $113,665 \mathrm{MJ}$ compared to 116,115MJ energy consumption predicted in $\mathrm{H} 2 \mathrm{~K} v 3$, narrowing the performance gap significantly. 
The performance gap between the predicted and calibrated energy consumption for this home was found to be mainly due to additional loads and occupancy behaviour.

\subsubsection{Performance Gap of House C}

For House C, the end-use energy consumption comparison between the HOT2000 models and $\mathrm{E}+$ calibrated are shown in Figure 17. The initial performance gap (H2K v1 compared to E+ calibrated) for this home is $50,616 \mathrm{MJ}$, a $77 \%$ increase in the electricity consumed compared to the predicted values. With the revised HOT2000 model, this performance gap is reduced to 14,012MJ (a $14 \%$ difference) as it take into account the higher occupancy and a doubled base load for two households.

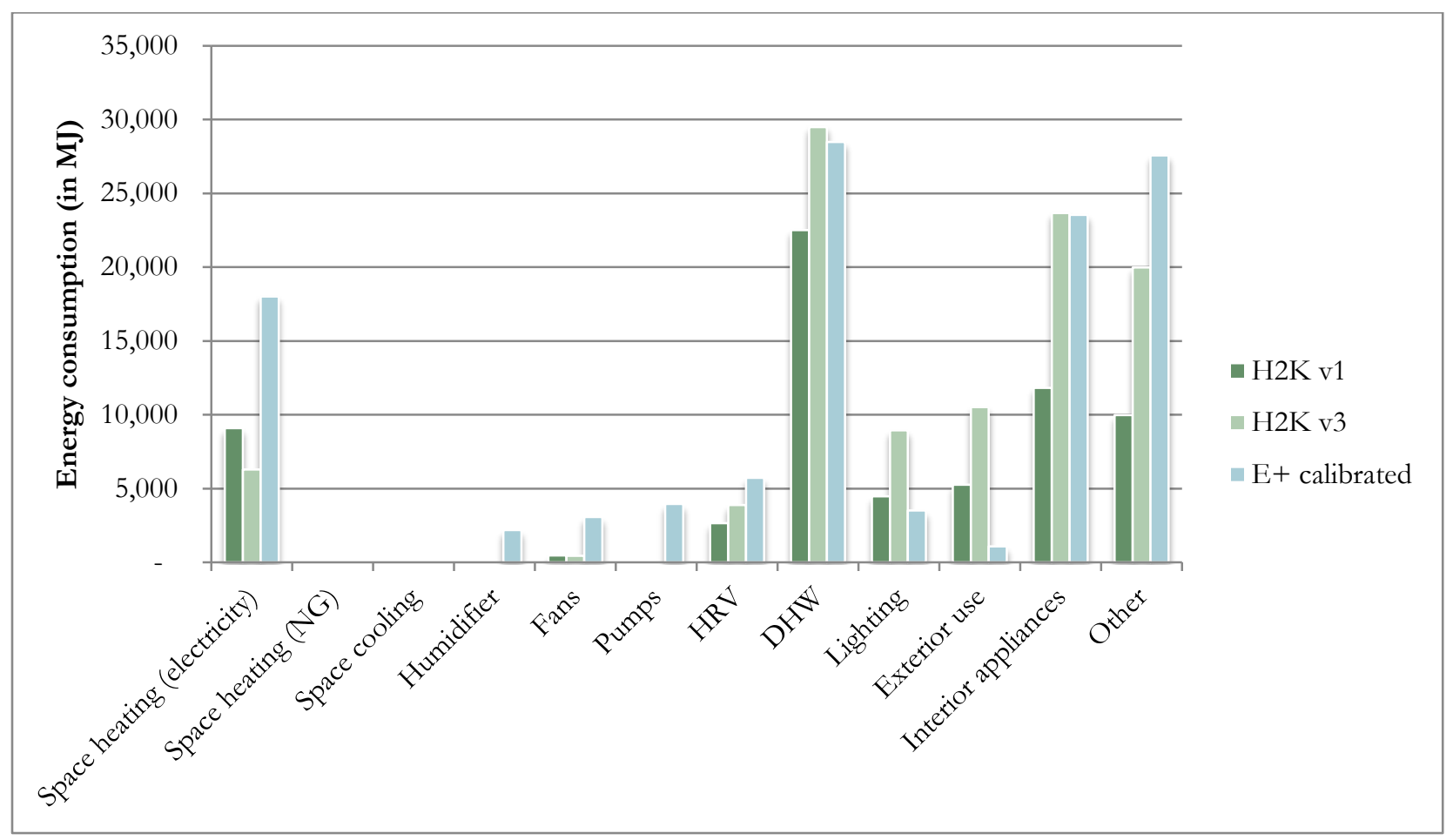

Figure 17: End-use energy consumption comparison between $\mathrm{H} 2 \mathrm{~K}$ v1, H2K v3 and E+ calibrated for House C.

The space heating electricity consumption between the models differ significantly, where the HOT2000 space heating estimations are less than half of that of the output from E+ calibrated. In HOT2000, the home was modeled to have a forced air system connected to a ground source heat 
pump, whereas the actual home (and in $\mathrm{E}+$ calibrated) is equipped with a radiant floor heating system connected to the ground source heat pump. The space heating electricity consumption for the home in EnergyPlus was found to increase as the systems and parameters were calibrated to closely match the actual building performance. However, this increase in the space heating electricity consumption does not push the value beyond the norm, as it is still significantly lower than the space heating energy intensity in the other two homes $\left(53 \mathrm{MJ} / \mathrm{m}^{2}\right.$ compared to $119 \mathrm{MJ} / \mathrm{m}^{2}$ and $132 \mathrm{MJ} / \mathrm{m}^{2}$ for House $\mathrm{A}$ and $\mathrm{B}$ respectively).

The HRV electricity consumption for E+ calibrated is higher compared to the HOT2000 models, since there are two HRV units in the building servicing the two households. The gap in the DHW electricity consumption between $\mathrm{H} 2 \mathrm{~K}$ v1 and $\mathrm{E}+$ calibrated is due to the higher occupancy in the actual home resulting in higher hot water consumption. With the doubled occupancy in H2K v3, the DHW electricity consumptions are nearly on par with each other. House C has the same DHW system hook up as House A (a ground source heat pump supplementing the DHW load), but due to the rated heating capacity of the heat pumps in House $\mathrm{C}$ being lower than the one in House $\mathrm{A}$ (6,273W and 18,756W respectively), we do not see a drastically lower DHW electricity consumption for House $\mathrm{C}$ as we did for House $\mathrm{A}$ in the $\mathrm{E}+$ calibrated model.

The lighting and exterior use electricity consumption is lower in the E+ calibrated model since the building utilizes LED lightbulbs throughout the homes. The initial difference in the appliance and other electricity consumption between $\mathrm{H} 2 \mathrm{~K}$ v1 and $\mathrm{E}+$ calibrated is essentially eliminated when the base load consumptions are doubled in $\mathrm{H} 2 \mathrm{~K}$ v3. E+ calibrated however has a higher "other" electricity consumption due to the additional loads in the home. 
The performance gap between the predicted electricity consumption by HOT2000 and the calibrated EnergyPlus model for House $C$ was determined to be a result of a difference in the space heating system modeled, program mechanics and additional loads in the home.

\subsection{EnerGuide Rating Comparison}

From creating the revised HOT2000 models and analyzing the performance gaps for these homes it was clear that the HOT2000 program does not have the flexibility or the capability to precisely model these energy efficient homes. In order to address the third research question posed for this thesis, the resulting EnerGuide rating from the models were compared to assess the impact of using a dynamic energy simulation program compared to a basic energy modeling program in a quantitative way. The EnerGuide rating value was decided to be the basis for comparison since it is the output that consultants used for the LEED for Homes certification process. As mentioned earlier, the EnerGuide rating is an evaluation of how energy efficient the home under assessment is, the equations used for the calculation of the EnerGuide rating is in the methodology section. Table 18 shows the LEED for Homes "Energy \& Atmosphere" points granted for certain EnerGuide rating values. The maximum points a house can gain under the "Energy \& Atmosphere" category is 28 points (with an EnerGuide rating of 100).

Table 18: "Energy \& Atmosphere" points earned from their respective EnerGuide rating values.

\begin{tabular}{|l|l|l|l|}
\hline EnerGuide rating & EA points & EnerGuide rating & EA points \\
\hline $\mathbf{7 9}$ & 6 & $\mathbf{8 6}$ & 18 \\
\hline $\mathbf{8 0}$ & 8 & $\mathbf{8 7}$ & 18.5 \\
\hline $\mathbf{8 1}$ & 10 & $\mathbf{8 8}$ & 19 \\
\hline $\mathbf{8 2}$ & 12 & $\mathbf{8 9}$ & 20 \\
\hline $\mathbf{8 3}$ & 14 & $\mathbf{9 0}$ & 21 \\
\hline $\mathbf{8 4}$ & 16 & $\mathbf{9 1}$ & 22 \\
\hline $\mathbf{8 5}$ & 17 & $\mathbf{9 2}$ & 23 \\
\hline
\end{tabular}


The following sections will compare the resulting EnerGuide rating values from the $\mathrm{H} 2 \mathrm{~K} v 2$, $\mathrm{E}+\mathrm{v} 2$ and $\mathrm{E}+$ calibrated outputs, with the exception of House $\mathrm{C}$ where $\mathrm{H} 2 \mathrm{~K}$ v3 will be compared in place of $\mathrm{H} 2 \mathrm{~K}$ v2. The outputs of $\mathrm{H} 2 \mathrm{~K}$ v3 are used for House $\mathrm{C}$ since the occupancy and base load of H2K v2 does not reflect the two households actually residing in the building (i.e. H2K v2 has a lower DHW and base load electricity assumptions). In these comparisons, H2K v2 (or v3) is used in place of $\mathrm{H} 2 \mathrm{~K} v 1$, since the author believes that the revisions made in $\mathrm{H} 2 \mathrm{~K} v 2$ (and v3) allow the models to be a closer representation of the actual homes.

The EnerGuide ratings from the E+ calibrated outputs were included in the comparison to examine how the energy efficiency rating of the home changes when the home is being occupied and how it differs from the assumptions used in the other two models.

\subsubsection{EnerGuide Rating Comparison for House A}

Figure 18 shows the difference in the values used in the EnerGuide rating calculations for House A for models H2K v1, H2K v2, E+ v2 and E+ calibrated, along with the resulting EnerGuide rating and LEED EA points gained. As discussed in an earlier section the EnerGuide rating decreased in $\mathrm{H} 2 \mathrm{~K}$ v2 with the revisions made to the model. When EnergyPlus is used in place of HOT2000 with similar assumptions for the heating set-point temperature and base loads (H2K v2 to E+ v2), the EnerGuide rating for House A increases by 2 points, from 87 to 89 , this increase would potentially generate an additional 1.5 LEED points. A further increase in the EnerGuide rating is seen for the E+ calibrated model (89.46 to 89.78).

The values in brackets are the EnerGuide ratings including the values up to the second decimal place, the number on the far right is the equivalent LEED for Homes "Energy \& Atmosphere" points granted for the given EnerGuide rating. The EnerGuide ratings are rounded to 
the nearest whole number, since it was noticed that HOT2000 rounded the EnerGuide output in the report this way.

\begin{tabular}{|c|c|c|}
\hline Estimated & & LEFD \\
\hline Energy & EnerGuide & EA \\
\hline Consumption & Rating & Points \\
\hline $49,558 \mathrm{MJ}$ & $90(89.78)$ & 21 \\
\hline $54,080 \mathrm{MJ}$ & $89(89.46)$ & 20 \\
\hline $61,311 \mathrm{MJ}$ & $87(87.06)$ & 18.5 \\
\hline $51,676 \mathrm{MJ}$ & $89(89.09)$ & 20 \\
\hline
\end{tabular}

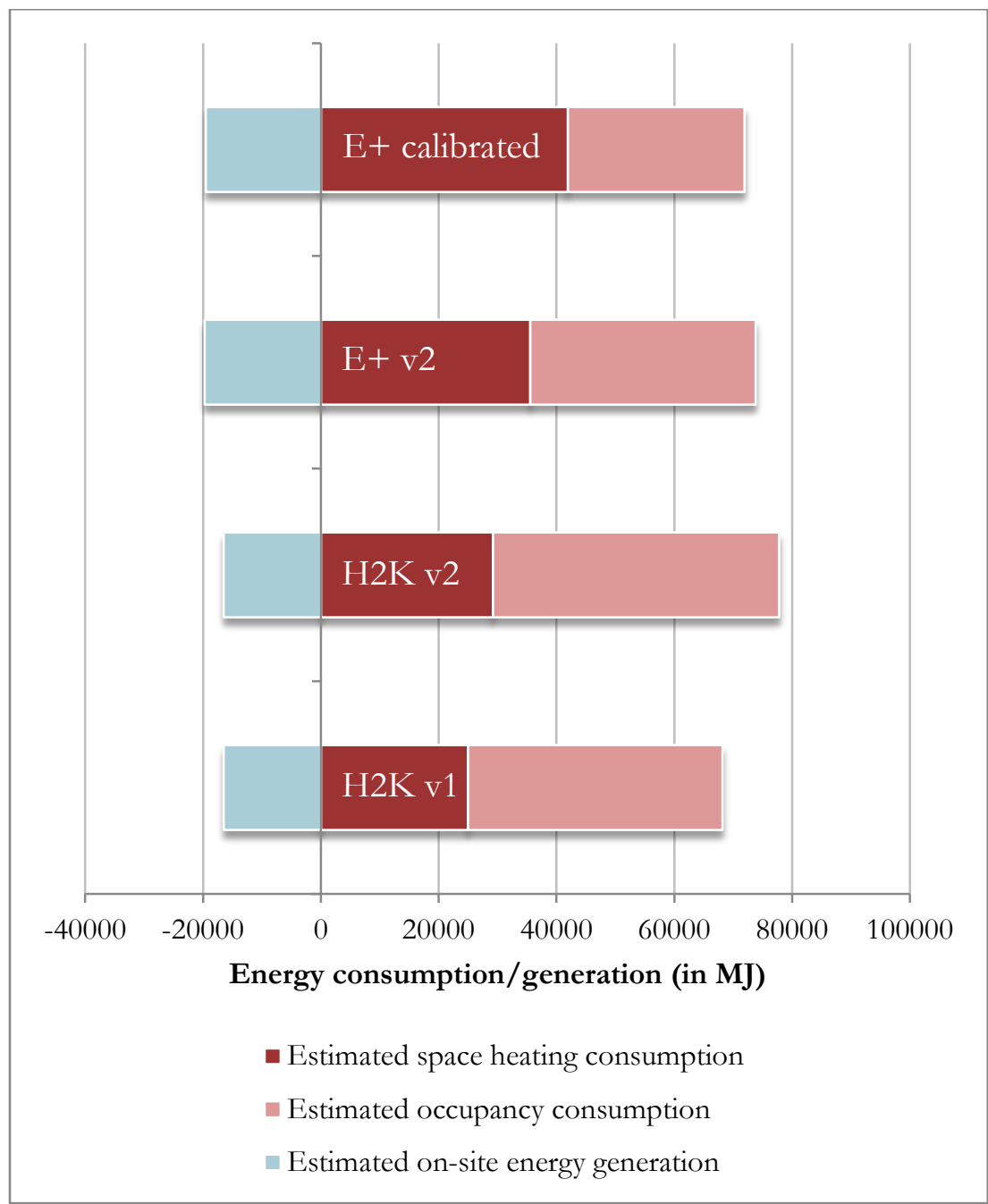




\subsubsection{EnerGuide Rating Comparison for House B}

Figure 19 displays the values used in the EnerGuide rating calculation from the energy models of House B with their respective EnerGuide ratings. For this home we also see an increase in the EnerGuide rating when EnergyPlus is used (E+v2), compared to H2K v2.

In the case for this house, the difference between the estimated total energy consumptions of the two models with similar system assumptions (H2K v2 and E+ v2) do not differ significantly. However, the space heating benchmark (used to calculate the EnerGuide rating) is higher for E+ v2 resulting in higher EnerGuide rating for the E+ v2 model when not rounded. The space heating benchmark is higher for the EnergyPlus models due to the choice in using the outer wall measurements which in turn increased the heated volume of the home used in the space heating benchmark calculation (i.e. E+ v2 has a lower space heating energy intensity compared to H2K v2). 


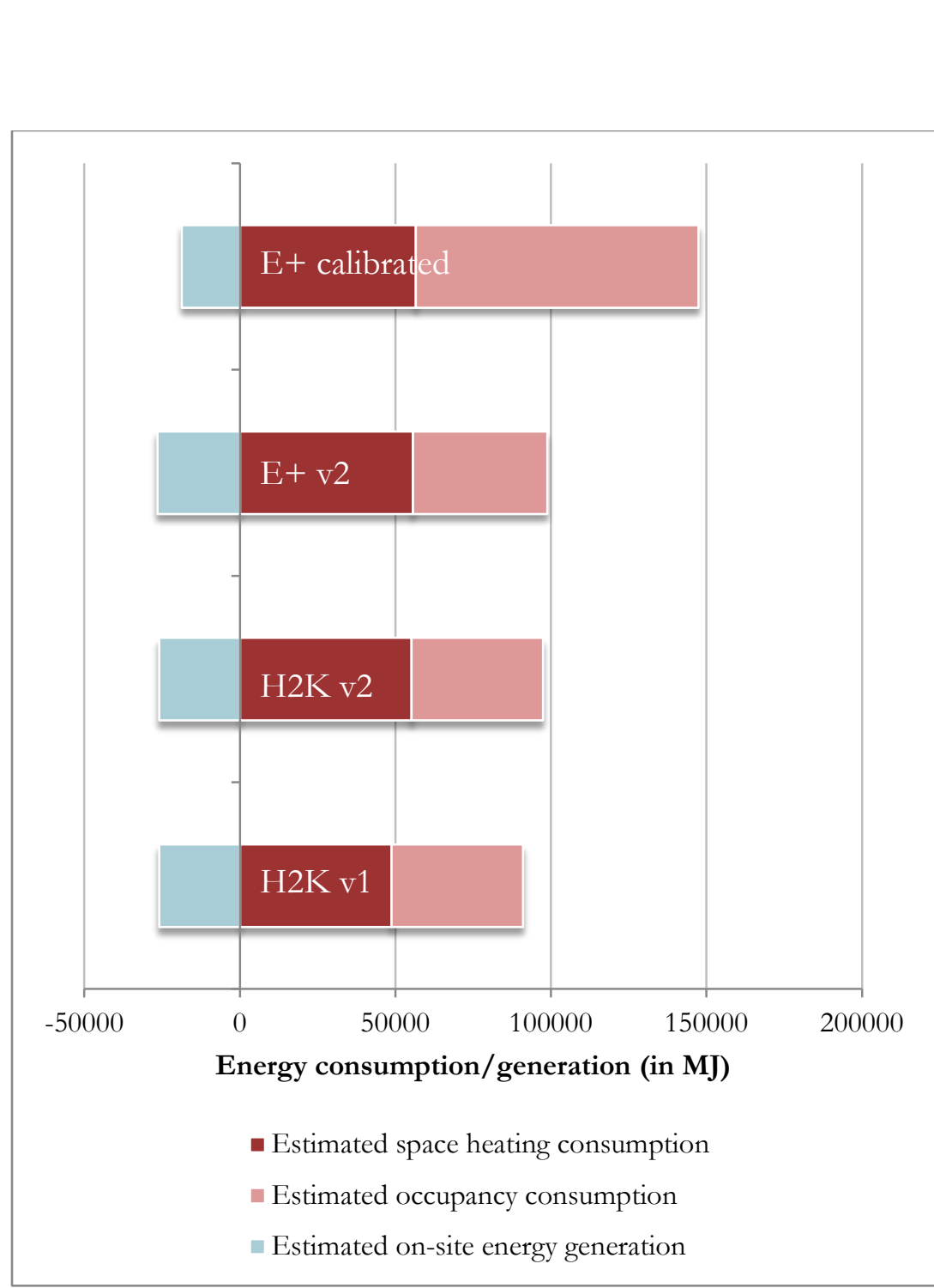

\section{Estimated \\ Total \\ LEED \\ Energy \\ EnerGuide \\ EA \\ Consumption \\ Rating \\ Points}

$128,749 \mathrm{MJ} \quad 79(79.06) \quad \mathrm{N} / \mathrm{A}$

72,317M

88 (88.24)

19

$71,514 \mathrm{MJ} \quad 88(87.78)$

65,113MJ

89 (88.87)

Figure 19: EnerGuide calculation values for energy models of House B.

When the E+ calibrated outputs are used to calculate the EnerGuide rating it is reduced significantly by 8 points to 79 . This does not meet the minimum requirement (of 80 ) for using the performance path for LEED certification. The rating of 79 is calculated when the boiler for the snow melting system is included in the exterior use portion of the base load. If the boiler energy consumption is excluded, the EnerGuide rating for the home is 86 (equivalent to 18 EA points).

For this home, an EnerGuide rating based on E+ v2 modeling when not rounded resulted in a slightly higher EnerGuide rating, due to the more accurate modeling of the radiant floor heating. However, as discussed in the performance gap section, a combination of higher set point 
temperatures for heating and additional loads significantly reduced the EnerGuide rating for this home when occupied as shown in the E+ calibrated model.

\subsubsection{EnerGuide Rating Comparison for House C}

Figure 21 shows the values used in the EnerGuide ratings for each of the energy models for House C.

\section{Estimated}

\section{Total}

Energy

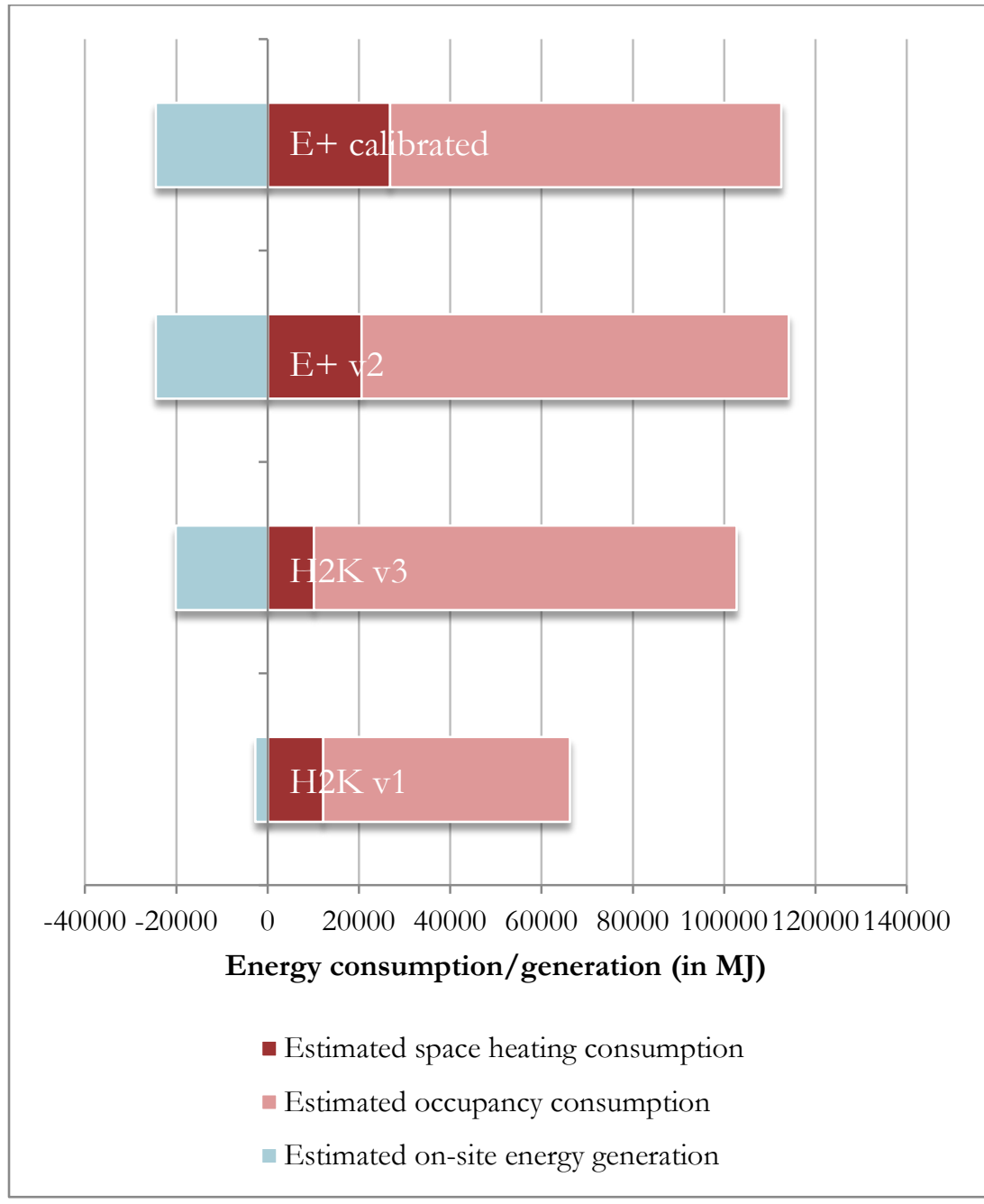

Consumption

$88,077 \mathrm{MJ}$

$89,682 \mathrm{MJ}$

$82,586 \mathrm{MJ}$

$63,517 \mathrm{MJ}$
$89(89.00)$

$89(88.80)$

89 (88.94)

EnerGuide Rating

LEED

EA

Points

19.5

19.5

19.5

$87(87.06)$

Figure 20: EnerGuide calculation values for energy models of House C.

When rounded to the nearest whole number, the EnerGuide ratings are the same for both $\mathrm{H} 2 \mathrm{~K} v 3$ and $\mathrm{E}+\mathrm{v} 2$ when the same set-point temperature and base load assumptions are used.

Looking at the breakdown of the components used in the EnerGuide calculation, the estimated total 
energy consumption for $\mathrm{H} 2 \mathrm{~K} v 3$ is approximately $7,000 \mathrm{MJ}$ lower than $\mathrm{E}+\mathrm{v} 2$, this difference is mainly due to the lower estimated space heating consumption in $\mathrm{H} 2 \mathrm{~K} v 3$. The estimated total energy consumption for the E+v2 model is higher, but like the other EnergyPlus models, the outer wall dimensions were used, increasing the heated volume for the building, equating to a higher benchmark total energy consumption, and nearly balancing the resulting EnerGuide rating value for these two models. The benefits of using EnergyPlus is not as clear for this home due to the internal gains reducing the space heating energy consumption in $\mathrm{H} 2 \mathrm{~K}$ v3.

The EnerGuide rating for the home when it is occupied is estimated to be 89 , and is marginally higher than the other models. This is a result of the home using LED lightbulbs throughout the home, which lowered the estimated occupancy consumption compared to the other models that used the base load assumptions for EnerGuide rating calculations.

\subsubsection{EnerGuide Rating Comparison Summary}

\section{Occupancy Factor}

It is clear that occupancy can have a significant impact on energy use, and so if this factor is included in the EnerGuide rating it can have a significant impact on the score of a house. The EnerGuide rating does not take into account individual occupancy patterns, but rather uses a standard occupancy. This allows house types to be rated similarly using standard assumptions, but it also means that the "predictions" in energy use that are estimated are not realistic. When occupants are conscious about their energy consumptions, the energy efficiency rating could increase from the predicted value, as seen in the case of House A. But when there are additional loads and higher heating set-point temperatures programmed, the actual energy consumption of a home increases beyond the predicted values and lowers the energy efficiency rating of the home, which was the case

for House B. House C, had a similar situation as House B, with higher loads, but those loads were 
offset by energy efficient light fixtures used in the home combined with a high exterior use electricity consumptions assumed for the other energy models. The values used in the base load consumptions assumed in the EnerGuide calculation is explored in a later section.

\section{$\underline{\text { HOT2000 as a Modeling Tool }}$}

When as-built differences in HOT2000 were accounted for in the revised model, the performance gap was narrowed down, emphasizing the importance of verifying inputs for energy modeling. However, HOT2000 does not have the capability to precisely model the HVAC and DHW systems in such advanced homes, which forces consultants to choose available components that resemble as closely as possible what is actually installed in the homes. This can be seen in the differences in $\mathrm{H} 2 \mathrm{~K}$ v2 (or v3) and the $\mathrm{E}+\mathrm{v} 2$ comparisons. When the HVAC and DHW systems are not accurately represented in the energy model, the breakdown of the energy consumption for the home is falsely represented, which was most evident in the case of House A's DHW energy consumption. Inaccurate breakdowns in the energy consumption could mislead home owners, designers and consultants on how the building uses energy. If the home owner wishes to reduce their energy consumptions, resources may be misallocated due to false information.

The use of EnergyPlus on the other hand, led to an increase in the EnerGuide ratings for 2 out of the 3 homes in the study (when the values are not rounded). Table 19 summarizes the EnerGuide rating comparison between the two programs for each of the homes. EnergyPlus was found to predict a higher PV electricity generation for the arrays on the homes compared to HOT2000 which helped increase the EnerGuide rating for the E+ v2 model for each of the homes. The PV generation prediction by EnergyPlus was not found to be overestimated as it was relatively similar to the actual PV generation for House A. For the third home (House C), if the estimated 
space heating consumption in $\mathrm{H} 2 \mathrm{~K}$ v3 was not severely decreased with the increase in internal loads, there could have been a slight increase in the EnerGuide rating with the use of EnergyPlus.

Table 19: Summary of EnerGuide ratings from energy models for each of the homes.

\begin{tabular}{|c|c|c|c|}
\hline & House A & House B & House C \\
\hline $\begin{array}{l}\text { H2K v1 EnerGuide } \\
\text { rating }\end{array}$ & 89 & 89 & 87 \\
\hline $\begin{array}{l}\text { H2K v2 EnerGuide } \\
\text { rating }\end{array}$ & 87 & 88 & 88 \\
\hline $\begin{array}{l}\text { E+ v2 EnerGuide } \\
\text { rating }\end{array}$ & 89 & 88 & 88 \\
\hline \multirow{2}{*}{$\begin{array}{l}\text { Contributing factor } \\
\text { to higher EnerGuide } \\
\text { rating in EnergyPlus }\end{array}$} & $\begin{array}{l}\text { Lower DHW } \\
\text { consumption }\end{array}$ & $\begin{array}{l}\text { Lower space heating } \\
\text { consumption }\end{array}$ & $\begin{array}{l}\text { Low space heating } \\
\text { consumption }\end{array}$ \\
\hline & High PV generation & Higher PV generation & Higher PV generation \\
\hline
\end{tabular}

\section{EnerGuide Rating from Simulation Program}

The EnerGuide rating is a well-established rating tool in Canada, but like any other tool, it needs to be applied correctly to generate accurate results (i.e. the energy model of a home should accurately represent the actual building). From the initial energy models created for these homes, there were some discrepancies between the models and the actual constructed building that resulted in higher EnerGuide ratings for some $\mathrm{H} 2 \mathrm{~K}$ v1 models. The energy model predicting the energy efficiency of a home should be verified so that it reflects the actual building, and if the HOT2000 program is found to not have the available input options to accurately model the systems in the homes, as found to be the case for all the homes in this study, it must be suggested that an energy simulation program that has the flexibility and capabilities to model new and intricate systems be used to calculate the EnerGuide rating of homes. With an energy simulation program that is as diverse and customizable as EnergyPlus, the consultant would not be required to look for substitutions for components that may not represent the actual. The EnerGuide rating will also reflect the energy efficiency of the building as a whole with the actual systems and components 
modeled in the simulation, rewarding the designers for their choices in building design, HVAC and DHW system. At the same time it is understood that the use of EnergyPlus is not as user-friendly as HOT2000 and is very time consuming to create error-free energy models. Nonetheless a change is required in the energy modeling program used to calculate the EnerGuide rating to facilitate accurate representation of energy efficient systems in home. 


\section{Discussion}

The following sections explore notable points and lessons learned from the research.

\subsection{EnerGuide Rating}

\subsubsection{EnerGuide Rating Compared to Energy Use and Carbon Intensity}

The use of energy use and/or carbon intensity as a means to benchmark a building's

performance has grown and has been used widely in practice (e.g. Energy Star Portfolio Manager and CarbonBuzz). However, homes that are LEED for Homes certified are only evaluated based on the EnerGuide rating from predicted energy consumptions, and the energy use or carbon intensities of the homes estimated during the design stage and intensities post-occupancy are not considered. The relationship between the carbon intensities and EnerGuide rating values of the homes are explored here. The carbon intensities are calculated by multiplying the energy consumptions by the respective carbon dioxide equivalent emission intensity (in $\mathrm{kgCO}_{2} \mathrm{e} / \mathrm{MJ}$ ). The emission intensities used for electricity and natural gas energy consumptions are listed in Table 20, these values are derived from the National Inventory Report by Environment Canada (2013). It is understood that electricity carbon emission intensities vary by location and time due to different electricity sources, and the values used represent the average in Ontario for 2010.

Table 20: Caron dioxide equivalent emission intensity by energy type.

\begin{tabular}{|l|l|l|}
\hline Energy type & Units & Carbon dioxide equivalent emission intensity \\
\hline Electricity & $\mathrm{kgCO}_{2} \mathrm{e} / \mathrm{MJ}$ & 0.0417 \\
\hline Natural gas & $\mathrm{kgCO}_{2} \mathrm{e} / \mathrm{MJ}$ & 0.0507 \\
\hline
\end{tabular}

The EnerGuide ratings from the energy models in this study were mapped alongside the carbon intensity from the model outputs in Figure 21 and 22 for House A and B respectively to compare the two approaches. The energy use and carbon intensity data for the homes are included in Appendix D. House C was excluded since the EnerGuide rating calculation was altered. 


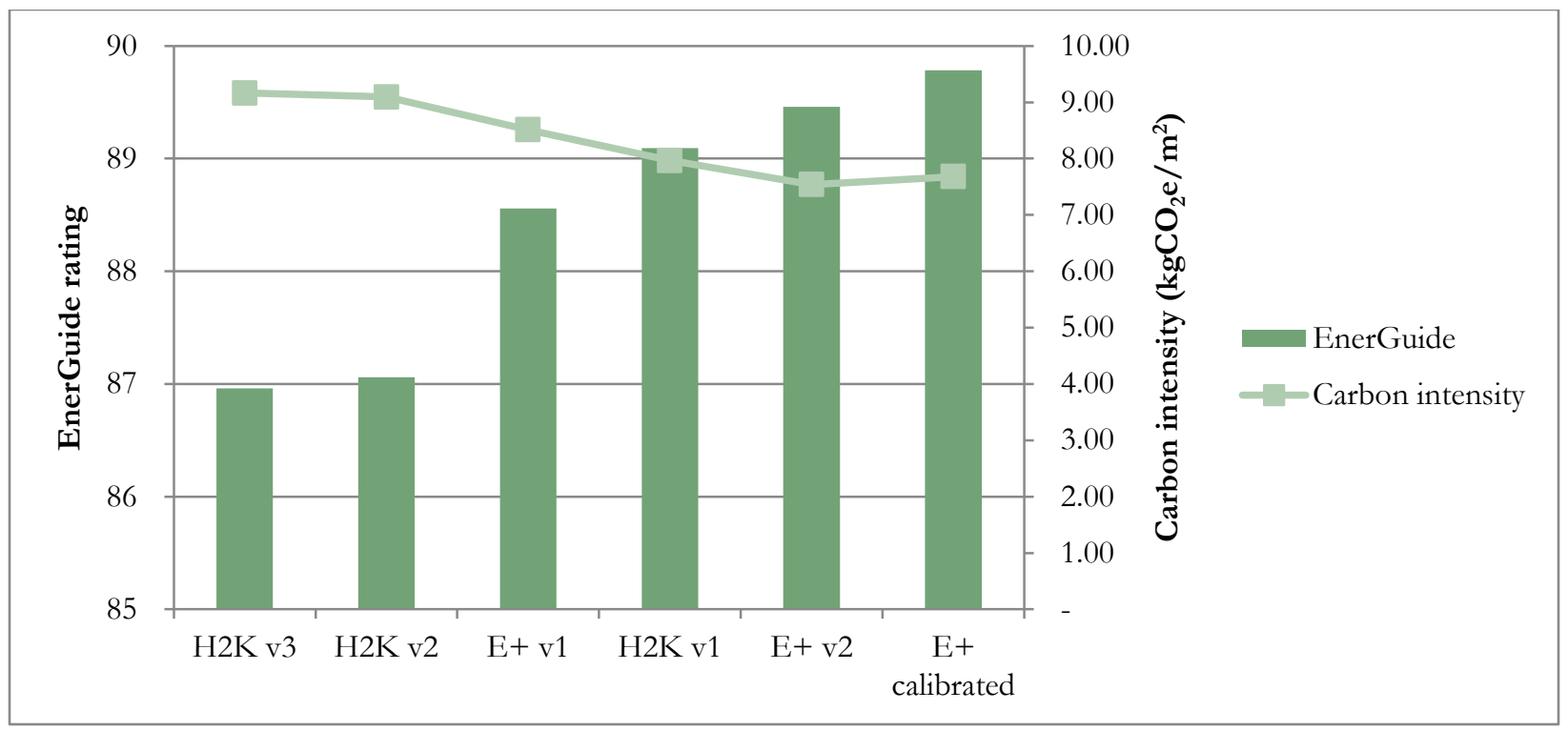

Figure 21: EnerGuide rating with carbon intensity for House A.

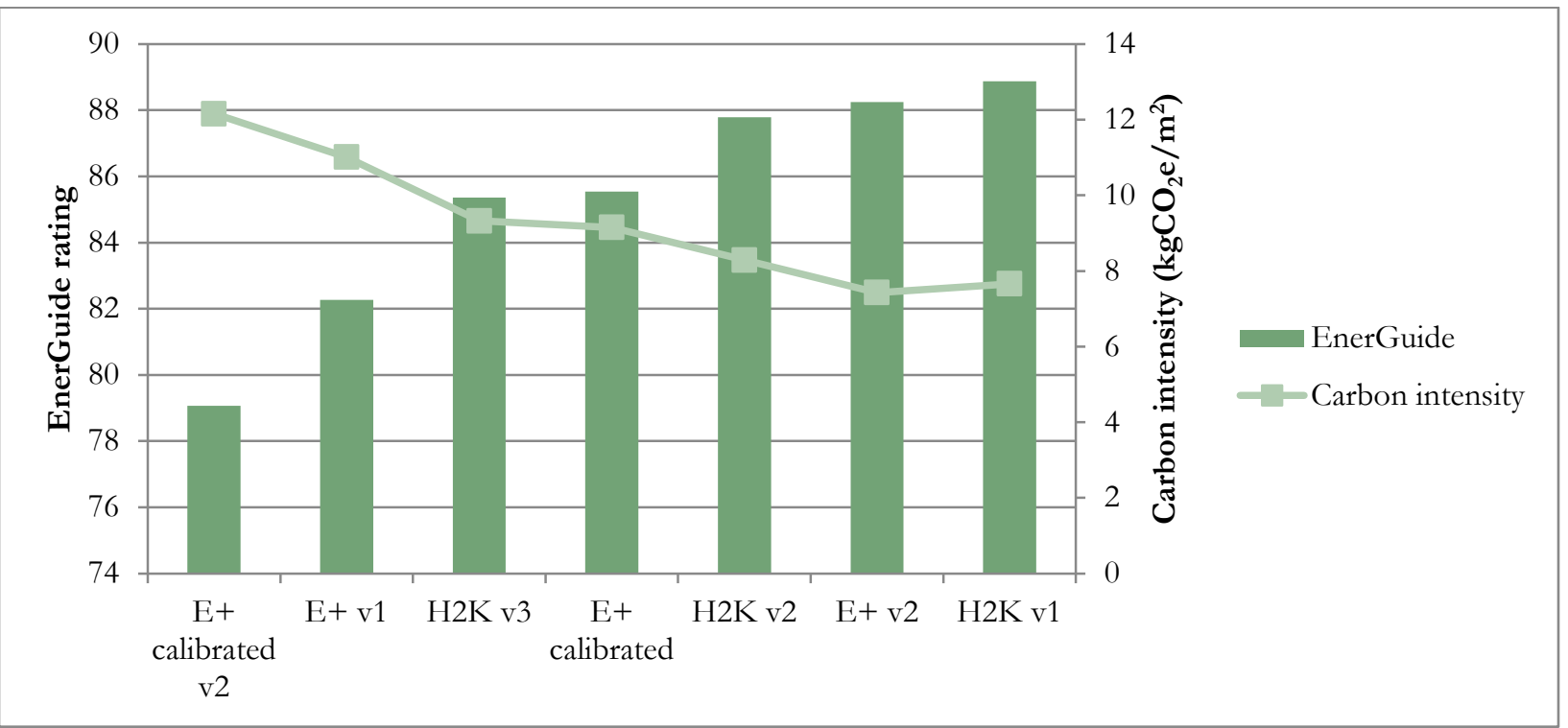

Figure 22: EnerGuide rating with carbon intensity for House B.

For both homes, the EnerGuide ratings seem to correlate well with the carbon intensities of the models, with the exception of the carbon intensities of $\mathrm{E}+\mathrm{v} 2$ which were lower than the intensities of $\mathrm{E}+$ calibrated and $\mathrm{H} 2 \mathrm{~K}$ v1 from House A and B respectively, but the EnerGuide rating of $\mathrm{E}+\mathrm{v} 2$ for both homes are not higher than those models. For House A, this discrepancy was due to the emission intensity difference between electricity and natural gas, as E+ calibrated had 
a higher natural gas consumption than $\mathrm{E}+\mathrm{v} 2$. For House $\mathrm{B}$, a slight difference in the floor area resulted in $\mathrm{E}+\mathrm{v} 2$ having a lower carbon intensity than $\mathrm{H} 2 \mathrm{~K} v 1$.

When the carbon intensities of the energy models from all the homes are laid out with their respective EnerGuide ratings (in Figure 23) it is clear that there is a disconnect between the EnerGuide rating and their respective carbon intensities when compared with other homes. For example, the H2K v3 model for House B holds an EnerGuide rating of 85.36, and has a carbon intensity of $9.33 \mathrm{kgCO}_{2} \mathrm{e} / \mathrm{m}^{2}$ (third point from the left), but there were energy models that yielded higher EnerGuide ratings while having greater carbon intensities. These discrepancies are seen elsewhere when comparing the EnerGuide rating and the carbon intensities from all the energy models of the homes.

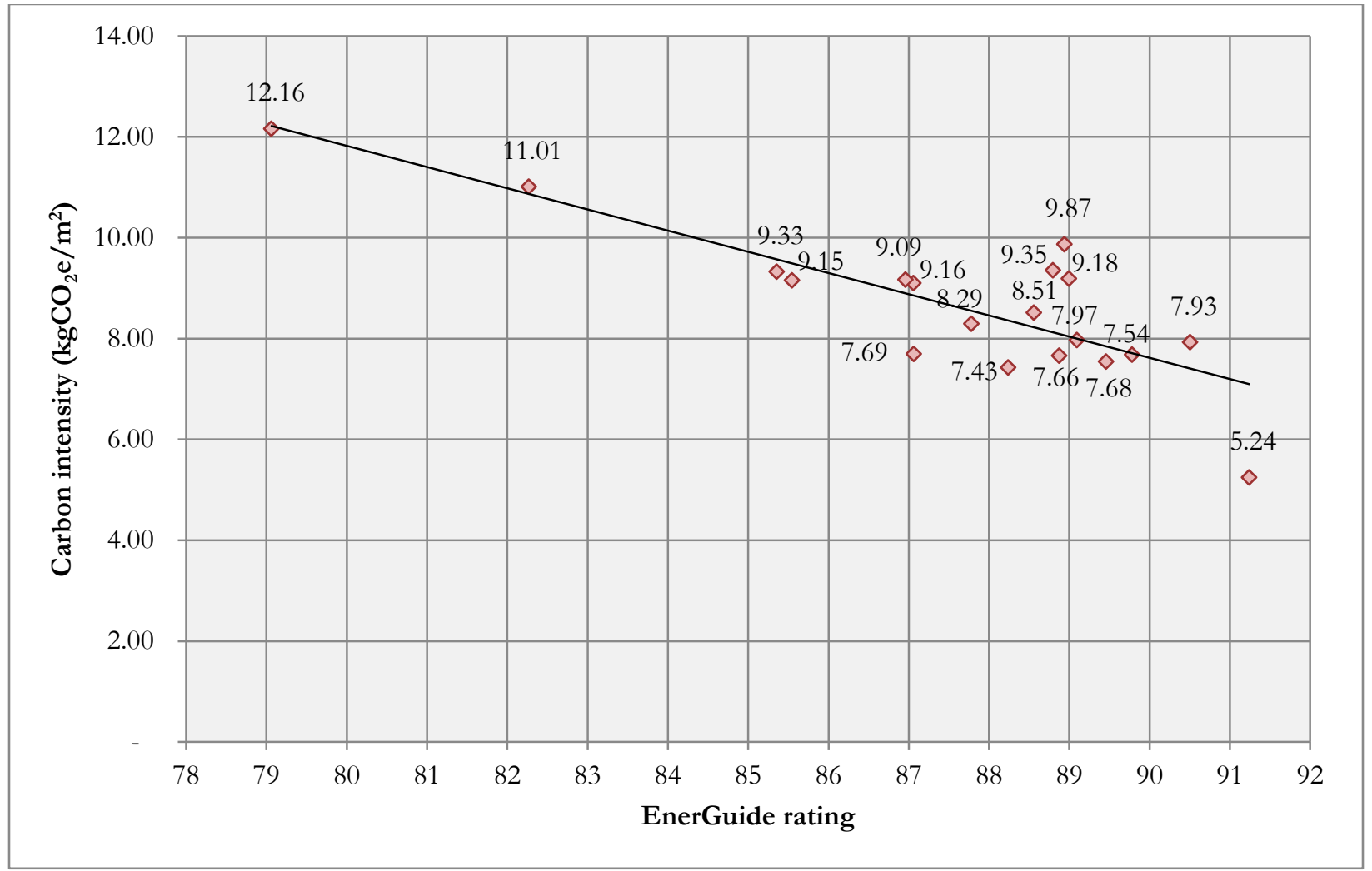

Figure 23: EnerGuide rating and carbon intensity from all models. 
To investigate this discrepancy, the approximate carbon intensities were calculated for each EnerGuide rating value from 80 to 100 for all three homes by working backwards from the calculation in section 4.3. and are shown in Figure 24. As a reference, House A has the smallest heated volume and floor area out of the three homes, and House $\mathrm{C}$ has the largest. This graph shows that larger homes must have lower carbon emissions per square meter in order to have the same EnerGuide rating as a smaller home.

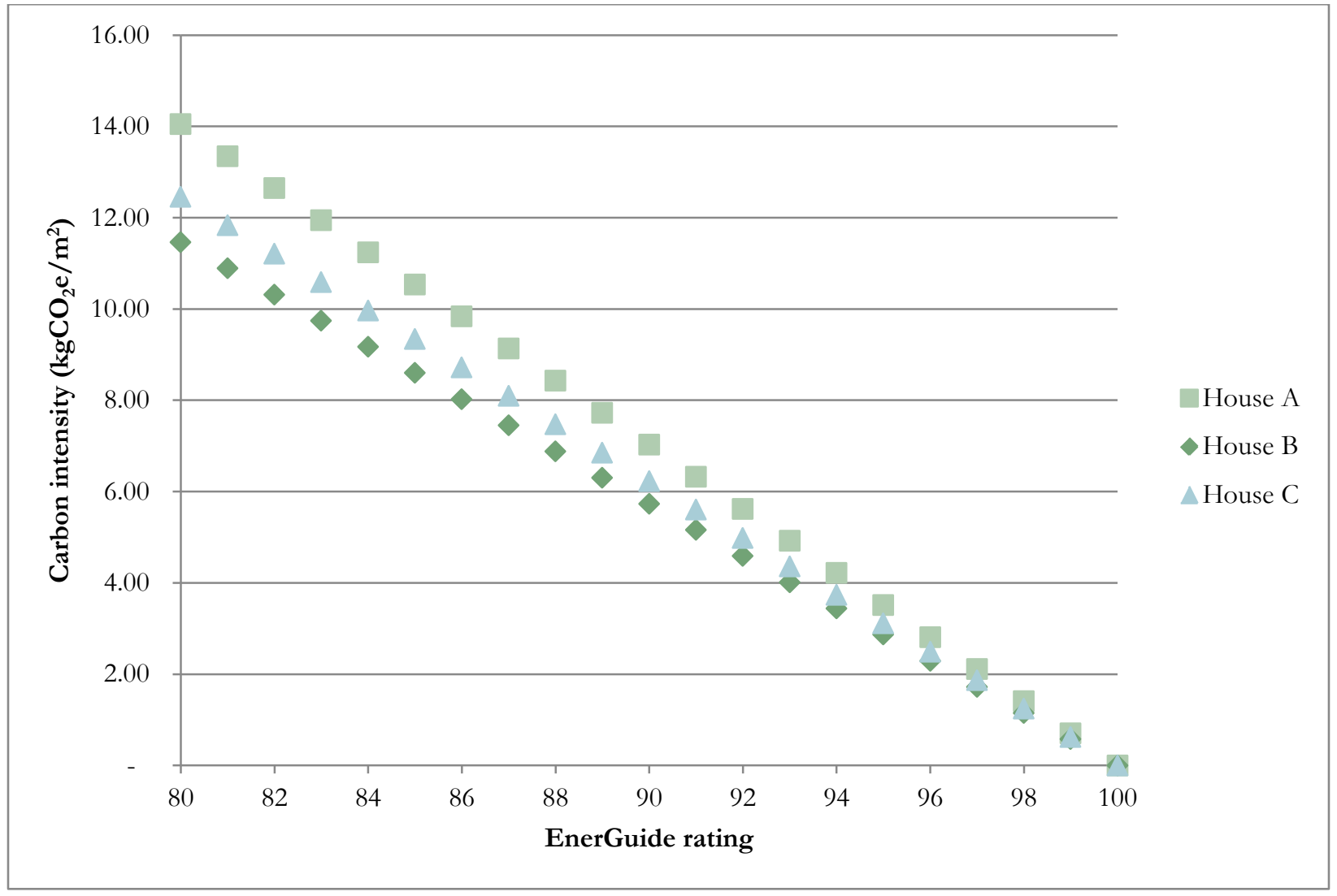

Figure 24: Approximate carbon intensities for EnerGuide ratings for the homes.

The EnerGuide rating calculation takes into consideration the heated volume of the home, and the energy efficiency of the home is evaluated based on what the base case energy consumption of a home of that size would be. The EnerGuide rating value is comparable when homes of similar sizes are compared but the values are not easily comparable with other homes that are difference in 
size in terms of carbon intensity (and likewise energy intensity). But requiring larger homes to have lower carbon intensity than a smaller home is an appropriate feature of the EnerGuide rating system, as it would encourage smaller homes if designers are aware of this trend. Additionally, the base load assumption of EnerGuide do not vary with house size, and for a larger home, when the carbon intensity is calculated, the carbon emission is spread over a greater floor area, resulting in lower carbon intensities from base load energy consumptions for larger homes.

The EnerGuide rating is a useful tool in assessing the energy efficiency of a home, but it is not currently used for benchmarking purposes, and with the current calculation method and assumptions it would not be viable, as explored in the following sections.

\subsubsection{EnerGuide Rating Calculation}

While calculating the EnerGuide ratings for each of the models, it was noticed that the estimated space heating and DHW energy consumptions were multiplied by a predetermined base efficiency or energy factor depending on the energy type, and doing so would reduce the estimated energy consumption and not taking into account the whole value that the program estimates. Within the documentation, the reasoning behind the use of the base efficiencies was to "[give credit] when higher-efficiency equipment is used, and penalties are applied when lower-efficiency equipment is used" (NRCan, 2005). But the formatting of the equations seem to award homes with equipment that utilize fossil fuel, as energy consumptions by fossil fuels are multiplied by a smaller efficiency value or energy factor which reduces the estimated total energy consumption for the home. With the current methodology, a home that uses natural gas may have a lower EnerGuide rating than a home that uses only electricity.

These base efficiencies were put in place decades ago to put equipment that used electricity and those that used fossil fuel on equal footing (i.e. the output from a $90 \%$ efficient natural gas 
furnace equaled the output of a 100\% efficient electric heating source) (A. Parekh, personal communication, March $24^{\text {th }}$ 2015). However, with the next generation EnerGuide rating system which will be introduced in the summer of 2015 , these "fuel equivalency" assumptions are to be removed.

\subsubsection{EnerGuide Base Load Assumptions}

From the performance gap analysis of these homes, it was pointed out that there was a gap between the predicted and calibrated lighting and exterior use electricity consumption for Houses B and C. For lighting, the gap is a result of the homes having LED lightbulbs installed throughout which reduces the electricity consumption by lighting fixtures. Figure 25 shows a comparison of the interior lighting electricity consumptions for each of the homes to the EnerGuide assumptions. House A utilizes mainly compact fluorescent lightbulbs and a few decorative incandescent lightbulbs in their home, putting them on par with the EnerGuide assumptions. Since House C consists of two households, the value was halved to show the lighting electricity consumption for one household for it to be considered on an equal level as the other homes and the EnerGuide assumptions. 


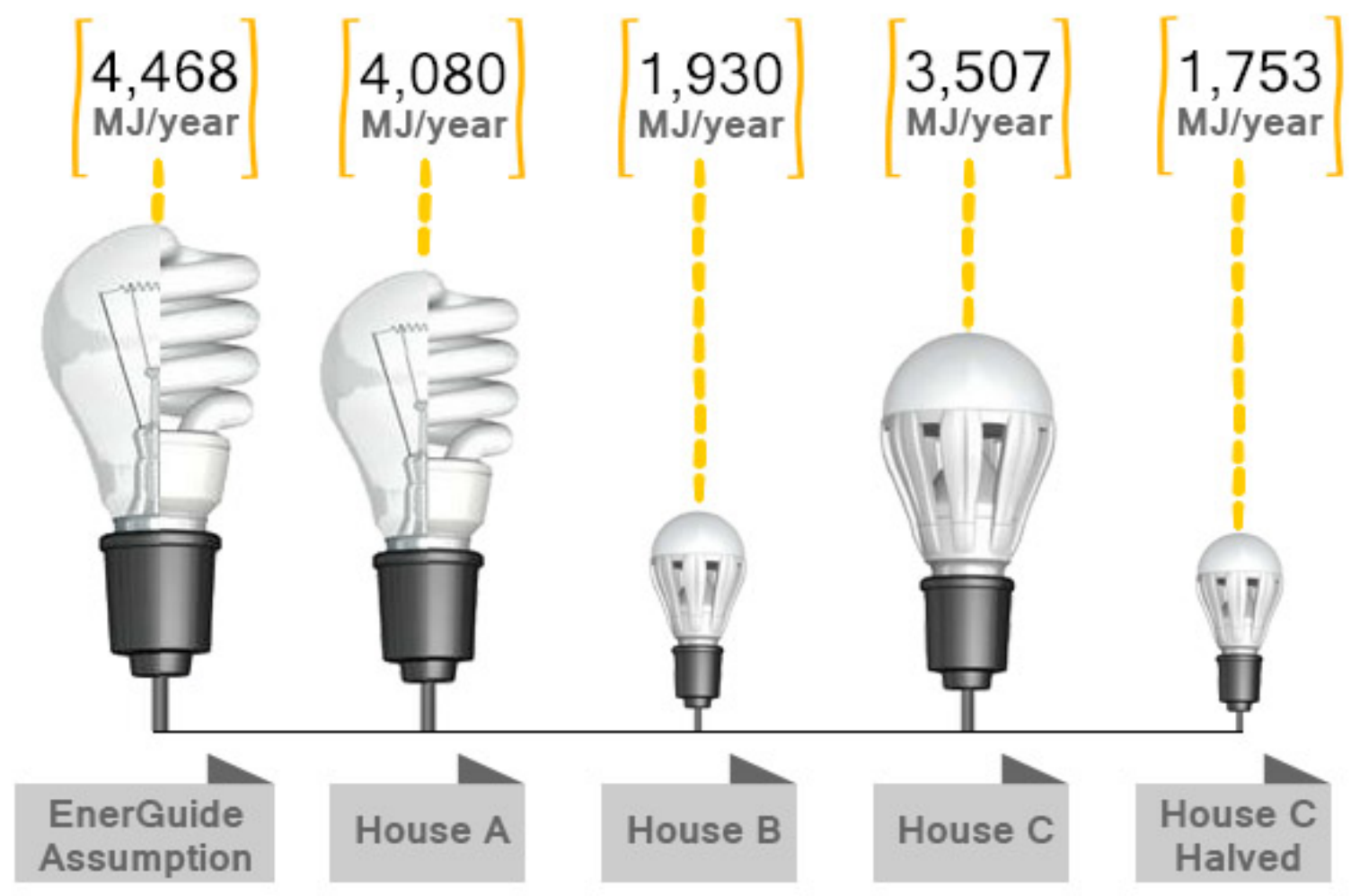

Figure 25: Interior lighting electricity consumption comparison.

The EnerGuide assumptions have set electricity consumptions for base loads that are based on standard operating conditions. These standard operating conditions are to be updated in the next generation EnerGuide rating system to better reflect the operation of residential homes with data gathered through the residential electricity evaluation protocol and other surveys of Canadian household energy use (Parekh, 2013). The updated assumptions are still averages of base load electricity consumptions that include fixtures and equipment that are old and inefficient. As a recommendation, for homes to be assessed on their energy efficiency for LEED for Homes certification, the consultants should be given the ability to alter the wattage of light fixtures and major appliances in the homes to have a base load electricity consumption that reflects the energy conscious choices that the designer and home owner have made. If a home is designed to have recessed LED lighting throughout the home, the power draw for each room in the EnerGuide 
assumptions would be multitudes higher than the actual. If the consultant is aware of the type of light fixtures to be installed and the type of lightbulbs to be used, they could input the total wattage of lighting for each room in the energy modeling program to be multiplied by the predicted duration of use to generate a daily lighting electricity consumption value that is specific to the assessed home. Base load appliance energy consumptions can be adjusted similarly, if the consultant working on the building energy modeling is aware of the appliances to be installed in the home, the rating provided by the manufacturer or a third party certifier such as Energy Star could be used in place of the standard rating used in the EnerGuide base load assumptions, to generate the daily appliance energy consumption of the home, instead of the using those of the average home.

Energy Star certified light fixtures and high efficiency appliances are granted points for the LEED for Homes certification, and depending on the extent of the base load energy consumption reduction in the home, the home may be double dipping and gaining more points for the same component if base load power draws are customizable. But if the EnerGuide rating is meant to be the energy efficiency rating of a home, it should not only be an assessment of how energy efficient the space heating and DHW systems are, but include energy efficient measures taken to reduce the base load energy consumption compared to the average home.

\subsection{Energy Program Comparison}

The following sections explore the notable points found when comparing the two programs; HOT2000 and EnergyPlus.

\subsubsection{Infiltration}

The infiltration inputs for HOT2000 are based on the blower door test completed for the homes. The required inputs are air change rate and the equivalent leakage area. In EnergyPlus, the user has the option to use the following air flow components to model infiltration; design flow rate, effective leakage area and flow coefficient. For ease of comparison, the effective leakage area or the 
design flow rate parameters were used to simulate the unintended exchange of air between the outdoor environment and the thermal zones for these homes.

While running the EnergyPlus simulations for House B, it was realized that infiltration affected the space heating demand significantly. The consultants inputted $1754.8 \mathrm{~cm}^{2}$ as the effective leakage area for House B, and when the same input is used in EnergyPlus the space heating energy consumption was found to be significantly higher, a 41,729MJ increase in space heating energy consumption from $\mathrm{H} 2 \mathrm{~K}$ v3 to $\mathrm{E}+\mathrm{v} 1$ for House B (a 73\% increase).

When creating the E+ v2 model for House B, with the whole house effective leakage area of $1754.8 \mathrm{~cm}^{2}$, according to the model the heat pumps would not have the capacity to heat the home. The air tightness of the home had been improved since the initial blower door test was done but another test was not completed for the home to have an updated effective leakage area. Having visited the home during the heating season, it was clear that the heat pumps were fully capable to providing adequate space heating for the home through the radiant floor system. In order for the energy simulation to have the air temperatures as programed in the thermostat by the occupants, the infiltration parameter was changed to the design flow rate option and the air change per hour was set to 1. Several air change rates were simulated to find an appropriate air change rate for the home, and at $1 \mathrm{ACH}$ the set-point temperature could be met and the space heating electricity consumption fell within the monthly energy consumption for calibration. When the simulation is run with 3.0ACH the space heating energy consumption is increased to $63,724 \mathrm{MJ}$ (from $50,800 \mathrm{MJ}$ ), and the zone air temperatures in the thermal zones from December to March fell far below $21^{\circ} \mathrm{C}$ (ranging from $14-18^{\circ} \mathrm{C}$ depending on the thermal zone). 


\subsubsection{Manufacture specifications for heat pumps}

When simulating heat pumps in EnergyPlus, the user is required to input coefficients for the heat pump's heating capacity and heating power consumption, for the cooling, the coefficients for the heat pump's total cooling capacity, sensible cooling capacity and cooling power consumption coefficients are required. These inputs are not asked for in HOT2000, and so in E+ v1, which is meant to equally compare the two programs using the same inputs, a zone HVAC template was used to generate the coefficients from the COPs of the heat pumps. The generated coefficients did not seem to change even when the COP inputs for the template were changed. The three homes have heat pumps with varying COPs for heating and cooling, however, the generated coefficients remained the same for all 3 models.

In $\mathrm{E}+\mathrm{v} 2$ and $\mathrm{E}+$ calibrated, the coefficients generated from the template were not used, instead the manufacture data was inputted into a spreadsheet prepared to be used in conjunction with EnergyPlus that would generate the coefficients using the catalog data for the heat pumps installed in the homes. With the coefficients generated from the catalog data, each heat pump in each of the homes has very specific coefficients that apply specifically to the heat pumps.

For House A, the change from E+ v1 to E+ v2 for space heating consisted of only the change in the coefficient used for the heat pump. With the use of coefficients generated from catalogue data, the space heating electricity consumption is increased from $18.64 \mathrm{GJ}$ in $\mathrm{E}+\mathrm{v} 1$ to 20.68GJ (plus an additional 7.68GJ from the water-to-water heat pump portion of the HVAC system) in $\mathrm{E}+\mathrm{v} 2$ when the supplementary heating fireplace is not taken into consideration. The change in the heat pump electricity consumption for the other two homes cannot be assessed in the same manner since the $\mathrm{E}+\mathrm{v} 1$ model simulated forced air systems, while in $\mathrm{E}+\mathrm{v} 2$, the space heating is changed to radiant floor heating and the heat pump types are water-to-water, and no longer waterto-air. The use of coefficients from the catalogue data in EnergyPlus help to simulate the heat pump 
performances specific to the model and the performance anticipated by the manufacturer, which is not an available feature in HOT2000.

\subsubsection{PV Generation and the Shading Effect of Arrays}

The PV electricity predicted by HOT2000 and EnergyPlus, along with the actual PV

generation of the PV arrays of the homes are shown in Figure 26. In general, it was found that the EnergyPlus models predicted a 15 to $20 \%$ higher PV electricity generation than HOT2000, and in the case of House A, the prediction by EnergyPlus was closest to the actual PV generation.

For House A, the actual PV generation was almost exactly replicated in the E+ calibrated model, but the HOT2000 model prediction was approximately $15 \%$ or 3,017MJ lower than the actual PV generation. 


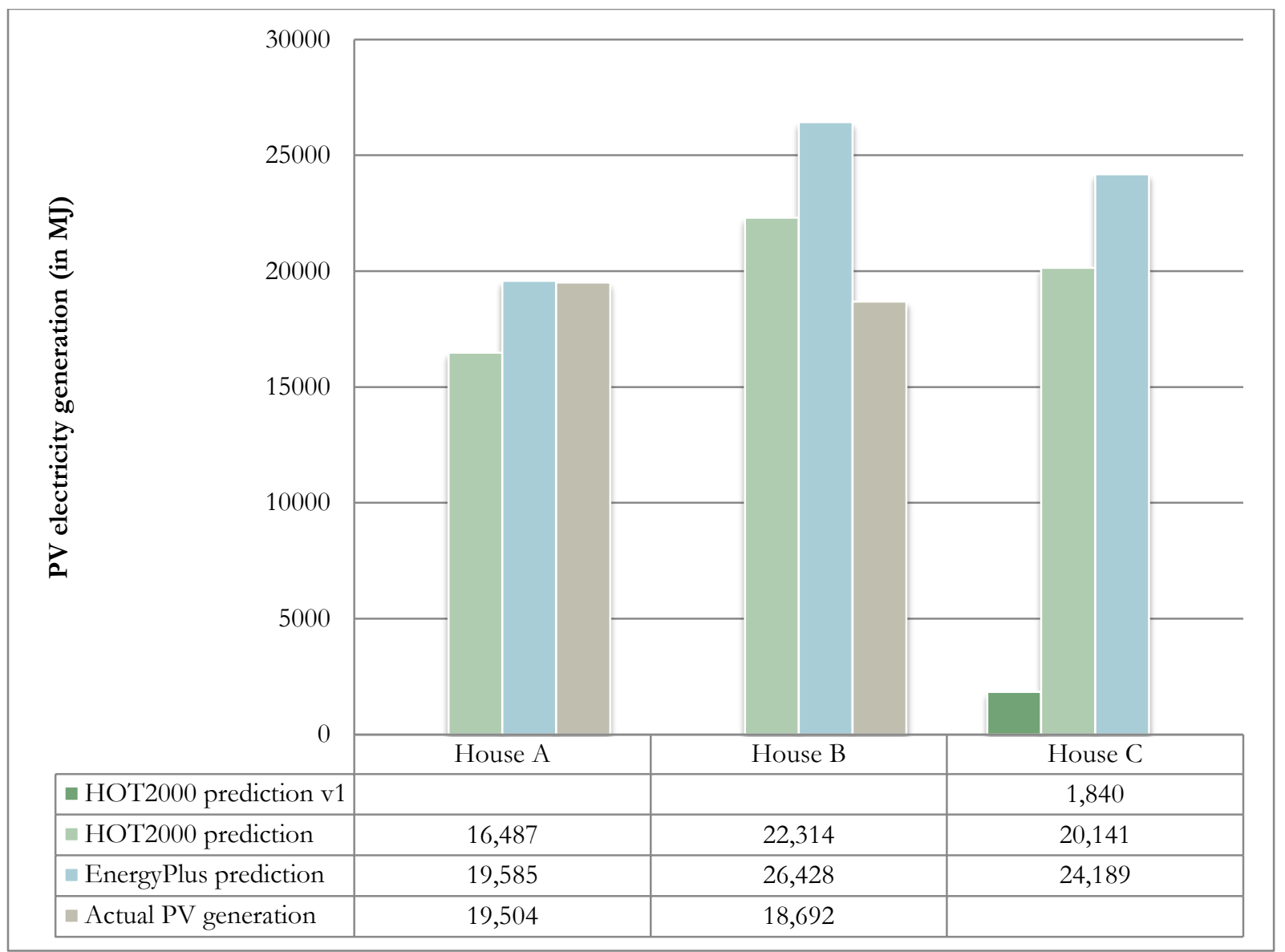

Figure 26: PV electricity generation predicted by HOT2000 and EnergyPlus compared against the actual electricity.

The HOT2000 PV generation predictions are unchanged for House A and B, whereas for House C, the PV generation inputs were revised.

For House B, unfortunately the PV panels are not maintained on a regular basis, reducing the efficiency of the panels significantly, especially during the winter. In the $\mathrm{E}+$ calibrated model, in order to replicate the actual electricity generation by the panels, the efficiencies during the winter months were reduced to 5-6\% from the specified module efficiency of $15.7 \%$. The monthly PV generation predictions by the two models are compared against the actual generated amounts in Figure 27, where during the winter the actual electricity generated by the PV panels are less than half of the predicted values. For the rest of the year, the HOT2000 predictions seem to be closer to the actual values. But since the panels are not regularly maintained, we do not know the full potential of 
what the actual PV electricity generation could be, and for this reason it is unclear which program was able to closely simulate the performance of well-maintained panels on this home.

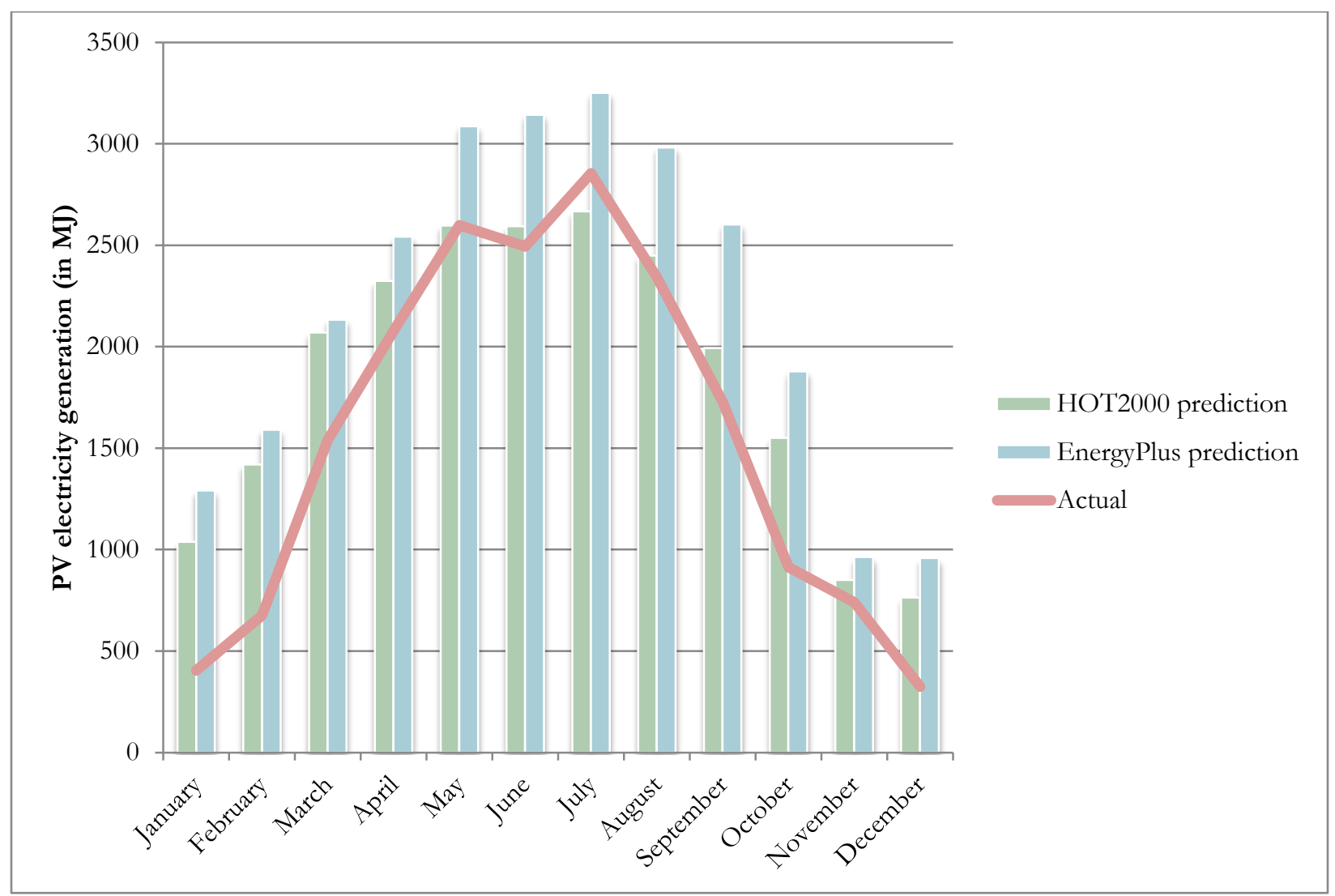

Figure 27: A monthly breakdown of the PV generation of the PV panels on House B.

For House C, the initial prediction in HOT2000 (H2K v1) was very low compared to the other homes as the PV panels in H2K v1 were modeled to face north, with a low grid absorption rate. Adjustments were made to the inputs based on the installed system in the revised HOT2000 models (H2K v2 \& 3) and the program estimated 20,141MJ of generated electricity. The EnergyPlus prediction for this system was $20 \%$ higher at $24,189 \mathrm{MJ}$. Due to the lack of data for this home, the author does not have the actual PV electricity generation to compare the predictions from the energy models. 
In the HOT2000 program, the PV generation for a home is included by inputting the array area, the slope and azimuth angle, along with specifications for the solar cells, whereas, in EnergyPlus, the PV arrays are placed on a surface (generally as a shading device on the building). When the PV electricity generations were considered in all the of the EnergyPlus models, there was a slight increase in the space heating energy consumption and a reduction in the cooling energy consumption. During the heating season, the PV arrays reduce the solar irradiance on the roofs of the homes, and this slightly increases the heating demand of the home. On the other hand, during the cooling season, the additional shading on the roofs helps to reduce the cooling load for the homes. For example, when the PV arrays were included in the E+v1 model for House B the space heating electricity consumption increased by 551MJ (477MJ from the heat pump and $74 \mathrm{MJ}$ increase in energy consumption by the fireplaces). During the cooling season, the cooling electricity consumption was reduced by 119MJ. Table 21 shows the values for space heating and cooling outputs from the E+ v1 model for House B with and with the PV arrays. The other models for all homes showed similar trends.

Table 21: Space heating and cooling energy consumption from the E+ v1 model of House B with and without PV arrays.

\begin{tabular}{|l|l|l|l|}
\hline & Without PV arrays & With PV arrays & Difference \\
\hline $\begin{array}{l}\text { Heating electricity } \\
\text { consumption }\end{array}$ & $61,529 \mathrm{MJ}$ & $62,006 \mathrm{MJ}$ & $+477 \mathrm{MJ}$ \\
\hline $\begin{array}{l}\text { Heating natural gas } \\
\text { consumption }\end{array}$ & $36,854 \mathrm{MJ}$ & $36,928 \mathrm{MJ}$ & $+74 \mathrm{MJ}$ \\
\hline $\begin{array}{l}\text { Cooling electricity } \\
\text { consumption }\end{array}$ & $1,512 \mathrm{MJ}$ & $1,393 \mathrm{MJ}$ & $-119 \mathrm{MJ}$ \\
\hline
\end{tabular}

Within the HOT2000 program the user is unable to add exterior shading devices besides those that affect fenestrations. Any physical shading devices such as PV arrays that are installed on the building cannot be simulated in HOT2000, which neglects the impacts that the shading devices have on the heating and cooling demand of the building being modeled. The changes in space 
heating and cooling energy consumptions seen for the homes modeled here were minimal, but nonetheless a difference between the two programs used that showcased the limitations of HOT2000.

\subsubsection{Humidification}

To the author's knowledge, there is no inclusion of humidification in the HOT2000 program. All the homes included in the study included an electric humidifier that was part of the forced air system that provided humidification during the heating season. Table 22 shows the humidifier electricity consumption for each home. The humidifier electricity consumption for the homes were minimal compared to space heating and DHW energy consumptions, but nonetheless a key part of the HVAC system during the heating season to provide thermal comfort to the occupants.

Table 22: Humidifier electricity consumption in each of the homes included in the study.

(Values are from the $\mathbf{E}+$ calibrated models.)

\begin{tabular}{|l|l|l|l|}
\hline & House A & House B & House C \\
\hline $\begin{array}{l}\text { Humidifier electricity } \\
\text { consumption }\end{array}$ & $5,990 \mathrm{MJ}$ & $4,260 \mathrm{MJ}$ & $2,196 \mathrm{MJ}$ \\
\hline
\end{tabular}

It would be recommended that the energy modeling program used for the EnerGuide rating output consider the electricity consumption of humidifiers, and include the energy consumption for humidification in the estimated space heating consumption calculation. Humidification may not provide heat to the space but it contributes to providing a comfortable living environment for the occupants during the heating season similar to the role of ventilation which is included.

\subsubsection{Flexibility}

As mentioned in several sections, EnergyPlus has a greater ability to customize inputs compared to HOT2000, and at the same time have more inputs required by the user. One instance where the author found HOT2000 to be restricting was when the H2K v3 model was created for House $\mathrm{C}$ with an increased base load consumptions and occupancy schedule. Once the values were 
doubled to take into account two households, the internal gains from the additional loads and people could not be adjusted by the user for it to not affect the space heating demands as significantly as it did. Due to the internal gains from the added base loads, the estimated space heating electricity consumption by the program for the home was significantly reduced, resulting in a significantly underestimated prediction. When modeling internal gains from people, light fixtures and interior equipment in EnergyPlus, the user is able to specify the fraction of radiant heating energy given off by people, lights and electric equipment, and have control over the usable internal gain in the building.

Not only did HOT2000 lack the ability to alter internal gains, but the program was found to be limited in its abilities to model the HVAC and DHW systems found in the homes in this study, and the required input fields in HOT2000 are the bare minimum representations of the equipment.

\subsection{Calibrating EnergyPlus Models}

The E+ calibrated models were calibrated to the best of the author's ability given the data available. Hourly electricity consumption are available for House A and B, but the author was not aware of their availability early on and was not able to update the E+ calibrated models to be calibrated to hourly data within the time frame of completing this thesis report. Calibrating the EnergyPlus models further to hourly data may require specific occupant behaviour information for each of the homes which may not be permitted by the ethic review board.

There were several obstacles in calibrating the EnergyPlus models. One specifically pertains to House C, where there was a lack of data available to the author. The author was never able to obtain the ground heat exchanger bore hole specifications for the building, and so the values used in House A were utilized since the buildings were similar in size. The questionnaire was not completed 
by the homeowner, but several inputs for the calibrated model were clarified through communication via email to finalize the $\mathrm{E}+$ calibrated model for House C.

The calibration process could have been made easier if the homes were sub-metered to have the data on the specific energy consumptions of certain equipment installed in the homes, and the confidence in the breakdown of the energy consumption in each home would be heightened. But having sub-metering installed in all the homes would be invasive and they would have to be installed in advance to gather enough data for a sufficient period of time.

Finally, when modeling ground source heat pumps in EnergyPlus, the vertical ground heat exchanger input parameter is used. There are several required inputs that pertain to the bore holes, ground, grout and pipe specifications. The user is also required to input the G-function data pairs (thermal response factors) for the bore hole arrangement specified. These non-dimensional Gfunction data points are generated by programs that model ground source heat pumps. A program to generate the G-function points was not easily accessible, instead the values were derived from the graph created by Bernier (2013), and therefore the data points used may not be the exact values that they ought to be. The use of G-function data points generated by an appropriate program would increase the accuracy of the models.

Understanding the limitations and obstacles, the author worked around them to create the energy models presented in this report. Improvements can be made in the models if resources were readily available.

\subsubsection{End-Use Energy Consumption Breakdown}

Since the homes in this study were not sub-metered, the actual end-use energy consumption breakdown is unknown, besides the distinction between electricity and natural gas consumption, therefore the accuracy of the end-use energy consumption breakdown of the E+ calibrated models 
are uncertain. When the homes were modeled in EnergyPlus, the breakdown in the energy consumption differed from those of HOT2000. This was mainly due to the variation in the HVAC and DHW system modeled, and inclusions of pumps and humidifier electricity consumptions in EnergyPlus. The investigation of the accuracy of EnergyPlus' end-use energy consumption breakdown in comparison to the actual is definitely an interesting work that can be pursued by researchers with access to sub-metered homes. 


\section{Conclusion}

The performance gap between the predicted and actual energy consumptions of 3 LEED for Homes certified buildings were investigated and the energy modeling program used for obtaining the EnerGuide rating for the LEED for Homes certification process was compared against a dynamic energy simulation program to assess the applicability of the use of the former for these energy efficient homes. This study had a small sample size and is not meant to draw conclusions of homes in Southern Ontario, but to provide a foundation for assessing the performance gap for residential homes and completing the feedback loop.

\subsection{Energy Performance Gap for LEED Certified Residential Homes}

For the homes included in this study, the actual energy use of the homes did not correlate well with the design stage energy modeling predictions. The energy performance gap of the homes ranged from 15,797 to $68,282 \mathrm{MJ}$ (a 23 to $77 \%$ increase in actual energy consumption compared to the predicted energy consumption by the consultants during the design stage for the homes). After the original energy models for the homes were revised to represent the homes to the best of the program's abilities, and correcting for input discrepancies, the gaps were reduced and narrowed down to $6,806 \sim 61,864 \mathrm{MJ}$ (in H2K v2).

\subsection{Sources of the Discrepancies}

There were several sources of discrepancies found for the performance gaps, one them being the energy modeling program used to estimate the energy consumption of the home was found to be limited in its capabilities of modeling the HVAC and DHW systems present in the homes. When a dynamic energy simulation program which has the capabilities of modeling the HVAC and DHW systems in the homes was used, without the added inputs for additional loads and occupancy behaviour, the performance gaps were further narrowed down to range from 611 to $51,777 \mathrm{MJ}$. The majority of the discrepancies in the energy consumption can be attributed to 
additional loads and energy consumption of special functions that were not included in the predicted energy consumption of the home.

The EnerGuide rating calculation methodology has a preset base load energy consumption that is assumed for the home regardless of the fixtures and equipment that are planned to be installed in the home that may predict a higher or lower base load energy consumption than the actual. The assumptions for the EnerGuide rating calculation are also limited to assessing buildings with one household which became an issue for House $\mathrm{C}$ which houses two households.

Occupant behaviour was also found to play a role in the magnitude of the performance gap. Energy efficient behaviours on the part of the occupants helped to reduce the total energy consumption of the home and reduce the performance gap created by additional loads or other discrepancies. On the other hand, occupant behaviour that deviated from the EnerGuide assumptions, such as higher heating set point temperatures, increased the gap between the predicted and actual energy consumption for the home.

\subsection{Added Value of Using a Dynamic Energy Simulation Program}

The basic energy modeling program that is used to generate the EnerGuide rating for the LEED for Homes submission was compared to the dynamic energy simulation program, and in order to assess the value in using a dynamic energy simulation program, the resulting EnerGuide rating from the outputs of the models created in each of the programs were compared. The EnerGuide rating calculated from the outputs of the EnergyPlus models for 2 out of the 3 homes were found to have a higher rating than those generated from the HOT2000 program. The increase in the EnerGuide rating was a result of lower space heating or DHW energy consumption when the actual HVAC and DHW systems in the homes are represented in the EnergyPlus model, in combination with a higher PV electricity generation estimated by EnergyPlus. With the use of 
EnergyPlus the user is able to model the systems and components that are physically in the home, along with the shading effect of PV arrays on roofs and humidification, which are not possible in HOT2000. Not only is the assessed home more accurately represented in the energy model, but a higher EnerGuide rating for the home in turn grants additional points for the home under the "Energy \& Atmosphere" category for the LEED for Homes certification process.

Taking into consideration occupant behaviour and additional loads may be difficult to do when predicting the energy consumption of a home. But the energy model should accurately reflect the home it is representing (at least in terms of assemblies and equipment) in order to eliminate any resulting performance gaps from inputs or model representation discrepancies. When the HOT2000 were revised to account for as-built differences, the predicted total energy consumptions of the homes were close to the actual (when additional loads were excluded), indicating that the results may be sufficient given that creating the models in HOT2000 is not very time consuming (albeit the breakdown of the energy consumption is uncertain). The findings from this study should however, encourage updates to the HOT2000 program to expand the program's capabilities to include HVAC and DHW systems that are currently being installed in energy efficient homes, or consider welcoming the use of a more versatile energy modeling programs to model the homes. Additionally, the study highlighted the importance of reviewing HOT2000 models to ensure that the models represent the as-built buildings to generate a close to accurate EnerGuide rating for the home. A program like EnergyPlus could be used when an accurate and more detailed energy modeling of a building is necessary.

Analysis of the EnerGuide rating values showed that the ratings are not comparable in terms of carbon intensities when homes of varying sizes are compared, and the current calculation method gives an unfair advantage to homes using natural gas. In addition to the improvements in the energy 
modeling program used for LEED for Homes, it would be in the best interest for the housing industry to improve the EnerGuide rating or have the inclusion of a rating system for design stage energy consumption of homes that can be benchmarked, and also have the capabilities to be applied to the actual energy consumption of the home during occupancy. This will encourage friendly competition amongst stakeholders, contribute towards a database for benchmarking energy efficient homes, and complete the feedback loop to narrow the design to operation performance gap in energy efficient homes. 


\section{Future Work}

This research sets precedence for the analysis of performance gaps of other LEED for Homes certified and future work could investigate if similar sources of discrepancies are found for other homes. The collection of residential home energy consumption can contribute to the benchmarking of LEED certified homes where home owners and designers can see where their building stands in comparison to other energy efficient homes. Benchmarking the energy consumption of residential homes will create a knowledge base and generate friendly competition amongst designers, and hopefully encourage energy efficient behaviours by occupants.

It was found that EnergyPlus models can be calibrated to match actual energy consumptions of a home, but the accuracy of the end-use distribution of energy for the homes was uncertain. A study which includes homes that are sub-metered could investigate the likeness in the simulated enduse distribution by a dynamic energy simulation program such as EnergyPlus to the actual end-use distribution of energy for homes.

An investigation of the EnerGuide rating system once the updated calculations are released may be warranted, and possibly conduct a comparison with other energy efficiency rating for residential homes. 


\section{Appendix A: Raw Data Used for Figure 2}

The following tables include the raw data that was used to plot the graph in Figure 2. The building types are as follows:

- Detached house (D1-2)

- Flat (F1-5)

- Maisonette (M1)

- Semi-detached house (SD1-2)

- Terraced house (T1-2)

The zero carbon energy component was not included in Figure 2.

Table 23: Raw data for the energy use intensity of residential buildings used in figure 2. Data obtained from CarbonBuzz. Buildings with both design and actual data were plotted on figure 2 .

\begin{tabular}{|c|c|c|c|c|c|c|c|c|c|c|}
\hline \multirow{3}{*}{$\begin{array}{l}\text { Building } \\
\text { code }\end{array}$} & \multicolumn{10}{|c|}{ Annual energy use intensity (in $\mathrm{kWh} / \mathrm{m}^{2}$ ) } \\
\hline & \multicolumn{5}{|c|}{ Design data } & \multicolumn{5}{|c|}{ Actual data } \\
\hline & Electricity & Thermal & $\begin{array}{l}\text { Total } \\
\text { energy } \\
\text { use } \\
\text { intensity }\end{array}$ & $\begin{array}{l}\text { Zero } \\
\text { carbon } \\
\text { energy }\end{array}$ & $\begin{array}{l}\text { Net } \\
\text { total }\end{array}$ & Electricity & Thermal & $\begin{array}{l}\text { Total } \\
\text { energy } \\
\text { use } \\
\text { intensity }\end{array}$ & $\begin{array}{l}\text { Zero } \\
\text { carbon } \\
\text { energy }\end{array}$ & $\begin{array}{l}\text { Net } \\
\text { total }\end{array}$ \\
\hline D1 & 16 & 0 & 16 & -14 & 2 & & & & & $\mathbf{N} / \mathbf{A}$ \\
\hline D2 & 66 & 161 & 227 & -7 & 220 & & & & & $\mathbf{N} / \mathbf{A}$ \\
\hline F1 & 15 & 47 & 62 & -8 & 54 & & & & & N/A \\
\hline F2 & 7 & 79 & 86 & -13 & 73 & & & & & $\mathbf{N} / \mathbf{A}$ \\
\hline F3 & 6 & 88 & 94 & -10 & 84 & & & & & $\mathbf{N} / \mathbf{A}$ \\
\hline F4 & 6 & 57 & 63 & 0 & 63 & & & & & N/A \\
\hline F5 & 15 & 50 & 65 & 0 & 65 & 25 & 50 & 75 & 0 & 75 \\
\hline M1 & 43 & 158 & 201 & 0 & 201 & & & & & N/A \\
\hline SD1 & 25 & 50 & 75 & -20 & 55 & & & & & N/A \\
\hline SD2 & 30 & 82 & 112 & -20 & 92 & 21 & 42 & 63 & -20 & 43 \\
\hline SD3 & 20 & 95 & 115 & 0 & 115 & & & & & N/A \\
\hline T1 & 21 & 37 & 58 & 0 & 58 & & & & & N/A \\
\hline $\mathrm{T} 2$ & 87 & 0 & 87 & 0 & 87 & 65 & 0 & 65 & 0 & 65 \\
\hline
\end{tabular}


Table 24: Raw data for the annual energy consumption of the residential buildings.

\begin{tabular}{|l|l|l|l|l|l|l|l|l|}
\hline \multirow{2}{*}{$\begin{array}{l}\text { Building } \\
\text { code }\end{array}$} & \multicolumn{7}{|c|}{ Annual energy consumption (in kWh) } \\
\cline { 2 - 9 } & Electricity & Thermal & $\begin{array}{l}\text { Zero } \\
\text { carbon } \\
\text { energy }\end{array}$ & $\begin{array}{l}\text { Net } \\
\text { total }\end{array}$ & Electricity & Thermal & $\begin{array}{l}\text { Zero } \\
\text { carbon } \\
\text { energy }\end{array}$ & $\begin{array}{l}\text { Net } \\
\text { total }\end{array}$ \\
\hline D1 & 11073 & 0 & -9992 & $\mathbf{1 0 8 1}$ & & & & N/A \\
\hline D2 & 43296 & 106194 & -4356 & $\mathbf{1 4 5 1 3 4}$ & & & N/A \\
\hline F1 & 1460 & 4700 & -770 & $\mathbf{5 3 9 0}$ & & & N/A \\
\hline F2 & 9485 & 106368 & -17344 & $\mathbf{9 8 5 0 9}$ & & & & N/A \\
\hline F3 & 4045 & 56753 & -6613 & $\mathbf{5 4 1 8 5}$ & & & & N/A \\
\hline F4 & 8934 & 85469 & 0 & $\mathbf{9 4 4 0 3}$ & & & & N/A \\
\hline F5 & 15000 & 50000 & 0 & $\mathbf{6 5 0 0 0}$ & 25000 & 50000 & 0 & 75000 \\
\hline M1 & 3655 & 13430 & 0 & $\mathbf{1 7 0 8 5}$ & & & & N/A \\
\hline SD1 & 296 & 599 & -228 & $\mathbf{6 6 7}$ & & & & N/A \\
\hline SD2 & 5000 & 13433 & -3107 & $\mathbf{1 5 3 2 6}$ & 3471 & 6865 & -3404 & 6932 \\
\hline SD3 & 2400 & 11400 & 0 & $\mathbf{1 3 8 0 0}$ & & & & N/A \\
\hline T1 & 2842 & 5032 & 0 & $\mathbf{7 8 7 4}$ & & & & N/A \\
\hline T2 & 6560 & 0 & 0 & $\mathbf{6 5 6 0}$ & 4905 & 0 & 0 & 4905 \\
\hline
\end{tabular}




\section{Appendix B: Questionnaire}

Attached is a sample of the questionnaire distributed to one of the households, along with the ethic's approval that the questionnaires used in this study were included under.

\section{Post-Occupancy Evaluation Home Survey}

\section{Consent agreement}

Please read this form and ask any questions before providing your consent.

The purpose of this questionnaire is to better understand how energy is used within your household. Your input will help generate the inputs for the energy modeling of your home to closely match your actual energy consumption on your energy bill.

This study is supervised by Dr. Mark Gorgolewski in Ryerson's Department of Architectural Science and is part of Moe Otsubo's thesis.

In order to participate in the questionnaire you must first provide your consent at the bottom of this form. Participation of this questionnaire is voluntary and your choice of whether or not to participate will not influence your future relations with Ryerson University. You are free to skip questions that make you uncomfortable or to withdraw your consent and stop your participation at any time.

Please rest assured that the information gathered from this questionnaire will only be used for the sole purpose of calibrating the energy model of your home and will not be used or distributed for any other purpose.

Please contact Moe Otsubo if you have any questions about the questionnaire.

Email: moe.otsubo@ryerson.ca

If you have questions regarding your rights as a human subject and as a participant in this study, you may contact the Ryerson University Research Ethics Board for information:

Research Ethics Board, c/o Office of the Vice President, Research and Innovation

Ryerson University

350 Victoria Street

Toronto, ON

M5B $2 K 3$

General consent:

By initialing below, you are indicating that you have read the information in this agreement and have had the opportunity to ask any questions. You agree to be in the study and have been informed that you can change your mind and withdraw your consent to participate at any time. By consenting you are not giving up any of your legal rights. 


\section{Instructions}

Please answer as many questions as you can and write any additional comments in the spaces provided. If you do not have an answer for a question, please leave it blank.

Once completed, please save the changes and return back via email to: moe.otsubo@ryerson.ca

If you have any questions please contact Moe Otsubo.

Email: moe.otsubo@ryerson.ca

Thank you for your participation.

\section{Background}

When did you move into your home? (MM/YYYY format)

How many people live with you who are over 18 ?

How many people live with you who are under 18 ?

When is your home usually occupied?

$\square$ Most of the time

$\square$ Evenings and weekends only

$\square$ Other:

\section{Air and Temperature}

Please indicate if you use any of the items below (Please check all that apply)

$\begin{array}{ll}\square \text { Ceiling fan } & \square \text { Portable fan } \\ \square \text { Portable heater } \\ \square \text { Other } \quad \square \text { Window or balcony door }\end{array}$

Please describe how, when, and why you use these items. 
How often is the fireplace used in the following months:

\begin{tabular}{|c|c|c|c|c|c|}
\hline & Never & $\begin{array}{l}\text { A few times a } \\
\text { week }\end{array}$ & $\begin{array}{c}\text { A few hours } \\
\text { everyday }\end{array}$ & $\begin{array}{l}\text { Majority of the } \\
\text { day everyday }\end{array}$ & $\begin{array}{c}\text { Always on all } \\
\text { day }\end{array}$ \\
\hline September & 0 & 0 & 0 & 0 & 0 \\
\hline October & O & $\mathrm{O}$ & $\bigcirc$ & O & $\mathrm{O}$ \\
\hline November & 0 & 0 & $\mathrm{O}$ & 0 & 0 \\
\hline December & O & $\mathrm{O}$ & $\mathrm{O}$ & $\bigcirc$ & $\mathrm{O}$ \\
\hline January & 0 & 0 & 0 & 0 & 0 \\
\hline February & 0 & $\mathrm{O}$ & $\mathrm{O}$ & $\bigcirc$ & $\bigcirc$ \\
\hline March & 0 & 0 & 0 & 0 & 0 \\
\hline April & $\mathrm{O}$ & 0 & $\mathrm{O}$ & $\bigcirc$ & $\mathrm{O}$ \\
\hline
\end{tabular}

How would you rate your ability to control the following:

\begin{tabular}{|c|c|c|c|c|c|c|c|}
\hline & $\begin{array}{c}\text { No } \\
\text { Control } \\
\text { (1) }\end{array}$ & 2 & 3 & 4 & 5 & 6 & $\begin{array}{l}\text { Full } \\
\text { control } \\
(7)\end{array}$ \\
\hline Heating & 0 & 0 & 0 & 0 & 0 & 0 & 0 \\
\hline Cooling & O & $\bigcirc$ & $\bigcirc$ & $\bigcirc$ & $\bigcirc$ & $\bigcirc$ & 0 \\
\hline Ventilation & 0 & 0 & 0 & 0 & 0 & 0 & 0 \\
\hline
\end{tabular}

What is the setpoint temperature on your home's thermostat in the winter?

What is the setpoint temperature on your home's thermostat in the summer?

How often do you adjust your thermostat in the following seasons?

\begin{tabular}{|l|c|c|c|c|c|c|c|}
\hline & Often (1) & 2 & 3 & 4 & 5 & 6 & $\begin{array}{c}\text { Not often } \\
\text { at all (7) }\end{array}$ \\
\hline Winter & $\bigcirc$ & 0 & $\bigcirc$ & $\bigcirc$ & 0 & $\bigcirc$ & $\bigcirc$ \\
\hline Summer & $\bigcirc$ & $\bigcirc$ & $\bigcirc$ & $\bigcirc$ & $\bigcirc$ & $\bigcirc$ & $\bigcirc$ \\
\hline
\end{tabular}


Please rate how often you open or close windows to adjust the temperature in your home during winter and summer.

\begin{tabular}{|l|c|c|c|c|c|c|c|}
\hline & Never (1) & 2 & 3 & 4 & 5 & 6 & Often (7) \\
\hline Winter & $\bigcirc$ & 0 & 0 & $\bigcirc$ & 0 & 0 & $\bigcirc$ \\
\hline Summer & $\bigcirc$ & $\bigcirc$ & $\bigcirc$ & $\bigcirc$ & $\bigcirc$ & $\bigcirc$ & $\bigcirc$ \\
\hline
\end{tabular}

Are there rooms in your home which are often too hot or too cold?

Yes

No

Don't know

If yes, please specify the times of day and times of year when this is a problem.

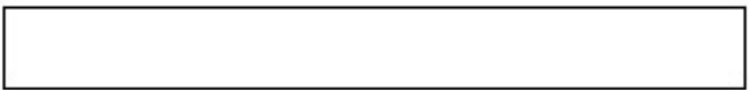

Insert comments regarding thermal comfort, heating, cooling and/or ventilation:

\section{Lighting}

Do you need to turn lights on during the day?

Daily

Sometimes

Never

Don't know

Please specify which rooms require lights during the day

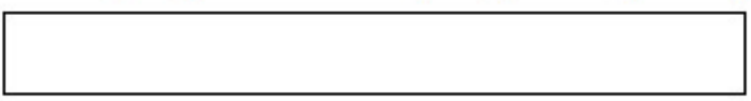

For each zone (a grouping of rooms) please indicate the time ranges that lights are turned on.

Time range(s) that lights are on on the Main Floor

Time range(s) that lights are on in the Master Bedroom and attached washroom 
Time range(s) that lights are on in the Bedroom and Office (including the hallway lights)

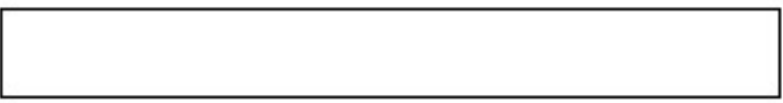

Time range(s) that lights are on in the Basement

For each zone please indicate the total number of light bulbs in lighting fixtures.

Number of lighting bulbs on the Main Floor (whole ground floor including washroom):

Number of lighting bulbs in the Master Bedroom (including en suite bathroom)

Number of lighting bulbs in the Bedroom and Office (including hallway washroom and staircase up to 3 rd floor)

Number of lighting bulbs in the Basement

Please check the type(s) of light bulbs used in your household (check all that apply)

$\square$ Incandescent

$\square \mathrm{CFL}$

$\square$ LED

$\square$ Don't know

$\square$ Other

How many exterior light fixtures are used on your property?

Please indicate the approximate wattage of the exterior light fixtures (leave blank if not known).

Insert comments regarding lighting conditions: 


\section{Energy use: Kitchen}

What is the electricity usage of the refrigerator in your household? (Please indicate units used. If unknown, please indicate the brand and model number of your refrigerator)

How often are the following small kitchen appliances used in your household?

\begin{tabular}{|l|c|c|c|c|c|}
\hline & Never & Rarely & Occasionally & Frequently & Always \\
\hline Microwave & 0 & 0 & 0 & 0 & 0 \\
\hline Toaster oven & 0 & 0 & 0 & 0 & 0 \\
\hline Blender/mixer & 0 & 0 & 0 & 0 & 0 \\
\hline Rice cooker & 0 & 0 & 0 & 0 & 0 \\
\hline Slow cooker & 0 & 0 & 0 & 0 & 0 \\
\hline
\end{tabular}

Please note any other small kitchen appliances that are used frequently in your household, and how often they are used:

How often is the outdoor barbeque set used on a weekly basis in the following months?

\begin{tabular}{|c|c|c|c|c|c|}
\hline & Never & $\begin{array}{c}1-2 \text { days a } \\
\text { week }\end{array}$ & $\begin{array}{c}\text { 3-4 days a } \\
\text { week }\end{array}$ & $\begin{array}{c}5-6 \text { days a } \\
\text { week }\end{array}$ & 7 days a week \\
\hline April & 0 & 0 & 0 & 0 & $\bigcirc$ \\
\hline May & $\bigcirc$ & $\bigcirc$ & $\bigcirc$ & $\bigcirc$ & $\bigcirc$ \\
\hline June & 0 & 0 & 0 & 0 & 0 \\
\hline July & $\mathrm{O}$ & $\bigcirc$ & $\mathrm{O}$ & $\mathrm{O}$ & $\mathrm{O}$ \\
\hline August & 0 & 0 & 0 & $\bigcirc$ & 0 \\
\hline September & 0 & $\bigcirc$ & $\bigcirc$ & $\bigcirc$ & $\bigcirc$ \\
\hline October & 0 & 0 & 0 & 0 & 0 \\
\hline
\end{tabular}

Please try and specify the approximate natural gas consumption of one cooking session by the barbeque set. 
How often do you have a cooked breakfast at home on average on a weekly basis? (As opposed to a cold breakfast i.e. yogurt, cereal, or eating out)
Never
Rarely
Occasionally
Frequently
Always

How often are the following meals cooked at home on average on a weekly basis?

\begin{tabular}{|c|c|c|c|c|c|}
\hline & Never & Rarely & Occasionally & Frequently & Always \\
\hline Lunch & & & 0 & & \\
\hline Dinner & & 0 & 0 & ก & \\
\hline
\end{tabular}

\section{Energy use: Bedroom, office and living room}

How many hours on average are the following electronics used on a daily basis? If there are more than one of the following electronics in the household being used please sum up the total usage hours.

Personal computer (desktop and/or laptop)

Computer monitor

Television (and associated electronics, e.g. cable box, DVD player)

Please list any other electronics used on a daily basis that would have a noticeable impact on your electricity consumption.

How many times does your household use the dryer on a weekly basis?

Insert comments regarding energy use in your household: 


\section{Domestic hot water use}

Please specify the type of shower head used in your household:

Old fixture (about 5.5 gallons per minute)

Low flow (aerating or laminar flow)

Or specify (in gpm):

How often is a shower taken in your household every week?

Please indicate the average length of showers taken in your household (in minutes).

How often is a bath taken in your household every week?

Do you take cooler baths and/or showers in the summers?

(1) Yes

No

Not sure

How many times does your household use your dishwasher per week?

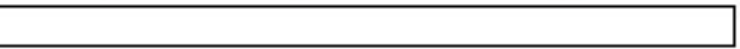

How many times does your household use the washer per week?

When laundry loads are done, what percentage of the loads are done using cold water?

Insert comments regarding domestic hot water use:

\section{Other}

If you have anything else you would like to add which would be relevant to the topics raised please mention them here.

Thank you for your help and your continued support.

Once completed, please save the changes and return to Moe Otsubo via email: moe.otsubo@ryerson.ca 


\section{RYERSONUNIVERSITY}

RESEARCH ETHICS BOARD

\section{To: Craig Brown}

Environmental Applied Science and Management

Re: REB 2012-240: Occupant Satisfaction and Behaviour in Green-intent Multi-Unit Residential Buildings and Office Settings

Date: September 29, 2014

\section{Dear Craig Brown,}

The review of your protocol REB File REB 2012-240 is now complete. This is a renewal for REB File. The project has been approved for a one year period. Please note that before proceeding with your project, compliance with other required University approvals/certifications, institutional requirements, or governmental authorizations may be required.

This approval may be extended after one year upon request. Please be advised that if the project is not renewed, approval will expire and no more research involving humans may take place. If this is a funded project, access to research funds may also be affected.

Please note that REB approval policies require that you adhere strictly to the protocol as last reviewed by the REB and that any modifications must be approved by the Board before they can be implemented. Adverse or unexpected events must be reported to the REB as soon as possible with an indication from the Principal Investigator as to how, in the view of the Principal Investigator, these events affect the continuation of the protocol.

Finally, if research subjects are in the care of a health facility, at a school, or other institution or community organization, it is the responsibility of the Principal Investigator to ensure that the ethical guidelines and approvals of those facilities or institutions are obtained and filed with the REB prior to the initiation of any research.

Please quote your REB file number (REB 2012-240) on future correspondence.

Congratulations and best of luck in conducting your research.

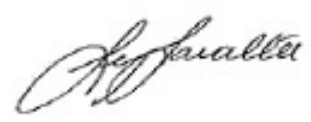

Lynn Lavallée, Ph.D.

Chair, Research Ethics Board 
Appendix C: Energy Consumption Outputs from Energy Modeling for All Homes

The following tables contain the outputs from each of the energy model for the homes in the study and the values used in the EnerGuide rating calculations.

\section{House A:}

Table 25: Energy model energy consumption outputs for House A.

\begin{tabular}{|c|c|c|c|c|c|c|c|}
\hline $\begin{array}{l}\text { Energy } \\
\text { consumption } \\
\text { (in MJ) }\end{array}$ & H2K v1 & H2K v2 & H2K v3 & $E+v 1$ & $E+v 2$ & $\begin{array}{l}\text { E+ } \\
\text { calibrated }\end{array}$ & Actual \\
\hline $\begin{array}{l}\text { Space } \\
\text { heating - } \\
\text { electricity }\end{array}$ & 16,191 & 24,571 & 24,216 & 16,260 & 27,139 & 25,971 & \\
\hline $\begin{array}{l}\text { Space } \\
\text { heating - } \\
\text { natural gas }\end{array}$ & 6,462 & 61 & 61 & 10,050 & 2,380 & 10,780 & \\
\hline $\begin{array}{l}\text { Space } \\
\text { cooling }\end{array}$ & 0 & 0 & 5,520 & 4,600 & 4,830 & 3,240 & \\
\hline Fans & 584 & 2,339 & 3,847 & 2,640 & 3,560 & 3,560 & \\
\hline HRV & 2,415 & 2,266 & 3,565 & 3,750 & 3,560 & 2,670 & \\
\hline Pumps & 0 & 0 & 0 & 1,230 & 2,720 & 2,720 & \\
\hline Humidifier & 0 & 0 & 0 & 0 & 1,860 & 5,990 & \\
\hline DHW & 11,628 & 17,033 & 17,027 & 17,020 & 6,411 & 4,458 & \\
\hline Lighting & 4,468 & 4,468 & 3,942 & 3,940 & 3,940 & 4,080 & \\
\hline Exterior use & 5,256 & 5,256 & 5,256 & 5,260 & 5,260 & 3,713 & \\
\hline Appliances & 11,826 & 11,826 & 18,396 & 18,400 & 18,400 & 10,385 & \\
\hline Other & 9,986 & 9,986 & 3,942 & 3,942 & 3,942 & 7,046 & \\
\hline TOTAL & 68,815 & 77,806 & 85,772 & 87,092 & 84,002 & 84,613 & 85,311 \\
\hline
\end{tabular}


Table 26: EnerGuide calculation values for House A energy models.

\begin{tabular}{|c|c|c|c|c|c|c|c|}
\hline & Units & H2K v1 & H2K v2 & H2K v3 & $E+v 1$ & $E+v 2$ & $\begin{array}{l}\text { E+ } \\
\text { calibrated }\end{array}$ \\
\hline $\begin{array}{l}\text { Estimated } \\
\text { space } \\
\text { heating } \\
\text { consumption }\end{array}$ & MJ & 25,002 & 29,224 & 29,701 & 29,735 & 35,567 & 41,959 \\
\hline $\begin{array}{l}\text { Estimated } \\
\text { occupancy } \\
\text { consumption }\end{array}$ & $M J$ & 43,160 & 48,564 & 48,557 & 48,557 & 38,236 & 29,965 \\
\hline $\begin{array}{l}\text { PV energy } \\
\text { generation }\end{array}$ & $M J$ & 16,487 & 16,477 & 16,477 & 19,585 & 19,723 & 19,504 \\
\hline $\begin{array}{l}\text { Net } \\
\text { estimated } \\
\text { total energy } \\
\text { consumption }\end{array}$ & MJ & 51,676 & 61,311 & 61,781 & 58,706 & 54,080 & 52,420 \\
\hline $\begin{array}{l}\text { Space } \\
\text { heating } \\
\text { benchmark }\end{array}$ & MJ & 43,606 & 43,606 & 43,606 & 51,467 & 51,467 & 51,467 \\
\hline $\begin{array}{l}\text { DHW } \\
\text { benchmark }\end{array}$ & $M J$ & 16,633 & 16,633 & 16,633 & 16,633 & 16,633 & 16,633 \\
\hline $\begin{array}{l}\text { Base load } \\
\text { benchmark }\end{array}$ & $M J$ & 31,536 & 31,536 & 31,536 & 31,536 & 31,536 & 31,536 \\
\hline $\begin{array}{l}\text { Benchmark } \\
\text { total energy } \\
\text { consumption }\end{array}$ & MJ & 94,761 & 94,761 & 94,761 & 102,621 & 102,621 & 102,621 \\
\hline $\begin{array}{l}\text { Energy } \\
\text { efficiency } \\
\text { rating ( } 2 \\
\text { decimal } \\
\text { places) }\end{array}$ & & 89.09 & 87.06 & 86.96 & 88.56 & 89.46 & 89.78 \\
\hline $\begin{array}{l}\text { EnerGuide } \\
\text { rating }\end{array}$ & & 89 & 87 & 87 & 89 & 89 & 90 \\
\hline
\end{tabular}




\section{House B:}

Table 27: Energy model energy consumption outputs for House B.

\begin{tabular}{|l|l|l|l|l|l|l|l|}
\hline $\begin{array}{l}\text { Energy } \\
\text { consumption } \\
\text { (in MJ) }\end{array}$ & H2K v1 & H2K v2 & H2K v3 & E+ v1 & E+ v2 & $\begin{array}{l}\text { E+ } \\
\text { calibrated }\end{array}$ & Actual \\
\hline $\begin{array}{l}\text { Space } \\
\text { heating - } \\
\text { electricity }\end{array}$ & 46,704 & 50,991 & 57,057 & 62,010 & 47,930 & 50,800 & \\
\hline $\begin{array}{l}\text { Space } \\
\text { heating - } \\
\text { natural gas }\end{array}$ & 0 & 68 & 154 & 36,930 & 4,430 & 1,937 & \\
\hline $\begin{array}{l}\text { Space } \\
\text { cooling }\end{array}$ & 0 & 0 & 1,298 & 1,390 & 0 & 0 & \\
\hline Fans & 2,044 & 4,031 & 4,810 & 2,150 & 1,570 & 2,100 & \\
\hline HRV & 0 & 76 & 4,629 & 4,770 & 4,770 & 4,770 & \\
\hline Pumps & 0 & 0 & 0 & 1,600 & 1,480 & 1,600 & \\
\hline Humidifier & 0 & 0 & 0 & 0 & 3,630 & 4,260 & \\
\hline DHW & 16,631 & 16,631 & 16,631 & 8,080 & 18,070 & 25,020 & \\
\hline Lighting & 4,468 & 4,468 & 3,942 & 3,940 & 3,940 & 1,930 & \\
\hline Exterior use & 5,256 & 5,256 & 5,256 & 5,260 & 5,260 & 40,174 & \\
\hline Appliances & 11,826 & 11,826 & 18,396 & 18,400 & 18,400 & 28,212 & \\
\hline Other & 9,986 & 9,986 & 3,942 & 3,940 & 3,940 & 4,393 & \\
\hline TOTAL & 96,915 & 103,333 & 116,115 & 148,470 & 113,420 & 165,197 & 166,351 \\
\hline
\end{tabular}


Table 28: EnerGuide calculation values for House B energy models.

\begin{tabular}{|c|c|c|c|c|c|c|c|}
\hline & Units & H2K v1 & H2K v2 & H2K v3 & $E+v 1$ & $E+v 2$ & $\begin{array}{l}\text { E+ } \\
\text { calibrated }\end{array}$ \\
\hline $\begin{array}{l}\text { Estimated } \\
\text { space heating } \\
\text { consumption }\end{array}$ & MJ & 48,748 & 55,158 & 65,720 & 98,690 & 55,597 & 56,530 \\
\hline $\begin{array}{l}\text { Estimated } \\
\text { occupancy } \\
\text { consumption }\end{array}$ & MJ & 42,305 & 42,305 & 42,305 & 36,772 & 43,241 & 90,910 \\
\hline $\begin{array}{l}\text { PV energy } \\
\text { generation }\end{array}$ & MJ & 22,314 & 22,323 & 22,323 & 26,428 & 26,521 & 18,692 \\
\hline $\begin{array}{l}\text { Net estimated } \\
\text { total energy } \\
\text { consumption }\end{array}$ & MJ & 65,113 & 71,514 & 85,701 & 109,034 & 72,317 & 128,749 \\
\hline $\begin{array}{l}\text { Space heating } \\
\text { benchmark }\end{array}$ & MJ & 65,898 & 65,898 & 65,898 & 71,833 & 71,833 & 71,833 \\
\hline $\begin{array}{l}\text { DHW } \\
\text { benchmark }\end{array}$ & MJ & 16,633 & 16,633 & 16,633 & 16,633 & 16,633 & 16,633 \\
\hline $\begin{array}{l}\text { Base load } \\
\text { benchmark }\end{array}$ & MJ & 31,536 & 31,536 & 31,536 & 31,536 & 31,536 & 31,536 \\
\hline $\begin{array}{l}\text { Benchmark } \\
\text { total energy } \\
\text { consumption }\end{array}$ & MJ & 117,052 & 117,052 & 117,052 & 122,987 & 122,987 & 122,987 \\
\hline $\begin{array}{l}\text { Energy } \\
\text { efficiency } \\
\text { rating ( } 2 \\
\text { decimal } \\
\text { places) }\end{array}$ & & 88.87 & 87.78 & 85.36 & 82.27 & 88.24 & 79.06 \\
\hline $\begin{array}{l}\text { EnerGuide } \\
\text { rating }\end{array}$ & & 89 & 88 & 85 & 82 & 88 & 79 \\
\hline
\end{tabular}




\section{House C:}

Table 29: Energy model energy consumption outputs for House C.

\begin{tabular}{|l|l|l|l|l|l|l|l|}
\hline $\begin{array}{l}\text { Energy } \\
\text { consumption } \\
\text { (in MJ) }\end{array}$ & H2K v1 & H2K v2 & H2K v3 & E+ v1 & E+ v2 & $\begin{array}{l}\text { E+ } \\
\text { calibrated }\end{array}$ & Actual \\
\hline $\begin{array}{l}\text { Space } \\
\text { heating - } \\
\text { electricity }\end{array}$ & 9,086 & 9,116 & 6,286 & 10,870 & 12,500 & 18,022 & \\
\hline $\begin{array}{l}\text { Space } \\
\text { cooling }\end{array}$ & 0 & 0 & 0 & 0 & 0 & 0 & \\
\hline Fans & 464 & 1,167 & 435 & 840 & 1,500 & 3,074 & \\
\hline HRV & 2,666 & 2,667 & 3,879 & 3,880 & 8,140 & 5,723 & \\
\hline Pumps & 0 & 0 & 0 & 1,420 & 4,030 & 3,946 & \\
\hline Humidifier & 0 & 0 & 0 & 0 & 2,360 & 2,196 & \\
\hline DHW & 22,499 & 19,556 & 29,499 & 23,510 & 30,281 & 28,493 & \\
\hline Lighting & 4,468 & 4,468 & 8,935 & 7,880 & 7,880 & 3,507 & \\
\hline Exterior use & 5,256 & 5,256 & 10,512 & 10,510 & 10,510 & 1,092 & \\
\hline Appliances & 11,826 & 11,826 & 23,652 & 23,387 & 23,387 & 23,550 & \\
\hline Other & 9,986 & 9,986 & 19,973 & 19,973 & 19,973 & 27,582 & \\
\hline TOTAL & 66,251 & 64,042 & 103,171 & 102,270 & 120,562 & 117,184 & 117,165 \\
\hline
\end{tabular}


Table 30: EnerGuide calculation values for House C energy models.

\begin{tabular}{|c|c|c|c|c|c|c|c|}
\hline & Units & H2K v1 & H2K v2 & H2K v3 & $E+v 1$ & $E+v 2$ & $\begin{array}{l}\text { E+ } \\
\text { calibrated }\end{array}$ \\
\hline $\begin{array}{l}\text { Estimated } \\
\text { space } \\
\text { heating } \\
\text { consumption }\end{array}$ & MJ & 12,211 & 12,944 & 10,165 & 14,382 & 20,551 & 26,862 \\
\hline $\begin{array}{l}\text { Estimated } \\
\text { occupancy } \\
\text { consumption }\end{array}$ & $M J$ & 54,028 & 51,086 & 92,562 & 85,827 & 93,612 & 85,694 \\
\hline $\begin{array}{l}\text { PV energy } \\
\text { generation }\end{array}$ & $M J$ & 1,840 & 20,141 & 20,141 & 24,189 & 24,481 & 24,479 \\
\hline $\begin{array}{l}\text { Net } \\
\text { estimated } \\
\text { total energy } \\
\text { consumption }\end{array}$ & MJ & 63,517 & 43,007 & 82,586 & 76,019 & 89,682 & 88,077 \\
\hline $\begin{array}{l}\text { Space } \\
\text { heating } \\
\text { benchmark }\end{array}$ & MJ & 47,036 & 47,036 & 47,036 & 57,795 & 57,795 & 57,795 \\
\hline $\begin{array}{l}\text { DHW } \\
\text { benchmark }\end{array}$ & $M J$ & 16,633 & 16,633 & 33,266 & 33,266 & 33,266 & 33,266 \\
\hline $\begin{array}{l}\text { Base load } \\
\text { benchmark }\end{array}$ & MJ & 31,536 & 31,536 & 63,072 & 63,072 & 63,072 & 63,072 \\
\hline $\begin{array}{l}\text { Benchmark } \\
\text { total energy } \\
\text { consumption }\end{array}$ & MJ & 98,190 & 98,190 & 149,345 & 160,104 & 160,104 & 160,104 \\
\hline $\begin{array}{l}\text { Energy } \\
\text { efficiency } \\
\text { rating ( } 2 \\
\text { decimal } \\
\text { places) }\end{array}$ & & 87.06 & 91.24 & 88.94 & 90.50 & 88.80 & 89.00 \\
\hline $\begin{array}{l}\text { EnerGuide } \\
\text { rating }\end{array}$ & & 87 & 91 & 89 & 91 & 89 & 89 \\
\hline
\end{tabular}




\section{Appendix D: Energy and Carbon Intensity Data for All Homes}

The following tables contain the energy use and carbon intensity related values used in section 7.3.1.

\section{House A:}

Table 31: Energy and carbon intensity values for House A.

\begin{tabular}{|c|c|c|c|c|c|c|c|}
\hline & & H2K v1 & H2K v2 & H2K v3 & $E+v 1$ & $E+v 2$ & $\begin{array}{l}\text { E+ } \\
\text { calibrated }\end{array}$ \\
\hline $\begin{array}{l}\text { Total energy } \\
\text { consumption }\end{array}$ & MJ & $68,815.26$ & $77,806.21$ & $85,772.47$ & $87,092.00$ & $84,002.00$ & $84,612.65$ \\
\hline $\begin{array}{l}\text { Total energy } \\
\text { intensity }\end{array}$ & $\mathrm{MJ} / \mathrm{m}^{2}$ & 244.91 & 276.91 & 305.26 & 287.43 & 277.23 & 279.25 \\
\hline $\begin{array}{l}\text { Total carbon } \\
\text { intensity }\end{array}$ & $\mathrm{kgCO}_{2} \mathrm{e} / \mathrm{m}^{2}$ & 10.41 & 11.54 & 12.72 & 12.28 & 11.62 & 11.96 \\
\hline \multicolumn{8}{|c|}{ The following values exclude energy consumption associated with cooling } \\
\hline $\begin{array}{l}\text { Electricity } \\
\text { consumption } \\
\text { (sans } \\
\text { cooling) }\end{array}$ & MJ & $47,253.20$ & $77,737.90$ & $78,208.23$ & $69,251.55$ & $71,663.25$ & $62,223.89$ \\
\hline $\begin{array}{l}\text { Natural gas } \\
\text { consumption } \\
\text { (sans } \\
\text { cooling) }\end{array}$ & MJ & $6,461.82$ & 61.48 & 61.48 & $10,050.00$ & $2,380.00$ & $10,780.00$ \\
\hline $\begin{array}{l}\text { PV energy } \\
\text { offset }\end{array}$ & MJ & $16,486.56$ & $16,476.95$ & $16,476.95$ & $19,585.50$ & $19,723.09$ & $19,504.13$ \\
\hline $\begin{array}{l}\text { Energy use } \\
\text { intensity } \\
\text { (sans } \\
\text { cooling) }\end{array}$ & $\mathrm{MJ} / \mathrm{m}^{2}$ & 186.21 & 218.23 & 219.90 & 212.51 & 193.31 & 190.39 \\
\hline $\begin{array}{l}\text { Carbon } \\
\text { emission } \\
\text { (sans } \\
\text { cooling) }\end{array}$ & $\mathrm{kgCO}_{2} \mathrm{e}$ & $2,925.77$ & $3,242.18$ & $3,261.80$ & $3,395.39$ & $3,106.71$ & $3,139.60$ \\
\hline $\begin{array}{l}\text { PV carbon } \\
\text { offset }\end{array}$ & $\mathrm{kgCO}_{2} \mathrm{e}$ & 686.94 & 686.54 & 686.54 & 816.06 & 821.80 & 812.67 \\
\hline $\begin{array}{l}\text { Net carbon } \\
\text { intensity } \\
\text { (sans } \\
\text { cooling) }\end{array}$ & $\mathrm{kgCO}_{2} \mathrm{e} / \mathrm{m}^{2}$ & 7.97 & 9.09 & 9.16 & 8.51 & 7.54 & 7.68 \\
\hline $\begin{array}{l}\text { EnerGuide } \\
\text { rating }\end{array}$ & & 89 & 88 & 87 & 88 & 89 & 89 \\
\hline
\end{tabular}




\section{House B:}

Table 32: Energy and carbon intensity values for House B.

\begin{tabular}{|c|c|c|c|c|c|c|c|c|}
\hline & & H2K v1 & H2K v2 & H2K v3 & $E+v 1$ & $E+v 2$ & $\begin{array}{l}\text { E+ } \\
\text { calibrate } \\
\text { d } \\
\text { without } \\
\text { boiler }\end{array}$ & $\begin{array}{l}\text { E+ } \\
\text { calibrate } \\
\text { d }\end{array}$ \\
\hline $\begin{array}{l}\text { Total energy } \\
\text { consumption }\end{array}$ & MJ & $96,914.59$ & $103,332.92$ & $116,114.53$ & $148,470.00$ & $113,420.00$ & $125,332.86$ & $165,196.54$ \\
\hline $\begin{array}{l}\text { Total energy } \\
\text { intensity }\end{array}$ & $\mathrm{MJ} / \mathrm{m}^{2}$ & 227.77 & 242.85 & 272.89 & 310.64 & 237.31 & 262.23 & 345.64 \\
\hline $\begin{array}{l}\text { Total carbon } \\
\text { intensity }\end{array}$ & $\begin{array}{l}\mathrm{kgCO}_{2} \\
\mathrm{e} / \mathrm{m}^{2}\end{array}$ & 13.51 & 14.43 & 16.27 & 18.01 & 14.01 & 15.44 & 17.88 \\
\hline \multicolumn{9}{|c|}{ The following values exclude energy consumption associated with cooling } \\
\hline $\begin{array}{l}\text { Electricity } \\
\text { consumption } \\
\text { (sans } \\
\text { cooling) }\end{array}$ & MJ & $80,283.60$ & $86,632.92$ & $97,117.56$ & $97,920.80$ & $84,305.85$ & $90,794.66$ & $90,794.66$ \\
\hline $\begin{array}{l}\text { Natural gas } \\
\text { consumption } \\
\text { (sans } \\
\text { cooling) }\end{array}$ & MJ & $16,630.99$ & $16,698.92$ & $16,784.25$ & $45,010.00$ & $22,500.00$ & $26,957.48$ & $66,821.16$ \\
\hline $\begin{array}{l}\text { PV energy } \\
\text { offset }\end{array}$ & MJ & $22,314.35$ & $22,323.49$ & $22,323.49$ & $26,428.37$ & $26,520.81$ & $18,691.78$ & $18,691.78$ \\
\hline $\begin{array}{l}\text { Energy use } \\
\text { intensity } \\
\text { (sans } \\
\text { cooling) }\end{array}$ & $\mathrm{MJ} / \mathrm{m}^{2}$ & 227.77 & 242.85 & 267.69 & 299.05 & 223.47 & 246.37 & 299.67 \\
\hline $\begin{array}{l}\text { Carbon } \\
\text { emission } \\
\text { (sans } \\
\text { cooling) }\end{array}$ & $\begin{array}{l}\mathrm{kgCO}_{2} \\
\mathrm{e}\end{array}$ & $4,188.95$ & $4,456.94$ & $4,898.14$ & $6,363.65$ & $4,654.30$ & $5,150.80$ & $7,173.33$ \\
\hline $\begin{array}{l}\text { PV carbon } \\
\text { offset }\end{array}$ & $\begin{array}{l}\mathrm{kgCO}_{2} \\
\mathrm{e}\end{array}$ & 929.76 & 930.15 & 930.15 & $1,101.18$ & $1,105.03$ & 778.82 & 778.82 \\
\hline $\begin{array}{l}\text { Net carbon } \\
\text { intensity } \\
\text { (sans } \\
\text { cooling) }\end{array}$ & $\begin{array}{l}\mathrm{kgCO}_{2} \\
\mathrm{e} / \mathrm{m}^{2}\end{array}$ & 7.66 & 8.29 & 9.33 & 11.01 & 7.43 & 9.15 & 12.16 \\
\hline $\begin{array}{l}\text { EnerGuide } \\
\text { rating }\end{array}$ & & 89 & 87 & 85 & 82 & 88 & 85 & 79 \\
\hline
\end{tabular}




\section{House C:}

Table 33: Energy and carbon intensity values for House C.

\begin{tabular}{|c|c|c|c|c|c|c|c|}
\hline & & H2K v1 & H2K v2 & H2K v3 & $E+v 1$ & $E+v 2$ & $\begin{array}{l}\text { E+ } \\
\text { calibrated }\end{array}$ \\
\hline $\begin{array}{l}\text { Total energy } \\
\text { consumption }\end{array}$ & MJ & $66,251.45$ & $64,042.01$ & $103,171.37$ & $102,270.00$ & $120,561.66$ & $117,183.52$ \\
\hline $\begin{array}{l}\text { Total energy } \\
\text { intensity }\end{array}$ & $\mathrm{MJ} / \mathrm{m}^{2}$ & 189.95 & 183.61 & 295.80 & 255.91 & 301.68 & 293.22 \\
\hline $\begin{array}{l}\text { Total carbon } \\
\text { intensity }\end{array}$ & $\mathrm{kgCO}_{2} \mathrm{e} / \mathrm{m}^{2}$ & 11.61 & 11.22 & 18.08 & 15.64 & 18.44 & 17.92 \\
\hline \multicolumn{8}{|c|}{ The following values exclude energy consumption associated with cooling } \\
\hline $\begin{array}{l}\text { Electricity } \\
\text { consumption } \\
\text { (sans } \\
\text { cooling) }\end{array}$ & MJ & $66,246.05$ & $64,036.25$ & $102,736.49$ & $100,215.74$ & $114,172.50$ & $112,565.16$ \\
\hline $\begin{array}{l}\text { PV energy } \\
\text { offset }\end{array}$ & MJ & $1,840.07$ & $20,141.03$ & $20,141.03$ & $24,189.17$ & $24,481.08$ & $24,479.37$ \\
\hline $\begin{array}{l}\text { Energy } \\
\text { intensity } \\
\text { (sans } \\
\text { cooling) }\end{array}$ & $\mathrm{MJ} / \mathrm{m}^{2}$ & 189.93 & 183.60 & 294.56 & 250.77 & 285.69 & 281.67 \\
\hline $\begin{array}{l}\text { Carbon } \\
\text { emission } \\
\text { (sans } \\
\text { cooling) }\end{array}$ & $\mathrm{kgCO}_{2} \mathrm{e}$ & $2,760.25$ & $2,668.17$ & $4,280.67$ & $4,175.67$ & $4,757.17$ & $4,690.29$ \\
\hline $\begin{array}{l}\text { PV carbon } \\
\text { offset }\end{array}$ & $\mathrm{kgCO}_{2} \mathrm{e}$ & 76.67 & 839.21 & 839.21 & $1,007.88$ & $1,020.04$ & $1,019.97$ \\
\hline $\begin{array}{l}\text { Net carbon } \\
\text { intensity } \\
\text { (sans } \\
\text { cooling) }\end{array}$ & $\mathrm{kgCO}_{2} \mathrm{e} / \mathrm{m}^{2}$ & 7.69 & 5.24 & 9.87 & 7.93 & 9.35 & 9.18 \\
\hline $\begin{array}{l}\text { EnerGuide } \\
\text { rating }\end{array}$ & & 87 & 91 & 88 & 90 & 88 & 89 \\
\hline
\end{tabular}




\section{References}

Aquacraft. (2005). Water and Energy Savings from High Efficiency Fxitures and Appliances in Single Family Homes.

ASHRAE. (2002). ASHRAE Guideline: Measurement and Energy and Demand Savings. Atlanta: ASHRAE Inc.

Bernier, M. (2013, May 3). Designing and Simulating Geothermal Bore Fields Using Thermal Reponse Factors. Montreal, Canada.

Bordass, B., Cohen, R., \& John, F. (2004). Energy Performance of Non-Domestic Buildings: Closing the Credibility Gap. Building Performance Congress, (pp. 1-10). Frankfurt.

Bordass, B., Cohen, R., Standeven, M., \& Leaman, A. (2001). Assessing building performance in use 2: technical performance of the Probe buildings. Building Research \& Information, 103-113.

Bordass, B., Cohen, R., Standeven, M., \& Leaman, A. (2001). Assessing building performance in use 3: energy performance of the Probe buildings. Building Research \& Information, 29(2), 114-128.

BRECSU. (2000). Energy Consumption Guide 19: Energy Use in Offices. Watford.

Building Use Studies Ltd. (2015). Retrieved May 1, 2015, from BUS methodology: http://www.busmethodology.org/

Carbon Trust. (2011). Closing the gap: Lessons learned on realizing the potential of low carbon building design. London: Queen's Printer and Controller.

CarbonBuzz. (2013). Evidence. Retrieved April 5, 2013, from CarbonBuzz website: http://www.carbonbuzz.org/evidencetab.jsp

CBE. (2015). Occupant Indoor Environmental Quality (IEQ) Survey. Retrieved May 13, 2015, from Industry Resource: http://www.cbe.berkeley.edu/research/survey.htm

Cooper, I. (2001). Post-occupancy evaluation - where are you? Building Research \& Information, 29(2), 158-163.

Dall'O', G., Sarto, L., \& Sanna, N. M. (2012). Comparison between predicted and actual energy performance for summer cooling in high-perfroamcen residential buildings in the Lombardy region (Italy). Energy and Buildings, 54, 234-242.

Energy Use Calculator. (2015). Calculate Electricity Usage. Retrieved March 13, 2015, from http://energyusecalculator.com/calculate_electrical_usage.htm

Environment Canada. (2013). National Inventory Report 1990-2011 Part 3. Minister of the Environment. 
Federal Facilities Council. (2002). Learning from Our Buildings: A State-of-the-Practice Summary of PostOccupancy Evaluation. Washington: National Academy Press.

Gill, Z., Tiemey, M., Pegg, I., \& Allan, N. (2010). Low-energy dwellings: the contribution of behaviours to actual performance. Building Research \& Information, 38(5), 491-508.

Gill, Z., Tierney, M., Pegg, I., \& Allan, N. (2011). Measured energy and water performance of an aspiring low energy/carbon affordable housing site in the UK. Energy and Buildings, 43, 117 125.

Hall, J., Uhlig, A., \& Bertolet, D. (2013). Building Performance Evaluation. Retrieved April 6, 2013, from GGLO LLC website: http://www.gglo.com/insight/bpe.aspx

Henninger, R. H., \& Witte, M. J. (2014). EnergyPlus Testing with Building Thermal Envelope and Fabric Load Tests from ANSI/ ASHRAE Standard 140-2011. Arlington Heights: GARD Analytics.

Hydes, K., McCarry, B., Mueller, T., \& Hyde, R. (2004). Understanding our green buildings: seven PostOccupancy Evaluations in British Columbia.

Isaacs, N., Saville-Smith, K., Camilleri, M., \& Burrough, L. (2010). Energy in New Zealand houses: comfort, physics and consumption. Building Research \& Information, 470-480.

Karlsson, F., Rohdin, P., \& Persson, M.-L. (2007). Measured and predicted energy demand of a low energy building: important aspects when using Building Energy Simulation. Building Services Engineering Research \& Technology, 223-235.

Lawrence Berkeley National Laboratory. (2015). Standby Power Summary Table. Retrieved March 3, 2015, from Standby Power: http://standby.lbl.gov/summary-table.html

Leaman, A., Stevenson, F., \& Bordass, B. (2010). Building evaluation: practice and principles. Building Research \& Information, 38(5), 564-577.

Maritime Geothermal. (2015). Direct Expansion Heat Pumps. Retrieved April 4, 2015, from Nordic Geothermal Heat Pumps: http://www.nordicghp.com/product/nordic-products/directexpansion-heat-pumps/

Menezes, A. C., Cripps, A., Bouchlaghem, D., \& Buswell, R. (2012). Predicted vs. actual energy performance of non-domestic buildings: Using post-occupancy evaluation data to reduce the performance gap. Applied Energy, 97, 335-364.

Mlecnik, E., Schutze, T., Jansen, S., Vries, G. d., Visscher, H., \& Hal, A. v. (2012). End-user experiences in nearly zero-energy houses. Energy and Buildings, 49, 471-478.

Molin, A., Rohdin, P., \& Moshfegh, B. (2011). Investigation of energy performance of newly built low-energy buildings in Sweden. Energy and Buildings, 43, 2822-2831. 
Newsham, G., Birt, B., Arsenault, C., Thompson, L., Veitch, J., Mancini, S., et al. (2012, August 31). Do green buildings outperform conventional buildings? Indoor environment and energy performance in North American offices.

NRCan. (2005). EnerGuide for New Houses: Administrative and Technical Procedures.

NRCan. (2013). Energy Efficiency Trends in Canada, 1990 to 2010. Public Works and Government Services Canada.

NRCan. (2014, December 05). HOT2000. Retrieved February 11, 2015, from Natural Resources Canada: http://www.nrcan.gc.ca/energy/software-tools/7421

Parekh, A. (2013, June 11). ERS Standard Operating Conditions.

Santin, O. G., Itard, L., \& Visscher, H. (2009). The effect of occupancy and building characteristics on energy use for space and water heating in Dutch residential stock. Energy and Building, 1223-1232.

Saunders, C. L., Landis, A. E., Jones, A. K., Schaefer, L. A., \& Bilec, M. M. (2012). Utilizing measured energy usage to analyze design phase energy models. 2012 IEEE International Symposium on Sustainable Systems and Technology (pp. 1-6). Boston: IEEE.

Turner, C. (2006). A Post-Occupancy Look at LEED Building Performance. HPAC Engineering, 2633.

Turner, C. (2006). LEED Building Performance in the Cascadia Region: A Post Occupancy Evaluation Report. Cascadia.

U.S. DOE. (2014, February 21). Weather Data Sources. Retrieved February 17, 2015, from EnergyPlus Energy Simulation Software: http://apps1.eere.energy.gov/buildings/energyplus/weatherdata_sources.cfm\#TMY2

UK Government. (2015, May 5). Energy Performance Certificates. Retrieved May 12, 2015, from GOV.UK: https://www.gov.uk/buy-sell-your-home/energy-performance-certificates

Usable Buildings. (2013). BUS Methodology. Retrieved April 11, 2013, from Usable Buildings: http:/ /www.usablebuildings.co.uk/WebGuideOSM/

Zalejska-Jonsson, A. (2012). Evaluation of low-energy and conventional residential buildings from occupants' perspective. Building and Environment, 58, 135-144. 